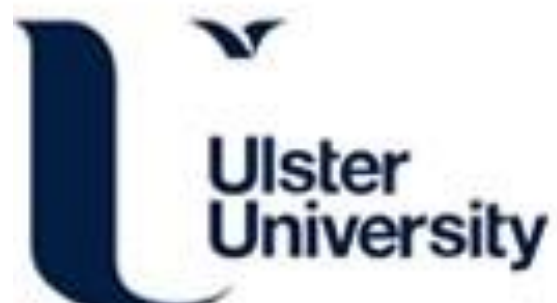

Interventions for preventing and treating pelvic and back pain in pregnancy

Pennick, V., \& Liddle, S. D. (2013). Interventions for preventing and treating pelvic and back pain in pregnancy. Cochrane Database of Systematic Reviews, Issue(CD0011), 1-100.

https://doi.org/10.1002/14651858.CD001139.pub3

Link to publication record in Ulster University Research Portal

\section{Published in:}

Cochrane Database of Systematic Reviews

Publication Status:

Published (in print/issue): 01/08/2013

DOI:

10.1002/14651858.CD001139.pub3

\section{Document Version}

Publisher's PDF, also known as Version of record

\section{General rights}

Copyright for the publications made accessible via Ulster University's Research Portal is retained by the author(s) and / or other copyright owners and it is a condition of accessing these publications that users recognise and abide by the legal requirements associated with these rights.

\section{Take down policy}

The Research Portal is Ulster University's institutional repository that provides access to Ulster's research outputs. Every effort has been made to ensure that content in the Research Portal does not infringe any person's rights, or applicable UK laws. If you discover content in the Research Portal that you believe breaches copyright or violates any law, please contact pure-support@ulster.ac.uk. 


\title{
Interventions for preventing and treating pelvic and back pain in pregnancy (Review)
}

\author{
Pennick V, Liddle SD
}

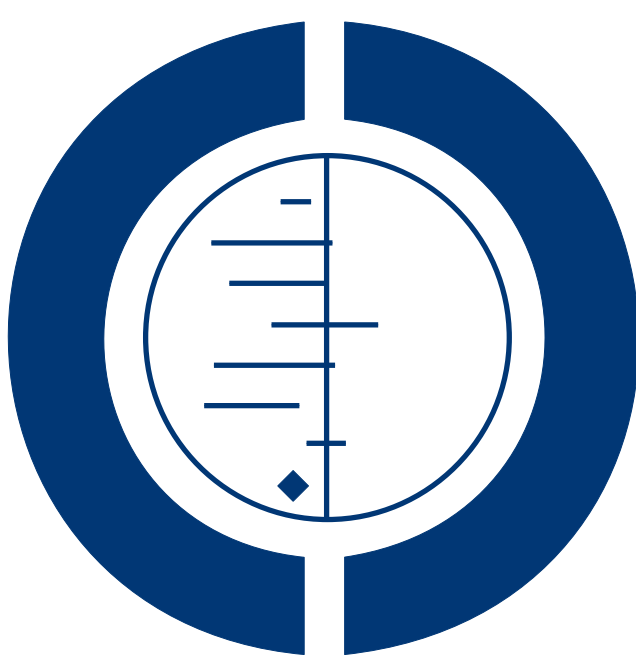

THE COCHRANE COLLABORATION $^{\circledR}$

This is a reprint of a Cochrane review, prepared and maintained by The Cochrane Collaboration and published in The Cochrane Library 2013, Issue 8

http://www.thecochranelibrary.com

\section{WILEY}

Interventions for preventing and treating pelvic and back pain in pregnancy (Review)

Copyright $\odot 2013$ The Cochrane Collaboration. Published by John Wiley \& Sons, Ltd. 
TABLE OF CONTENTS

HEADER

ABSTRACT

PLAIN LANGUAGE SUMMARY

OBJECTIVES

METHODS

RESULTS . . . . . . . . . . . . . . . . . . . . . . . . . . . . . . . 11

Figure 1. . . . . . . . . . . . . . . . . . . . . . . . . . . . . . . . . . . . . . 13

ADDITIONAL SUMMARY OF FINDINGS . . . . . . . . . . . . . . . . . . . . . . . . . . . 17

DISCUSSION . . . . . . . . . . . . . . . . . . . . . . . . . . . . . . . . . . . . . . 25

AUTHORS' CONCLUSIONS . . . . . . . . . . . . . . . . . . . . . . . . . . . . . . . . . .

ACKNOWLEDGEMENTS . . . . . . . . . . . . . . . . . . . . . . . . . . . . . . . . . 28

REFERENCES . . . . . . . . . . . . . . . . . . . . . . . . . . . . . . . . . . . . . . 28

CHARACTERISTICS OF STUDIES . . . . . . . . . . . . . . . . . . . . . . . . . . . . . . . . . . . .

DATA AND ANALYSES . . . . . . . . . . . . . . . . . . . . . . . . . . . . . . . . . . . 85

Analysis 1.1. Comparison 1 Low-back pain: any exercises + usual prenatal care versus usual prenatal care, Outcome 1 Pain intensity.

Analysis 1.2. Comparison 1 Low-back pain: any exercises + usual prenatal care versus usual prenatal care, Outcome 2 Disability.

Analysis 2.1. Comparison 2 Low-back pain: water gymnastics + usual prenatal care versus usual prenatal care, Outcome 1

Number of women taking sick leave because of back pain after 32 weeks' gestation.

Analysis 3.1. Comparison 3 Low-back pain: support belts, Outcome 1 Low-back pain, measured with VAS; 0 to 10; $0=$ no pain.

Analysis 4.1. Comparison 4 Pelvic pain: deep versus superficial acupuncture, Outcome 1 Evening pain. . . . . .

Analysis 5.1. Comparison 5 Pelvic + low-back pain: any exercises + usual prenatal care versus usual prenatal care, Outcome

1 Women who reported pain on Visual Analogue Scale.

Analysis 5.2. Comparison 5 Pelvic + low-back pain: any exercises + usual prenatal care versus usual prenatal care, Outcome 2 Women who reported LBP/PGP-related sick leave.

Analysis 6.1. Comparison 6 Pelvic + low-back pain: acupuncture + usual prenatal care versus usual prenatal care, Outcome 1 Number of women who reported decreased pain.

Analysis 7.1. Comparison 7 Pelvic + low-back pain: acupuncture + usual prenatal care versus individualised physio + usual prenatal care, Outcome 1 Numbers of women rating treatment as good or excellent. . . . . . . . . . . . 92

APPENDICES . . . . . . . . . . . . . . . . . . . . . . . . . . . . . . . . . . . . . 92

FEEDBACK . . . . . . . . . . . . . . . . . . . . . . . . . . . . . . . . . . . . . . 94

WHAT'S NEW . . . . . . . . . . . . . . . . . . . . . . . . . . . . . . . . . . . . . 95

HISTORY . . . . . . . . . . . . . . . . . . . . . . . . . . . . . . . . . . . . . . . . 96

CONTRIBUTIONS OF AUTHORS . . . . . . . . . . . . . . . . . . . . . . . . . . . . . . . . . . . . . . . . . . . . . . .

DECLARATIONS OF INTEREST . . . . . . . . . . . . . . . . . . . . . . . . . . . . . . . . . . . . . . . . . . .

SOURCES OF SUPPORT . . . . . . . . . . . . . . . . . . . . . . . . . . . . . . . . . . . . . . . . . . . . . . . . . . . .

DIFFERENCES BETWEEN PROTOCOL AND REVIEW . . . . . . . . . . . . . . . . . . . . . . . . . . . . . . 98

INDEX TERMS . . . . . . . . . . . . . . . . . . . . . . . . . . . . . . . . . . . . . 98

Interventions for preventing and treating pelvic and back pain in pregnancy (Review)

Copyright @ 2013 The Cochrane Collaboration. Published by John Wiley \& Sons, Ltd. 


\title{
[Intervention Review]
}

\section{Interventions for preventing and treating pelvic and back pain in pregnancy}

\author{
Victoria Pennick ${ }^{1}$, Sarah D Liddle ${ }^{2}$ \\ ${ }^{1}$ Cochrane Editorial Unit, The Cochrane Collaboration, London, UK. ${ }^{2}$ Institute of Nursing and Health Research, University of Ulster, \\ Newtownabbey, Ireland \\ Contact address: Victoria Pennick, Cochrane Editorial Unit, The Cochrane Collaboration, 11-13 Cavendish Square, London, W1G \\ 0AN, UK. vpennick@cochrane.org.
}

Editorial group: Cochrane Pregnancy and Childbirth Group.

Publication status and date: New search for studies and content updated (no change to conclusions), published in Issue 8, 2013.

Review content assessed as up-to-date: 14 December 2012.

Citation: Pennick V, Liddle SD. Interventions for preventing and treating pelvic and back pain in pregnancy. Cochrane Database of Systematic Reviews 2013, Issue 8. Art. No.: CD001139. DOI: 10.1002/14651858.CD001139.pub3.

Copyright (C) 2013 The Cochrane Collaboration. Published by John Wiley \& Sons, Ltd.

\begin{abstract}
A B S T R A C T
Background

More than two-thirds of pregnant women experience low-back pain (LBP) and almost one-fifth experience pelvic pain. Pain increases with advancing pregnancy and interferes with work, daily activities and sleep.
\end{abstract}

\section{Objectives}

To assess the effects of interventions for preventing and treating pelvic and back pain in pregnancy.

\section{Search methods}

We searched the Cochrane Pregnancy and Childbirth Group's Trials Register (18 July 2012), identified related studies and reviews from the Cochrane Back Review Group search strategy to July 2012, and checked reference lists from identified reviews and studies.

\section{Selection criteria}

Randomised controlled trials (RCTs) of any treatment to prevent or reduce the incidence or severity of pelvic or back pain in pregnancy.

Data collection and analysis

Two review authors independently assessed risk of bias and extracted data. Quality of the evidence for outcomes was assessed using the five criteria outlined by the GRADE Working Group.

\section{Main results}

We included 26 randomised trials examining 4093 pregnant women in this updated review. Eleven trials examined LBP $(\mathrm{N}=1312)$, four examined pelvic pain $(\mathrm{N}=661)$, and 11 trials examined lumbo-pelvic (LBP and pelvic) pain $(\mathrm{N}=2120)$. Diagnoses ranged from self-reported symptoms to the results of specific tests. All interventions were added to usual prenatal care and unless noted, were compared to usual prenatal care.

For LBP, there was low-quality evidence that in general, the addition of exercise significantly reduced pain (standardised mean difference (SMD) -0.80 ; 95\% confidence interval (CI) -1.07 to -0.53 ; six RCTs, $\mathrm{N}=543$ ), and disability (SMD -0.56 ; $95 \%$ CI -0.89 to -0.23 ; two RCTs, $\mathrm{N}=146$ ); and water-based exercise significantly reduced LBP-related sick leave (risk ratio (RR) $0.40 ; 95 \%$ CI 0.17 to 0.92 ;

Interventions for preventing and treating pelvic and back pain in pregnancy (Review)

Copyright @ 2013 The Cochrane Collaboration. Published by John Wiley \& Sons, Ltd. 
one RCT, $\mathrm{N}$ = 241). Low-quality evidence from single trials suggested no significant difference in pain or function between two types of pelvic support belt, between osteopathic manipulation (OMT) and usual care or sham ultrasound (sham US). Very low-quality evidence suggested that a specially-designed pillow may relieve night pain better than a regular pillow.

For pelvic pain, there was moderate-quality evidence that acupuncture significantly reduced evening pain better than exercise; both were better than usual care. Low-quality evidence from single trials suggested that adding a rigid belt to exercise improved average pain but not function; acupuncture was significantly better than sham acupuncture for improving evening pain and function, but not average pain; and evening pain relief was the same following either deep or superficial acupuncture.

For lumbo-pelvic pain, there was moderate-quality evidence that an eight- to 20-week exercise program reduced the risk of women reporting lumbo-pelvic pain (RR 0.85; $95 \%$ CI 0.73 to 1.00 ; four RCTs, $\mathrm{N}=1344$ ); but a 16 - to 20 -week training program was no more successful than usual care at preventing pelvic pain (one RCT, $\mathrm{N}=257$ ). Low-quality evidence suggested that exercise significantly reduced lumbo-pelvic-related sick leave (RR 0.76; 95\% CI 0.62 to 0.94 , two RCTs, $\mathrm{N}=1062$ ), and improved function. Low-quality evidence from single trials suggested that OMT significantly reduced pain and improved function; either a multi-modal intervention that included manual therapy, exercise and education (MOM) or usual care significantly reduced disability, but only MOM improved pain and physical function; acupuncture improved pain and function more than usual care or physiotherapy; pain and function improved more when acupuncture was started at 26- rather than 20- weeks' gestation; and auricular (ear) acupuncture significantly improved these outcomes more than sham acupuncture.

When reported, adverse events were minor and transient.

\section{Authors' conclusions}

Moderate-quality evidence suggested that acupuncture or exercise, tailored to the stage of pregnancy, significantly reduced evening pelvic pain or lumbo-pelvic pain more than usual care alone, acupuncture was significantly more effective than exercise for reducing evening pelvic pain, and a 16- to 20 -week training program was no more successful than usual prenatal care at preventing pelvic or LBP. Low-quality evidence suggested that exercise significantly reduced pain and disability from LBP.

There was low-quality evidence from single trials for other outcomes because of high risk of bias and sparse data; clinical heterogeneity precluded pooling. Publication bias and selective reporting cannot be ruled out.

Physiotherapy, OMT, acupuncture, a multi-modal intervention, or the addition of a rigid pelvic belt to exercise seemed to relieve pelvic or back pain more than usual care alone. Acupuncture was more effective than physiotherapy at relieving evening lumbo-pelvic pain and disability and improving pain and function when it was started at 26-rather than 20-weeks' gestation, although the effects were small.

There was no significant difference in LBP and function for different support belts, exercise, neuro emotional technique or spinal manipulation (SMT), or in evening pelvic pain between deep and superficial acupuncture.

Very low-quality evidence suggested a specially-designed pillow may reduce night-time LBP.

Further research is very likely to have an important impact on our confidence in the estimates of effect and is likely to change the estimates. Future research would benefit from the introduction of an agreed classification system that can be used to categorise women according to presenting symptoms.

\section{PLAIN LANGUAGE SUMMARY}

\section{Interventions for preventing and treating pelvic and back pain in pregnancy}

Many women experience low-back (LBP) or pelvic pain during pregnancy. Pain usually increases as pregnancy advances, interfering with work, daily activities, and sleep.

We included 26 randomised trials (RCTs) involving 4093 women. Eleven examined LBP (1312 women); four examined pelvic pain (661 women); 11 examined both conditions together (lumbo-pelvic pain) (2120 women). Unless noted, interventions were added and compared to usual prenatal care.

Moderate-quality evidence showed that acupuncture or exercise, tailored to the stage of pregnancy, significantly reduced evening pelvic or lumbo-pelvic pain. Acupuncture was significantly more effective than exercise for reducing evening pelvic pain. A 16- to 20-week 
training program was no more successful than usual care in preventing pelvic or LBP. Low-quality evidence suggested that exercise reduced pain and disability from LBP. Reported adverse effects were minor and transient. Further research is likely to change the estimates of effect of these interventions. An agreed classification system for categorising women is overdue.

LBP: there was low-quality evidence that exercise significantly reduced pain (six RCTs) and disability (two RCTs). From single trials; exercise in water significantly reduced LBP-related sick leave; pain and physical function were similar when wearing pelvic support belts or having osteo-manipulative therapy (OMT) compared with usual care or sham ultrasound. Very low-quality evidence suggested that a specially-designed pillow may relieve night pain better than a regular pillow.

Pelvic pain: there was moderate-quality evidence that acupuncture reduced evening pain better than exercise; both were better than usual care (one RCT). From single trials: exercise plus a rigid belt improved average pain but not function; acupuncture was better than sham acupuncture for evening pain and function, but not average pain. There was no difference in evening pain after either deep or superficial acupuncture.

Lumbo-pelvic pain: there was moderate-quality evidence that an eight- to 20-week exercise program reduced the risk of lumbopelvic pain; but a 16- to 20 -week training program was no better than usual care for preventing pain (four RCTs). From single trials: exercise significantly reduced lumbo-pelvic-related sick leave and improved function; OMT significantly improved pain and function; a combination of manual therapy, exercise and education improved pain and function; acupuncture improved these outcomes more than usual care or physiotherapy; pain and function improved more when acupuncture was started at 26- rather than 20-weeks' gestation. Ear acupuncture significantly improved these outcomes more than sham acupuncture. 


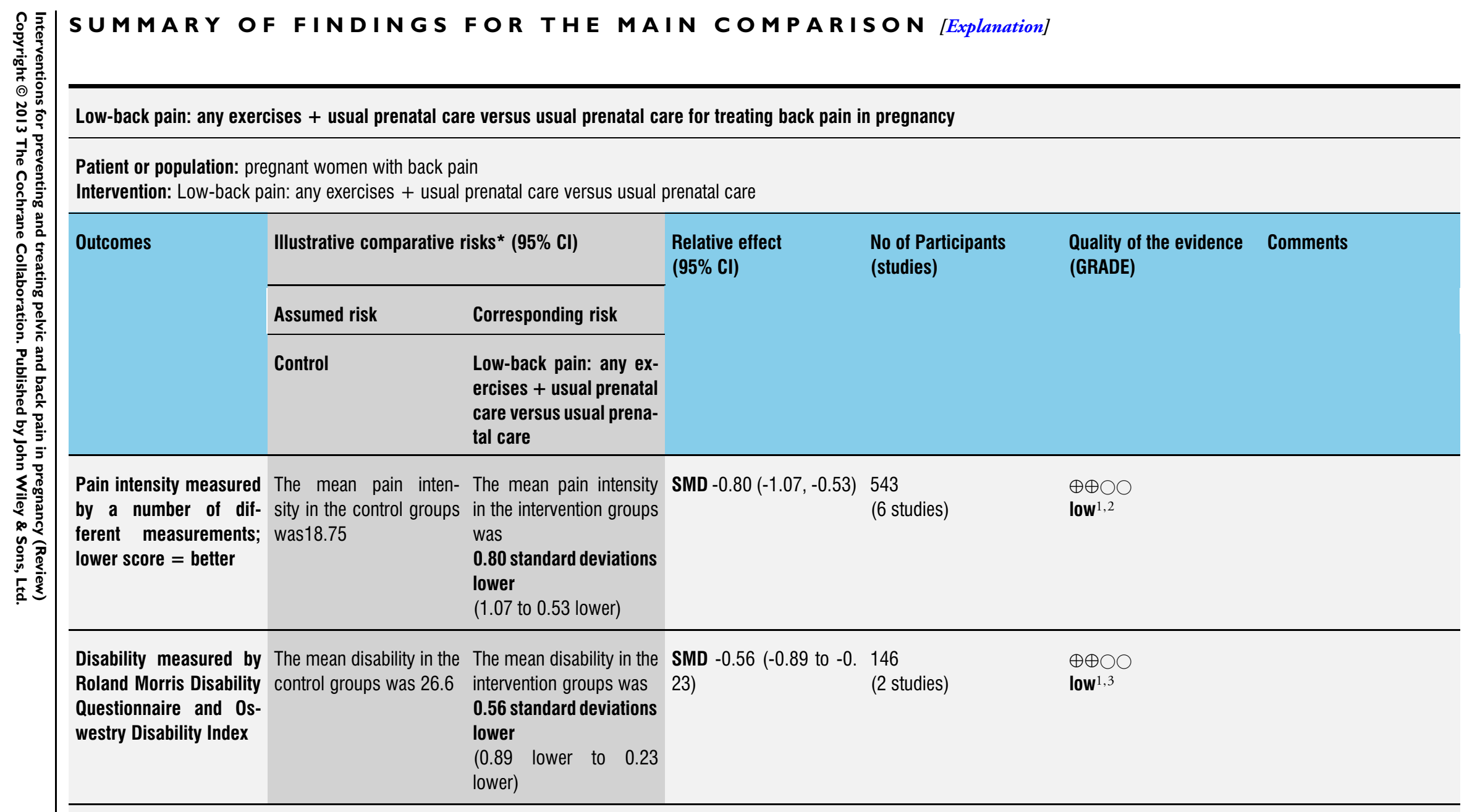

*The basis for the assumed risk (e.g. the median control group risk across studies) is provided in footnotes. The corresponding risk (and its $95 \%$ confidence interval) is based on the assumed risk in the comparison group and the relative effect of the intervention (and its $95 \% \mathrm{Cl}$ ).

CI: Confidence interval; SMD: standardised mean difference 
GRADE Working Group grades of evidence

High quality: Further research is very unlikely to change our confidence in the estimate of effect.

Moderate quality: Further research is likely to have an important impact on our confidence in the estimate of effect and may change the estimate.

Low quality: Further research is very likely to have an important impact on our confidence in the estimate of effect and is likely to change the estimate.

Very low quality: We are very uncertain about the estimate.

${ }^{1}$ poor or no description of randomisation process, allocation concealment, blinding of research personnel

2 two of the studies provided data that were more extreme than the other results, although all the results are positive. If these two are

removed, the estimate of effect becomes much more modest, but still significant

${ }^{3}$ sparse data 


\section{B A C K G R O U N D}

\section{Description of the condition}

Back and pelvic pain are common in pregnancy and tend to increase as pregnancy advances; in some cases the pain radiates into the buttock and leg. However, much still remains unclear about these very distinct but related conditions (Vermani 2010; Vleeming 2008). For many women, pain can become so severe that it interferes with ordinary daily activities, disturbs sleep and contributes to high levels of sick leave (Kalus 2007; Mogren 2006; Skaggs 2007). Global prevalence is reported to range from $24 \%$ to $90 \%$, in part, because there is currently no universally recognised classification system for the condition (Vermani 2010; Vleeming 2008). A recent prospective study of 325 pregnant women from the Middle East found that almost two-thirds reported low-back pain (LBP), pelvic pain or both, during their current pregnancy (Mousavi 2007), with similar proportions reported by a sample of pregnant women $(\mathrm{N}=599$ ) in the United States (Skaggs 2007). Relapse rates are high in subsequent pregnancies (Mogren 2005; Skaggs 2007), and a postpartum prevalence of $24.7 \%$ (range $0.6 \%$ to $67 \%$ ) (Wu 2004) underlines the importance of developing effective treatment programmes for this condition. Despite these figures, it is estimated that over $50 \%$ of women receive little or no intervention from healthcare providers (Greenwood 2001; Skaggs 2007). These numbers suggest that more studies are needed to establish the underlying aetiology and pathogenesis of the conditions (Mørkved 2007). Current theories include: altered posture with the increased lumbar lordosis (exaggerated curvature of the lower spine) necessary to balance the increasing anterior weight of the womb, and inefficient neuromuscular control (Vleeming 2008). Several risk factors have also been identified including increased weight during pregnancy, previous history of LBP and low job satisfaction (Albert 2006; Vleeming 2008).

Whilst back and pelvic pain may occur together in pregnancy, pelvic pain (posterior pain arising from the region of the sacroiliac joints, anterior pain from the pubic symphysis, or both) can often occur on its own, along with residual symptoms postpartum. A follow-up to a cohort study of 870 pregnant women with pelvic pain found that $10 \%$ still experienced moderate or severe pain 18 months after delivery, and were seriously hindered in more than one activity (Rost 2006). Estimates of the prevalence of pregnancyrelated pelvic pain vary (depending on the type of study, diagnostic criteria and precision of identifying the pain), however, the best evidence suggests a point prevalence of 20\% (Vleeming 2008). Van de Pol 2007 also reported that, whilst prognosis was generally good, those women reporting pelvic pain were less mobile than those reporting back pain only, and experienced more co-morbidity and depressive symptoms; these findings are supported by a recent review (Vermani 2010). The need for a uniform terminology in order to promote research and management of these conditions is widely recognised. There are a number of tests validated for distinguishing low-back from pelvic pain; Vermani 2010 and Vleeming 2008 provide details of these tests.

\section{Description of the intervention}

European guidelines recommend that low-back (Airaksinen 2006) and pelvic pain (Vleeming 2008), are managed by providing adequate information and reassurance to the patient, encouraging her to stay active, continue normal daily activities and work if possible, and by offering individualised exercises where appropriate. Similarly, pre-natal practitioners in the United Kingdom and Nordic countries give women information on how to manage LBP, pelvic pain or both during their pregnancy and may refer them to physiotherapy for a more specific treatment programme. In the United States, women are taught that LBP is a normal part of pregnancy. Interventions that have been used to date to help manage the pain include exercises, frequent rest, hot and cold compresses, an abdominal support belt, massage, acupuncture, chiropractic, aromatherapy, relaxation, herbs, yoga, Reiki and acetaminophen (Vermani 2010).

For this review, we conducted a broad search for studies that assessed the effects of any intervention that prevented or treated back pain, pelvic pain, or a combination for women in any stage of their pregnancy. We identified studies investigating the effects of: exercise (land- or water-based), pelvic belts, osteopathic manipulation (OMT), spinal manipulation (SMT) and neuro emotional techniques, a special pillow, acupuncture, acupuncture plus exercises, and a multi-modal approach incorporating manual therapy, exercise and education.

\section{How the intervention might work}

\section{Exercise (land- or water-based)}

Exercise therapy is a management strategy that is supervised or 'prescribed' and encompasses a group of interventions ranging from general physical fitness or aerobic exercise, to muscle strengthening, various types of flexibility and stretching exercises (Cochrane Back Review Group). Regular exercise can have both physical and psychological benefits, depending on the content of each programme, and the individual's adherence (ACSM 2006). The exercises recommended for pregnancy-related LBP are similar to those used for non-specific LBP, with minor modifications, and are thought to have a similar mechanism of action (Vermani 2010).

\section{Manual therapy (SMT and OMT)}

Spinal manipulation (SMT) is defined as a high velocity thrust to a joint beyond its restricted range of movement. Spinal mobilisation involves low-velocity, passive movements within or at the limit of 
joint range (Cochrane Back Review Group). Most studies do not make a clear distinction between these two, because in clinical practice, these two techniques are part of a 'manual therapy package', that may also include soft tissue/myofascial release. Manual therapy is thought to influence the spinal 'gating' mechanism and the descending pain suppression system at spinal and supraspinal levels to decrease pain. In addition, it is thought to return a vertebra to its normal position or restore lost mobility (Maigne 2003). Osteopathic manipulation (OMT) is a hands-on, whole body approach to diagnose, treat, and prevent illness or injury, during which the osteopathic physician moves muscles and joints using techniques including stretching, gentle pressure and resistance (American Osteopathic Association).

\section{Acupuncture, alone or with exercises}

Acupuncture is needle puncture at classical meridian points, aimed at promoting the flow of 'Qi' or energy. The acupuncturist must avoid certain acupuncture points in pregnancy that supply the cervix and uterus (which have been used to induce labour), but the technique in general is considered to be safe (Moffatt 2013; Vermani 2010). Needles may be stimulated manually or electrically. Acupuncture is thought to stimulate the body's own pain relieving opioid mechanisms (Lin 2008). Placebo or sham acupuncture is needling of traditionally unimportant sites, superficial insertion or non-stimulation of the needles once placed. There is some evidence that sham acupuncture may produce similar results to real acupuncture, raising the possibility that the effect of acupuncture may be a result of the stimulation of pressure receptors, regardless of their location (Field 2008).

\section{Multi-modal approach, including manual therapy, exercise and education}

A combination of aspects of manual therapy and exercise, along with education that includes information about correct posture, relaxation techniques (Vermani 2010), instructions to keep the knees together and bent when turning in bed, and to avoid activities such as jarring, bouncing and stretching joints to their extreme (Lile 2003; Mens 2009).

\section{Pelvic belts and pillows}

Pelvic belts are a form of lumbar support that can help to: (1) correct deformity; (2) limit spinal motion; (3) stabilise the lumbar spine; (4) reduce mechanical loading; and (5) provide miscellaneous effects such as massage, heat or placebo. They may be made of flexible or rigid materials (Cochrane Back Review Group). Mens 2006 suggests that pelvic belts may stimulate the action of the corset muscle around the tummy and stabilising muscle of the spine along with the pelvic floor muscles.

Pillows are used to provide support and reduce mechanical loading of symptomatic joints in women with pregnancy-related pelvic and/or back pain.

\section{Why it is important to do this review}

Given the number of new studies investigating the effectiveness of interventions for preventing and managing back and pelvic pain in pregnancy and the change in methodological standards for Cochrane reviews, it seemed prudent to update this review again.

\section{O B J E C T I VES}

To assess the effects of interventions for preventing and treating pelvic and back pain in pregnancy.

\section{METHODS}

\section{Criteria for considering studies for this review}

\section{Types of studies}

Any randomised controlled trials that evaluated any intervention for preventing or treating pelvic and back pain in pregnancy. We excluded quasi-randomised trials (those which use techniques for allocating participants to groups that may be prone to bias).

\section{Types of participants}

Trials that included pregnant women at any point in their pregnancy who were at risk of developing, or suffering from pelvic or back pain, as reported symptomatically by the women or diagnosed by clinicians using specific diagnostic tests.

\section{Types of interventions}

Trials that examined any intervention intended to reduce the incidence or severity of pelvic and back pain in pregnancy. We did not put parameters on the types of interventions. We grouped the trials to allow us to examine interventions that specifically addressed back pain, pelvic pain or the two in combination. Under each population, we grouped the interventions under exercise, manual therapy, acupuncture, multi-modal approach, pelvic belts and pillows, depending on the trials identified. Interventions were compared to usual prenatal care (in some trials referred to as 'no treatment'), or usual prenatal care plus another intervention.

\section{Types of outcome measures}

We excluded studies that diagnosed back or pelvic pain, identified back or pelvic pain as intermediate or proxy outcomes only, started interventions prior to pregnancy but measured the back or pelvic pain during pregnancy, or started the trial during pregnancy when their goal was to assess postpartum outcomes and therefore the 
only measurements conducted during pregnancy were baseline values.

\section{Primary outcomes}

Women's own rating of usefulness of a treatment, reduction of symptoms, participation in usual activities and adverse effects (reported by women and assessors) measured at the end of treatment, during pregnancy.

- Pain intensity (pain levels);

- activities of daily living;

- days off work; or

- adverse effects for women and infants; as defined by trialist.

\section{Search methods for identification of studies}

\section{Electronic searches}

We searched the Cochrane Pregnancy and Childbirth Group's Trials Register by contacting the Trials Search Co-ordinator (18 July 2012).

The Cochrane Pregnancy and Childbirth Group's Trials Register is maintained by the Trials Search Co-ordinator and contains trials identified from:

1. monthly searches of the Cochrane Central Register of Controlled Trials (CENTRAL);

2. weekly searches of MEDLINE;

3. weekly searches of Embase;

4. handsearches of 30 journals and the proceedings of major conferences;

5. weekly current awareness alerts for a further 44 journals plus monthly BioMed Central email alerts.

Details of the search strategies for CENTRAL, MEDLINE and Embase, the list of handsearched journals and conference proceedings, and the list of journals reviewed via the current awareness service can be found in the 'Specialized Register' section within the editorial information about the Cochrane Pregnancy and Childbirth Group.

Trials identified through the searching activities described above are each assigned to a review topic (or topics). The Trials Search Co-ordinator searches the register for each review using the topic list rather than keywords.

We also identified potential trials by searching the Trials Register of the Cochrane Back Review Group (CBRG) by contacting the Trials Search Co-ordinator, most recently in July 2012 and by following up on trials that were listed as 'ongoing' in prior literature searches. The CBRG Trials Register is populated by the results of monthly electronic database searches (MEDLINE, Embase, CINAHL, PsycInfo, Index to Chiropractic Literature), by handsearching selected journals and conference proceedings, by quarterly searches of CENTRAL and international healthcare guideline sources and by the results of specific searches and reference checks of included studies for individual reviews (Cochrane Back Review Group). Regular searches for ongoing trials of back and neck pain treatments are conducted in the U.S National Institute of Health database of clinical trials, ClinicalTrials.gov, as well as via the World Health Organization's International Clinical Trials Registry Platform Search Portal.

\section{Searching other resources}

We checked the reference lists of included studies and related systematic reviews (Airaksinen 2006; Anderson 2005; Ee 2008; Field 2008; Richards 2012; Vermani 2010).

We did not apply any language restrictions.

\section{Data collection and analysis}

For the methods used when assessing the studies identified in the previous version of this review (Pennick 2007), see Appendix 1. For this update, we used the following methods when assessing the 47 trial reports identified by the updated search to July 2012 (Abolhasani 2010; Bandpei 2010; Beyaz 2011; Chitryniewicz 2010; de Jonge-Vors 2011; Depledge 2005; Eggen 2012; Ekdahl 2010; Elden 2008; Elden 2008b; Elden 2008c; Field 1999a; Field 2012; Foxcroft 2011; Gil 2011; Gross 2012; Granath 2006; Greene 2009; Hagberg 2007; Hagen 2010; Haugland 2006; Hensel 2008; Kalus 2006; Kalus 2007; Kashanian 2009; Kluge 2011; Kohama 2006; Ladefoged 2012; Lund 2006; Licciardone 2007; Licciardone 2010; Mens 2012; Moholdt 2011; Momoi 1999; Mørkved 2007; Peters 2007; Peterson 2012; Schoenfeld 2011; Singh 2008; Sedaghati 2007; Stafne 2012; Thorell 2012; Torstensson 2009; Wang 2007; Wang 2008; Wang 2009b; Zand 2011.

\section{Selection of studies}

The two review authors independently assessed all the potential studies we identified as a result of the search strategy. Based on information from the titles and abstracts, we obtained the full text of any articles that appeared to meet the inclusion criteria, or lacked sufficient information to make a decision. We made all final decisions for inclusion after reading the full-text of the article, discussing our individual thoughts and reaching consensus when needed. A former review author (Gavin Young) was available if needed for further consultation. Reports that were not in English were assessed for inclusion by colleagues with the appropriate language skills, by using Google Translate (Google Translate) to translate the article into English, or both.

\section{Data extraction and management}

We used the data extraction form developed by the Cochrane Pregnancy and Childbirth Group to extract data. For eligible trials, two review authors independently extracted the data, resolving 
discrepancies through discussion, entered them into Review Manager software (RevMan 2012) and checked for accuracy.

When information regarding any of the above was unclear, we attempted (without success in all but three cases (Eggen 2012; Elden 2005; Stafne 2012) to contact authors of the original reports to provide further details. The trials to which this refers are identified in the notes section of the Characteristics of included studies table.

\section{Assessment of risk of bias in included studies}

The two review authors independently assessed the risk of bias for each study using the criteria outlined below and in The Cochrane Handbook for Systematic Reviews of Interventions (Higgins 2011). Again, we shared our findings and resolved disagreement through discussion. We entered our decisions and supporting documentation into the 'Risk of bias' tables.

\section{(I) Random sequence generation (checking for possible selection bias)}

For each included trial, we described the method used to generate the allocation sequence in sufficient detail to allow an assessment of whether it should produce comparable groups.

We assessed the method as:

- low risk of bias (any truly random process, e.g. random number table; computer random number generator);

- high risk of bias (any non-random process, e.g. odd or even date of birth; hospital or clinic record number);

- unclear risk of bias.

\section{(2) Allocation concealment (checking for possible selection} bias)

For each included trial, we described the method used to conceal the allocation sequence in sufficient detail to determine whether the intervention allocation could have been foreseen in advance of, or during recruitment, or changed after assignment.

We assessed the methods as:

- low risk of bias (e.g. telephone or central randomisation; consecutively numbered sealed opaque envelopes);

- high risk of bias (open random allocation; unsealed or nonopaque envelopes, alternation; date of birth);

- unclear risk of bias.

\section{(3.1) Blinding of participants and personnel (checking for possible performance bias)}

For each included trial, we described the methods used, if any, to blind study participants and personnel from knowledge of which intervention a participant received. Trials were judged at low risk of bias if they were blinded, or if we judged that the lack of blinding could not have affected the results. Blinding was assessed separately for different outcomes or classes of outcomes.

We assessed the methods as:
- low, high or unclear risk of bias for participants;

- low, high or unclear risk of bias for personnel.

\section{(3.2) Blinding of outcome assessment (checking for possible detection bias)}

For each included trial, we described the methods used, if any, to blind outcome assessors from knowledge of which intervention a participant received. We assessed blinding separately for different outcomes or classes of outcomes.

We assessed methods used to blind outcome assessment as:

- low, high or unclear risk of bias.

(4) Incomplete outcome data (checking for possible attrition bias due to the amount, nature and handling of incomplete outcome data)

For each included trial, and for each outcome or class of outcomes, we described the completeness of data, including attrition and exclusions from the analysis. We stated whether attrition and exclusions were reported and the numbers included in the analysis at each stage (compared with the total randomised participants), reasons for attrition or exclusion where reported, and whether missing data were balanced across groups or were related to outcomes. Where sufficient information was reported, or supplied by the trial authors, we re-included missing data in the analyses which we undertook.

We assessed methods as:

- low risk of bias (e.g. no missing outcome data; missing outcome data balanced across groups and less than 20\%);

- high risk of bias (e.g. numbers or reasons for missing data imbalanced across groups; 'as treated' analysis done with substantial departure of intervention received from that assigned at randomisation);

- unclear risk of bias.

\section{(5) Selective reporting (checking for reporting bias)}

For each included trial, we described how we investigated the possibility of selective outcome reporting bias and what we found. We assessed the methods as:

- low risk of bias (where it was clear that all of the trial's prespecified outcomes and all expected outcomes of interest to the review were reported);

- high risk of bias (where not all the trial's pre-specified outcomes were reported; one or more reported primary outcomes were not prespecified; outcomes of interest were reported incompletely and so could not be used; trial failed to include results of a key outcome that would have been expected to have been reported);

- unclear risk of bias. 
(6) Other bias (checking for bias due to problems not covered by (I) to (5) above)

For each included trial, we described any important concerns we had about other possible sources of bias: Were the groups similar at baseline regarding the most important prognostic indicators? Were co-interventions avoided or similar? Was the compliance acceptable in all groups? Was the timing of the outcome assessment similar in all groups? Other?

We assessed whether each trial was free of other problems that could put it at risk of bias:

- low risk of other bias;

- high risk of other bias;

- unclear whether there is risk of other bias.

\section{(7) Overall risk of bias}

We made explicit judgements about whether trials were at high risk of bias, according to the criteria given in the Cochrane Handbook (Higgins 2011). With sufficient data, we would have assessed the likely magnitude and direction of the bias and whether it was likely to have impacted the findings by undertaking sensitivity analyses.

\section{Measures of treatment effect}

\section{Dichotomous data}

For dichotomous data (e.g. absenteeism, presence of pain, satisfaction with treatment), we present results as summary risk ratios (RR) with 95\% confidence intervals (95\% CI).

\section{Continuous data}

For continuous data (e.g. intensity of pain, disability), we used the mean difference (MD) if outcomes were measured in the same way between trials. We used the standardised mean difference (SMD) to combine trials that measured the same outcome, but used different methods. We presented both summary results with 95\% CI.

We used Cohen's three levels to guide our classification of the estimates of effect as small, medium or large (Cohen 1988).

- Small (MD less than $10 \%$ of the scale (e.g. less than $10 \mathrm{~mm}$ on a $100 \mathrm{~mm}$ visual analogue scale (VAS)); SMD or "d" scores less than 0.5 ; RR, less than 1.25 or greater than 0.8 (depending on whether it reports risk of benefit or risk of harm)).

- Medium (MD $10 \%$ to $20 \%$ of the scale; SMD or "d" scores from 0.5 to less than 0.8 ; RR between 1.25 to 2.0 , or 0.5 to 0.8 ).

- Large (MD greater than $20 \%$ of the scale; SMD or "d" scores equal to or greater than 0.8 ; RR greater than 2.0 or less than 0.5$)$.

To determine if an estimate of effect was clinically significant, we were guided by work conducted in low-back pain research; we considered $30 \%$ on VAS/numerical rating scale (NRS) for pain as clinically significant (Ostelo 2008), and two to three points on the Roland-Morris Disability Questionnaire (RMDQ) or 8\% to $12 \%$ for function (Bombardier 2001).

\section{Unit of analysis issues}

\section{Cross-over trials}

One cross-over trial met the inclusion criteria in an earlier version of this review. Should we identify further cross-over trials, we will extract data from the phases of the trial, as parallel trials, and consider the impact of incorporating the data with those of parallel trials.

\section{Dealing with missing data}

For included studies, we noted levels of and reasons for attrition. With sufficient data, we would have explored the impact of including studies with high levels of missing data (more than 20\%) in the overall assessment of treatment effect by using sensitivity analyses.

For all outcomes, we carried out analyses, as far as possible, on an intention-to-treat basis, i.e. we attempted to include all participants randomised to each group in the analyses, and all participants were analysed in the group to which they were allocated, regardless of whether or not they received the allocated intervention. The denominator for each outcome in each study was the number randomised minus any participants whose outcomes were known to be missing.

\section{Assessment of heterogeneity}

We only combined the results of studies that we determined were clinically homogeneous for population, intervention, comparison and outcome. We assessed statistical heterogeneity in each metaanalysis using the $\mathrm{Tau}^{2}, \mathrm{I}^{2}$ and $\mathrm{Chi}^{2}$ statistics. We regarded heterogeneity as substantial if the $\mathrm{I}^{2}$ was greater than $30 \%$ and either the $\mathrm{Tau}^{2}$ was greater than zero, or there was a low $\mathrm{P}$ value (less than 0.10) in the Chi² test for heterogeneity (Riley 2011).

\section{Assessment of reporting biases}

Had there been 10 or more trials in a meta-analysis, we would have investigated reporting biases (such as publication bias) using funnel plots.

\section{Data synthesis}

For trials we considered to be clinically homogeneous, we combined the data using the Review Manager software (RevMan 2012) and a fixed-effect method. If there was some clinical heterogeneity, 
but a summary effect was still considered to be clinically meaningful, or if there was substantial statistical heterogeneity, we used random-effects meta-analysis. For random-effects analyses, we presented the results as the average treatment effect with $95 \%$ confidence intervals, and the estimates of $\mathrm{Tau}^{2}$ and $\mathrm{I}^{2}$ statistics.

For all outcomes, we assessed the quality of the body of evidence by using the five criteria outlined by the GRADE Working Group (Schünemann 2009; Appendix 3). When we used RevMan to calculate the estimate of effect, we also created a 'Summary of findings' table to illustrate the results and quality of the evidence. If we either extracted data directly from the papers or data were not provided, we assessed the quality of the evidence with the GRADE criteria and accompanied our results with a brief description of the criteria that contributed to the downgrade (i.e. study design, inconsistency, indirectness, sparse data, publication bias).

\section{Subgroup analysis and investigation of heterogeneity}

Had there been sufficient data, we had planned to conduct subgroup and sensitivity analyses to investigate heterogeneity for all primary outcomes.

With sufficient data, we had planned to carry out the following subgroup analyses.

1. Gestational age by trimester.

2. Different techniques and duration of interventions.

3. Number of previous pregnancies.

4. Number of fetuses.

In future updates, with sufficient data, we will carry out subgroup analyses and assess subgroup differences by interaction tests available within RevMan (RevMan 2012). We will report the results of subgroup analyses quoting the $\mathrm{Chi}^{2}$ statistic and $\mathrm{P}$ value, and the interaction test $\mathrm{I}^{2}$ value.

\section{Sensitivity analysis}

With sufficient data, we had planned to conduct sensitivity analyses to determine the effects of selection, performance and attrition bias on the estimates of effect, by excluding trials at high risk of bias due to these potential biases from the analyses, in order to assess whether this made any difference to the overall result. In future updates, with sufficient data, we plan to do so.

\section{RE S U L T S}

\section{Description of studies}

\section{Results of the search}

The review completed in 2002 (Young 2002) contained three trials: two examined interventions for women with low-back pain
(Kihlstrand 1999; Thomas 1989), one examined an intervention for a mixed population with pelvic and low-back pain (LBP) (Wedenberg 2000). One trial was excluded because it used a quasirandomised sequence generation.

The first update of the review (Pennick 2007) included eight trials (1305 women), described in nine publications. Seven were randomised controlled trials, and the eighth used a cross-over design (Thomas 1989). The literature search, updated to February 6, 2006 had identified 11 potentially relevant reports: five trials, described in six reports, were included: two trials examined women with low-back pain (Garshasbi 2005; Suputtitada 2002), one examined women with pelvic pain (Elden 2005), and two more examined a mixed population with pelvic and back pain (Kvorning 2004; Martins 2005); two trials were identified as ongoing, and three were excluded because they were quasi-randomised trials (QRCTs).

The current update includes 26 trials, described in 30 reports. The literature search, updated to July 18,2012 , identified 47 potentially relevant reports from both the Cochrane Pregnancy and Childbirth and the Cochrane Back Review Groups' Trials Registers.

\section{Included studies}

We included 18 new randomised trials in this update, reported in 30 publications: five were reported in multiple publications: Eggen 2012; Elden 2008; Kalus 2007; Licciardone 2010; and Wang 2009a; 13 were published in single reports (Bandpei 2010; Depledge 2005; Ekdahl 2010; Gil 2011; Gross 2012; Kashanian 2009; Kluge 2011; Lund 2006; Mørkved 2007; Peters 2007; Peterson 2012; Sedaghati 2007; Stafne 2012); four were ongoing trials (Abolhasani 2010; Greene 2009; Hensel 2008; Moholdt 2011).

This review now includes 26 randomised trials examining 4093 pregnant women. Eleven trials examined LBP $(\mathrm{N}=1312$; Bandpei 2010; Garshasbi 2005; Gil 2011; Kalus 2007; Kashanian 2009; Kihlstrand 1999; Licciardone 2010; Peterson 2012; Sedaghati 2007; Suputtitada 2002; Thomas 1989); four looked at pelvic pain ( $\mathrm{N}=661$; Depledge 2005; Elden 2005; Elden 2008; Lund 2006); and 11 trials examined women with both LBP and pelvic pain $(\mathrm{N}=2120$; Eggen 2012; Ekdahl 2010; Gross 2012; Kluge 2011; Kvorning 2004; Martins 2005; Mørkved 2007; Peters 2007; Stafne 2012; Wang 2009a; Wedenberg 2000).

The LBP trials looked at the effects of exercise, on land (Bandpei 2010; Garshasbi 2005; Gil 2011; Kashanian 2009; Sedaghati 2007; Suputtitada 2002), and in water (Kihlstrand 1999), use of pelvic belts (Kalus 2007), osteopathic manipulation (OMT) (Licciardone 2010), spinal manipulation (SMT) and neuro emotional technique Peterson 2012, and use of a special pillow (Thomas 1989). Trials investigating pelvic pain included pelvic belts (Depledge 2005), acupuncture (Elden 2008; Lund 2006), and acupuncture plus exercises (Elden 2005). Women with both LBP and pelvic pain were given exercises (Eggen 2012; Kluge 
2011; Martins 2005; Mørkved 2007; Stafne 2012), OMT (Peters 2007), a multi-modal approach of manual therapy, exercise and education (Gross 2012), and acupuncture (Ekdahl 2010; Kvorning 2004; Wang 2009a; Wedenberg 2000).

The controls used were generally described as 'no treatment', which was usual prenatal care. The more recent acupuncture trials used sham acupuncture as a control (Elden 2008; Wang 2009a), tested the optimal time to start treatment with acupuncture (Ekdahl 2010), examined different acupuncture stimulation modes (Lund 2006), or the relative effectiveness against physiotherapy (Wedenberg 2000). Relative effectiveness was examined between spinal manipulation and neuro emotional technique (Peterson 2012), two types of pelvic belts (Kalus 2007) and pillows (Thomas 1989); sham ultrasound was used as a control against OMT (Licciardone 2010).

All trials looked at treatment; two trials also looked at interventions that may prevent LBP (Sedaghati 2007; Thomas 1989) and two that may prevent lumbo-pelvic pain (Eggen 2012; Mørkved 2007).

See tables of Characteristics of included studies; Characteristics of ongoing studies for further details.

\section{Excluded studies}

The review authors for the original review and the 2007 update excluded four trials after full-text review because they were QRCTs. For this update, we excluded 17 trials after review of the full-text: eight were QRCTs or CCTs, one measured postpartum outcomes only, five lacked a clear description of study design or were not parallel studies, two were investigating depression, not LBP, and one included women who were not pregnant at the time of the intervention, but were at the inception of the back pain. See table of Characteristics of excluded studies for further details.

\section{Risk of bias in included studies}

Overall, the risks of bias were high, raising concerns about the confidence we could put in the estimates of effect. See Figure 1 for a summary of these risks of bias in each trial; see the 'Risk of bias' tables in the Characteristics of included studies for details. 
Figure I. 'Risk of bias' summary: review authors' judgements about each risk of bias item for each included study.

\begin{tabular}{|c|c|c|c|c|c|c|c|}
\hline & 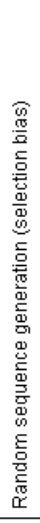 & 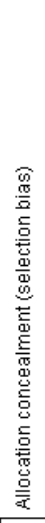 & 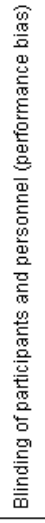 & 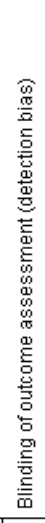 & 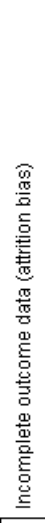 & 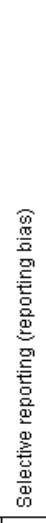 & 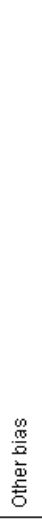 \\
\hline Bandpei 2010 & $\odot$ & $?$ & 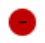 & $\theta$ & $\odot$ & $?$ & $\odot$ \\
\hline Depledge 2005 & + & $?$ & $?$ & ? & + & $\odot$ & $\odot$ \\
\hline Eggen 2012 & $\odot$ & + & 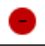 & 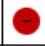 & + & + & $\odot$ \\
\hline Ekdahl 2010 & ? & + & $\odot$ & ? & + & $\odot$ & $\odot$ \\
\hline Elden 2005 & 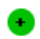 & + & $\Theta$ & $\odot$ & + & $\odot$ & $\oplus$ \\
\hline Elden 2008 & $\odot$ & $\odot$ & $\odot$ & $\odot$ & $\odot$ & $\odot$ & $\odot$ \\
\hline Garshasbi 2005 & ? & $\odot$ & $\Theta$ & $\odot$ & $\theta$ & $\theta$ & $\odot$ \\
\hline Gil 2011 & 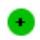 & $?$ & $\theta$ & $\theta$ & $?$ & $\odot$ & $\odot$ \\
\hline Gross 2012 & $?$ & $?$ & $?$ & ? & $?$ & $?$ & ? \\
\hline Kalus 2007 & + & $\odot$ & $\Theta$ & $\theta$ & $\Theta$ & $\odot$ & $\Theta$ \\
\hline Kashanian 2009 & $?$ & $?$ & $?$ & ? & + & $\theta$ & ? \\
\hline Kihlstrand 1999 & ? & + & $\Theta$ & ? & $\theta$ & $\theta$ & $\odot$ \\
\hline Kluge 2011 & + & $\odot$ & $\Theta$ & $\theta$ & $\odot$ & $\odot$ & + \\
\hline Kvorning 2004 & $\odot$ & $\odot$ & $\Theta$ & $\odot$ & $\theta$ & $\theta$ & $\Theta$ \\
\hline Licciardone 2010 & ? & $?$ & $\Theta$ & $\theta$ & $\theta$ & $\odot$ & $\odot$ \\
\hline Lund 2006 & $?$ & 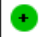 & 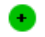 & $\odot$ & $\theta$ & 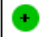 & 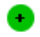 \\
\hline Martins 2005 & + & $\Theta$ & $?$ & ? & $\Theta$ & $\theta$ & $\Theta$ \\
\hline Mørkved 2007 & $\odot$ & + & $\Theta$ & ? & + & $\odot$ & ? \\
\hline Peters 2007 & $?$ & $?$ & $?$ & $?$ & $?$ & $\odot$ & ? \\
\hline Peterson 2012 & $?$ & + & $\Theta$ & $\theta$ & $\odot$ & $\odot$ & $\Theta$ \\
\hline Sedaghati 2007 & $?$ & $?$ & $\theta$ & ? & $\theta$ & $\odot$ & ? \\
\hline Stafne 2012 & + & $\odot$ & $\theta$ & $\theta$ & - & + & $\odot$ \\
\hline Suputtitada 2002 & $?$ & $?$ & $\Theta$ & ? & $\Theta$ & $\odot$ & ? \\
\hline Thomas 1989 & $?$ & $?$ & $\Theta$ & $\theta$ & $\theta$ & $\theta$ & $?$ \\
\hline Wang 2009a & $\odot$ & $?$ & $\odot$ & 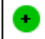 & + & + & + \\
\hline Wedenberg 2000 & ? & + & $\Theta$ & ? & $\theta$ & $\theta$ & 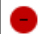 \\
\hline
\end{tabular}




\section{Allocation}

Of the 26 reports, only 13 of them adequately reported on the method of randomisation, although all but one were identified as 'randomised controlled trials'; 14 adequately reported on an appropriate method of allocation concealment.

\section{Blinding}

Blinding is very difficult to carry out in non-pharmacological trials, especially when symptoms are the outcomes of interest; nonetheless, lack of blinding of research personnel and participants still has the potential to introduce bias. Four trials reported that the providers and the participants were blinded, while six reported that the outcome assessors were blinded. Of these, only one reduced the bias for blinding by asking all participants if they felt the treatment they had received was credible (Wang 2009a).

\section{Incomplete outcome data}

Eleven trials reported that the women were analysed in the groups to which they were randomised; most of the trials only analysed data from those who completed trials, although two (Licciardone 2010; Peterson 2012) imputed missing data in order to present a full data set. Attrition rates ranged from zero to more than $20 \%$. In seven of the trial reports, it was difficult to determine the exact numbers randomised and withdrawn, reasons for the withdrawal and the group membership of those who withdrew. Eleven of the more recent publications included a CONSORT flow chart that traced the enrolment, randomisation, follow-up and analysis of participants (Schulz 2010).

\section{Selective reporting}

We did not specifically search for protocols to determine what outcomes had been planned, however, five studies were identified from study registration databases during the most recent literature search update (Eggen 2012; Elden 2008; Kalus 2007; Licciardone 2010; Wang 2009a). Seventeen trials provided data on the outcomes they had identified in the description of the methods in either the publication or the study registration report, in a form that enabled us to include them in analyses; for one trial, we calculated the end of treatment score and standard deviation using the RevMan calculator to enable us to include the data (Bandpei 2010).

\section{Other potential sources of bias}

Six trials were either dissimilar at baseline in important prognostic characteristics (Gil 2011; Martins 2005; Peterson 2012;
Wedenberg 2000), reported very different co-interventions between the groups, or reported co-interventions that would make it difficult to determine the real effect of the intervention (Gil 2011; Kalus 2007; Kvorning 2004; Martins 2005; Wedenberg 2000). Seven trials provided insufficient information on baseline equality between groups or similarity of co-interventions to allow us to determine if they were at risk for these biases: three trials were either abstracts or short communications, for which we were unable to obtain the full reports (Gross 2012; Kashanian 2009; Peters 2007), while four more full reports failed to include sufficient details (Mørkved 2007; Sedaghati 2007; Suputtitada 2002; Thomas 1989).

One trial used a cross-over design in which all participants were analysed at the end of each treatment, without allowing for either a wash-out period, or at an advanced stage of pregnancy and increased risk of back pain. The data were presented as summaries for each treatment rather than comparing the groups at the end of each phase. We did not include these data in our analyses.

\section{Effects of interventions}

See: Summary of findings for the main comparison Low-back pain: any exercises + usual prenatal care versus usual prenatal care for treating back pain in pregnancy; Summary of findings 2 Low-back pain: water gymnastics + usual prenatal care versus usual prenatal care for treating back pain in pregnancy; Summary of findings 3 Low-back pain: support belts for treating back pain in pregnancy; Summary of findings 4 Pelvic pain: deep versus superficial acupuncture for treating pelvic pain in pregnancy; Summary of findings 5 Pelvic + low-back pain: any exercises + usual prenatal care versus usual prenatal care for preventing and treating pelvic and back pain in pregnancy; Summary of findings 6 Pelvic + low-back pain: acupuncture + usual prenatal care versus usual prenatal care for preventing and treating pelvic and back pain in pregnancy; Summary of findings 7 Pelvic + low-back pain: acupuncture + usual prenatal care versus individualised physio + usual prenatal care for preventing and treating pelvic and back pain in pregnancy

\section{Low-back pain (LBP)}

This review now includes 11 trials that examined women with pregnancy-related LBP $(\mathrm{N}=1312$ randomised). Seven trials investigated the effects of exercise, either on land $(\mathrm{N}=627$ randomised; Bandpei 2010; Garshasbi 2005; Gil 2011; Kashanian 2009; Sedaghati 2007; Suputtitada 2002), or in water ( $N=258$ randomised; Kihlstrand 1999), one trial studied the effects of spinal manipulation (SMT) and neuro emotional technique ( $\mathrm{N}=$ 57 randomised; Peterson 2012), and one the use of a special pillow to relieve pregnancy-related low-back pain ( $\mathrm{N}=109$ randomised; 
Thomas 1989). The land- and water-based exercises were added to usual prenatal care and compared to prenatal care alone; Kalus 2007 ( $\mathrm{N}=115$ randomised) compared the effects of the BellyBra against those of Tubigrip; Licciardone 2010 ( $\mathrm{N}=146$ randomised) added osteopathic manipulation (OMT) to usual prenatal care and compared it with sham ultrasound (sham US) added to usual prenatal care and usual care by itself.

\section{Exercise (land- or water-based)}

There was low-quality evidence from six trials (543 women analysed; Bandpei 2010; Garshasbi 2005; Gil 2011; Kashanian 2009; Sedaghati 2007; Suputtitada 2002) that exercise - in general added to usual prenatal care significantly reduced pain (standardised mean difference (SMD) $-0.80 ; 95 \%$ confidence interval (CI) -1.07 to -0.53 ; $\mathrm{Tau}^{2}=0.05 ; \mathrm{I}^{2}=50 \%$ Analysis 1.1 ) and disability (SMD $-0.56 ; 95 \%$ CI -0.89 to $-0.23 ; \mathrm{Tau}^{2}=0.00$; $\mathrm{I}^{2}=0 \%$; Analysis 1.2; two trials, 146 women analysed; Bandpei 2010; Gil 2011; Summary of findings for the main comparison) more than usual prenatal care by itself. All of the trials reported effects in the same direction, so the intervention seemed to reduce pain and disability, but there is considerable uncertainty about the size of the effect, due to concern about the accuracy of reporting in Gil 2011 and Suputtitada 2002. See further details in the Discussion. None of the interventions, gestational ages or outcomes was sufficiently similar, nor were sufficient data provided to allow us to perform a meta-analysis to determine the estimate of effect of any specific exercise for a specific group of pregnant women.

There was low-quality evidence from one trial that water-based exercises added to usual prenatal care reduced LBP-related sick leave more than usual prenatal care by itself. In Kihlstrand 1999 ( $\mathrm{N}=241$ analysed), women were $40 \%$ less likely to take sick leave due to their LBP at 32-weeks' gestation (risk ratio (RR) 0.40; $95 \%$ CI 0.17 to 0.92 ; Analysis 2.1; Summary of findings 2). Lowback pain was not measured until one week postpartum, which is outside the timelines of this review.

\section{Manual therapy}

There was low-quality evidence (study design limitations, sparse data) from one trial (Licciardone 2010, N = 144 analysed) that there was no significant difference in pain relief between usual prenatal care plus OMT and usual prenatal care alone (effect size 0.27; $95 \%$ CI -0.13 to 0.68 ), while back-related function deteriorated significantly less in the usual care plus OMT group (effect size $0.72 ; 95 \%$ CI 0.13 to 1.14 ). There was also low-quality evidence suggesting that usual care plus OMT did not significantly reduce pain (effect size 0.14 . 95\% CI -0.26 to 0.55 ) or improve backrelated function (effect size $0.35,95 \%$ CI -0.06 to 0.76 ) any more than usual care plus sham US. All results were extracted directly from the paper.

There was low-quality evidence (study design limitations, sparse data) from one trial (Peterson 2012, N = 50 analysed) that while the majority of women in each of the groups (exercise, neuro emotional technique and SMT) improved in function and pain, there was no statistically significant difference between the groups. All results were extracted directly from the paper.

\section{Pelvic belts and pillows}

There was low-quality evidence from one trial (Kalus 2007; N = 94 analysed) that there was no significant difference between the BellyBra's and the Tubigrip's ability to relieve pain (mean difference (MD) -0.20 ; $95 \% \mathrm{CI}-1.19$ to 0.79 ) or to increase the women's ability to perform activities of daily living (MD - 0.90; 95\% CI 1.81 to 0.01 ; Analysis 3.1; Summary of findings 3).

There was very low-quality evidence from one trial (serious study design limitations, sparse data) that the Ozzlo pillow (a speciallydesigned pillow) placed under the pregnant abdomen relieved night-time pain better than a regular pillow in the same position. When using the Ozzlo pillow (Thomas 1989; $\mathrm{N}=92$ analysed), women reported significantly lower intensity of backache at night and during the day, but no significant difference in their ability to sleep through the night. The women's impressions were that the Ozzlo pillow was at least moderately more effective than a regular pillow for preventing or relieving their back pain and at least moderately more valuable for supporting them while sleeping. These results should be regarded with caution since the estimate of effect was measured for all women who used each pillow, rather than comparing each phase of this cross-over trial independently.

\section{Adverse effects}

There were no serious adverse effects noted for either the mother or the neonate in any of the studies. Women who participated in water-based exercise did not develop any more urinary tract or uterine infections than those who received usual prenatal care. There were no data reported on the (primary) preventative aspects of any of these interventions, although there was a sense that they may have prevented further development of pain and disability, therefore may have had some secondary preventative consequences.

\section{Pelvic pain}

This review now includes four trials $(\mathrm{N}=661$ randomised $)$ investigating interventions for managing pelvic pain; (Depledge 2005; N $=90$ randomised) compared the effects of two types of pelvic belts (rigid versus non-rigid) added to exercise with exercise alone; different acupuncture techniques were compared in two trials (Elden 2008; Lund 2006; $\mathrm{N}=185$ randomised), and acupuncture or exercise was added to and compared to usual prenatal care in one trial (Elden 2005; $\mathrm{N}=386$ randomised). 


\section{Pelvic belts with exercise}

There was low-quality evidence (study design limitations, sparse data) from one trial (Depledge 2005; $\mathrm{N}=87$ analysed) that there was a significant reduction of average pain in the group that received exercise alone or exercise plus a rigid belt and no significant pain reduction in the group that had exercise plus a nonrigid belt, but there were no data provided that compared results between groups. There was also low-quality evidence that there was no significant difference between the three groups in pelvic girdle pain-related function. Data were not presented in a fashion that allowed us to analyse them.

\section{Acupuncture, alone or with exercise}

Since the techniques studied were different in the two trials, we were unable to pool the data on the most effective method of providing acupuncture.

There was low-quality evidence (study design limitations, sparse data) from one trial (Elden 2008; $\mathrm{N}=108$ analysed) that there was no significant difference in pain relief between usual care plus acupuncture and usual care plus non-penetrating sham acupuncture (median evening pain on VAS 36 and 41 respectively, $\mathrm{P}=$ 0.483 ); usual care plus acupuncture showed significant improvement in activities of daily living over usual care plus non-penetrating sham acupuncture (median disability rating index (DRI) 44 and 55 respectively, $\mathrm{P}=0.001$ ), which was further illustrated in the two groups by the number of women who worked regularly (28/57 (acupuncture) versus 16/57 (control group), $\mathrm{P}=0.041$ ). All results were extracted directly from the paper.

There was also low-quality evidence from one trial (Lund 2006; N $=47$ analysed) that there was no significant difference in evening pain between women who received deep acupuncture and those who received superficial acupuncture (RR 1.06; $95 \%$ CI 0.73 to 1.54; Analysis 4.1; Summary of findings 4). Data for activities of daily living were provided for the participants as one group, therefore we cannot provide results for individual techniques.

One trial examined the effects on pelvic pain of adding acupuncture or stabilising exercises to usual prenatal care versus usual prenatal care alone (Elden 2005; N = 330 analysed). There was moderate quality evidence (sparse data) that after one week of treatment, those who received usual care reported significantly more intense evening pain than those who had received either acupuncture (difference of medians: $27 ; 25$ th to 75 th percentiles 13.3 to 29.5; $\mathrm{P}<0.001$ ) or stabilising exercises (difference of medians: 13 ; 25 th to $75 \%$ percentiles 2.7 to 17.5 ; $\mathrm{P}=0.0245$ ). Those who received acupuncture reported significantly less intense evening pain than those who received stabilising exercises (difference of medians: $-14 ; 25$ th to 75 th percentiles -18 to -3.3 ; $\mathrm{P}=0.0130$ ). These data were taken directly from the published report.

There were no lasting adverse effects noted; complaints of needle pain, slight bleeding, fainting, and sleepiness were noted for both acupuncture and sham acupuncture.

\section{Mixed population with pelvic and low-back pain}

This review now includes 11 trials $(\mathrm{N}=2120$ randomised $)$ that examined women who had both LBP and pelvic pain; they were given exercises (Eggen 2012; Kluge 2011; Martins 2005; Mørkved 2007; Stafne 2012; N = 1532 randomised), osteopathic manipulation (Peters 2007; N = 60 randomised), a multi-modal intervention that included manual therapy, exercise and education (Gross 2012; N = 169 randomised); or acupuncture alone (Ekdahl 2010; Kvorning 2004; Wang 2009a; Wedenberg 2000; N = 359 randomised).

\section{Exercise}

There was moderate quality evidence from four trials (Eggen 2012; Martins 2005; Mørkved 2007; Stafne 2012; N = 1344 analysed) that an eight- to 20 -week exercise training program reduced the risk of women reporting lumbo-pelvic pain by $15 \%$ (RR 0.85 ; $95 \%$ CI 0.73 to 1.00 ; $\mathrm{Tau}^{2}=0.02$; $\mathrm{I}^{2}=82 \%$; Analysis 5.1; Summary of findings 5); however, heterogeneity was high. This suggests that the average reduction amongst trials ranged from $0 \%$ to $27 \%$, while the distribution of effects in individual trials were wider than this, possibly explaining, in part, some of the heterogeneity. There was moderate quality evidence from two trials (Mørkved 2007; Stafne 2012; N = 1062 analysed) that a 12-week training program reduced the risk of women reporting lumbopelvic-related sick leave by $24 \%$ (RR 0.76 ; $95 \%$ CI 0.62 to 0.94 ; $\mathrm{Tau}^{2}=0.00 ; \mathrm{I}^{2}=0 \%$; Analysis 5.2), and improved functional status (results could not be pooled). As with the LBP trials, there was insufficient clinical homogeneity amongst exercise trials to be able to analyse or support a specific set of exercises for a specific group of women.

\section{Manual therapy}

There was low-quality evidence (study design limitations, sparse data) from one trial (Peters 2007; $\mathrm{N}=57$ analysed) that OMT significantly reduced pain (68\% improvement versus $0 \%$; $<$ $0.0005)$ and improved disability (28\% improvement versus $20 \%$ deterioration); data were extracted directly from the paper.

\section{Multi-modal}

There was low-quality evidence (study design limitations, sparse data) from one trial (Gross 2012; N = 169 analysed) that women who received either a multi-modal intervention that included manual therapy, exercise and education (MOM) or usual care reported significantly improved disability, but only those in the MOM group reported improved pain and physical function $(\mathrm{P}<$ 0.05; further data not provided). 


\section{Acupuncture}

Four trials measured the effects of adding acupuncture to usual prenatal care. However, because of differences in interventions, comparisons, techniques and outcome measures, we were unable to pool any of the results. Therefore, there is only low-quality evidence for any of the outcomes, although each trial reported positive results in favour of acupuncture in pain reduction and improved function (Summary of findings 6).

Ekdahl 2010 ( $\mathrm{N}=32$ analysed) examined the difference between acupuncture started at 20 weeks' and 26 weeks' gestation. They found that both regimens relieved pain, but significantly more in the group that started later. The later group also reported improvement in function despite increased physical restrictions, but data were not provided for between-group comparisons.

In Kvorning 2004 ( $\mathrm{N}=72$ analysed), 60\% of the women who completed the acupuncture treatment reported their pain intensity had decreased, compared to only $14 \%$ of the control group, who received usual prenatal care, suggesting a four-fold benefit from acupuncture (RR 4.16; 95\% CI 1.77 to 9.78; Analysis 6.1). The women who received usual prenatal care also used analgesics (5/ 35), TENS (6/35), physiotherapy (6/35) and a sacroiliac belt (15/ $35)$ to help them relieve the pain. Four out of the 37 women in the acupuncture group also used a sacroiliac belt for support.

Wang 2009a ( $\mathrm{N}=152$ analysed) compared the effects of auricular (ear) acupuncture, sham auricular acupuncture and a waiting list control. All women reported pain relief and improved functional status, but those in the acupuncture group reported significantly more pain relief and functional improvement than those in either the sham acupuncture or control group; data were not provided for between-group comparisons. Sixty-eight per cent of those in the acupuncture group reported a clinically significant improvement in pain after two weeks of treatment (paper states 30\% reduction is clinically significant), as compared to $32 \%$ in the sham acupuncture group $(\mathrm{P}=0.02)$ and $18 \%$ in the control group $(\mathrm{P}<$ $0.001)$. These data were extracted directly from the paper.

Women who received either acupuncture or physiotherapy ( Wedenberg 2000; $\mathrm{N}=46$ analysed) all reported a reduction in evening pain intensity and disability after completing their pro- gram, with the acupuncture group reporting significantly less intense pain $(\mathrm{P}<0.01)$ and lower disability scores than the physiotherapy group. Neither summary data nor analyses were provided for pain. Of note: none of the 30 participants were lost to followup in the acupuncture group (two were not analysed because they received both treatments), while $12 / 30$ were lost to follow-up in the physiotherapy group; for those who completed the study, there was no significant difference between groups for satisfaction with treatment, with a RR of 1.24 (95\% CI 0.96 to 1.60; Analysis 7.1; Summary of findings 7 ).

\section{Prevention}

There was low-quality evidence (study design limitations, sparse data) from one trial (Mørkved 2007; N = 301 analysed) that suggested a 12 -week training program prevented lumbo-pelvic pain in every one in 8.1 women treated (NNT analysis), and moderate quality evidence (sparse data) from one trial (Eggen 2012; N $=213$ analysed) that a 16 - to 20 -week training program was no more successful than usual prenatal care at preventing pelvic pain (odds ratio (OR) 1.03 (95\% CI 0.66 to 1.59 )) or LBP (OR 0.77 (95\% CI 0.50 to 1.19$)$ ); data extracted directly from papers. In Mørkved 2007, 95\% CI for number NNTB (number needed to benefit) was not provided.

\section{Adverse effects}

There were only minor, transient adverse effects reported by those who received acupuncture (small subcutaneous haematomas at insertion site) in Wedenberg 2000 and Wang 2009a. Although the adverse effects reported by those women who received physiotherapy (preterm uterine contractions, pre-eclampsia) were unlikely to have been caused by the physiotherapy, they withdrew from the study (Wedenberg 2000). Thirty-eight per cent of the women who received acupuncture in Kvorning 2004 also reported some minor, transient adverse effects (local pain, heat or sweating, local haematoma, tiredness, nausea, weakness). There were no reported problems with any of the deliveries or neonates. 
ADDITIONALS SMMARY OF F I N I NG S [Explanation]

Low-back pain: water gymnastics + usual prenatal care versus usual prenatal care for treating back pain in pregnancy

Patient or population: pregnant women with back pain

Intervention: Low-back pain: water gymnastics + usual prenatal care versus usual prenatal care

\begin{tabular}{|c|c|c|c|c|c|c|}
\hline \multirow[t]{3}{*}{ Outcomes } & \multicolumn{2}{|c|}{ Illustrative comparative risks* (95\% CI) } & \multirow{3}{*}{$\begin{array}{l}\text { Relative effect } \\
(95 \% \mathrm{CI})\end{array}$} & \multirow{3}{*}{$\begin{array}{l}\text { No of Participants } \\
\text { (studies) }\end{array}$} & \multirow{3}{*}{$\begin{array}{l}\text { Quality of the evidence } \\
\text { (GRADE) }\end{array}$} & \multirow[t]{3}{*}{ Comments } \\
\hline & Assumed risk & Corresponding risk & & & & \\
\hline & Control (usual care) & water gymnastics & & & & \\
\hline \multirow{2}{*}{$\begin{array}{l}\text { Number of women tak- } \\
\text { ing sick leave because } \\
\text { of back pain after } 32 \\
\text { weeks' gestation }\end{array}$} & \multicolumn{2}{|l|}{ Study population } & \multirow{2}{*}{$\begin{array}{l}\text { RR } 0.4 \\
(0.17 \text { to } 0.92)\end{array}$} & \multirow{2}{*}{$\begin{array}{l}241 \\
\text { (1 study) }\end{array}$} & \multirow{2}{*}{$\begin{array}{l}\oplus \oplus \bigcirc \bigcirc \\
\text { low }^{1,2}\end{array}$} & \\
\hline & 144 per 1000 & $\begin{array}{l}\mathbf{5 8} \text { per } \mathbf{1 0 0 0} \\
\text { (24 to } 132)\end{array}$ & & & & \\
\hline
\end{tabular}

*The basis for the assumed risk (e.g. the median control group risk across studies) is provided in footnotes. The corresponding risk (and its $95 \%$ confidence interval) is based on the assumed risk in the comparison group and the relative effect of the intervention (and its $95 \% \mathrm{Cl}$ ).

CI: Confidence interval; RR: Risk ratio;

GRADE Working Group grades of evidence

High quality: Further research is very unlikely to change our confidence in the estimate of effect.

Moderate quality: Further research is likely to have an important impact on our confidence in the estimate of effect and may change the estimate.

Low quality: Further research is very likely to have an important impact on our confidence in the estimate of effect and is likely to change the estimate.

Very low quality: We are very uncertain about the estimate.

${ }^{1}$ unclear methods of randomisation; research personnel not blinded

2 sparse data 
Low-back pain: support belts for preventing and treating pelvic and back pain in pregnancy

Patient or population: pregnant women with back pain

Intervention: Low-back pain: support belts

\begin{tabular}{|c|c|c|c|c|c|c|}
\hline \multirow[t]{3}{*}{ Outcomes } & \multicolumn{2}{|c|}{ Illustrative comparative risks* $(95 \% \mathrm{Cl})$} & \multirow{3}{*}{$\begin{array}{l}\text { Relative effect } \\
(95 \% \mathrm{Cl})\end{array}$} & \multirow{3}{*}{$\begin{array}{l}\text { No of Participants } \\
\text { (studies) }\end{array}$} & \multirow{3}{*}{$\begin{array}{l}\text { Quality of the evidence } \\
\text { (GRADE) }\end{array}$} & \multirow[t]{3}{*}{ Comments } \\
\hline & Assumed risk & Corresponding risk & & & & \\
\hline & Control & $\begin{array}{l}\text { Low-back pain: support } \\
\text { belts }\end{array}$ & & & & \\
\hline $\begin{array}{l}\text { BellyBra versus Tubigrip } \\
\text { - Low-back Pain }\end{array}$ & $\begin{array}{l}\text { The mean Bellybra ver- } \\
\text { sus Tubigrip back pain in } \\
\text { the control group was } 4 \text {. } \\
7 \text {, measured on VAS } 0 \text { to } \\
10\end{array}$ & $\begin{array}{l}\text { The mean Bellybra versus } \\
\text { Tubigrip - back pain in the } \\
\text { intervention group was } \mathbf{0} \text {. } \\
2 \text { lower ( } 1.19 \text { lower to } 0 . \\
79 \text { higher) }\end{array}$ & $\begin{array}{l}\text { MD }-0.20(95 \% \mathrm{Cl}-1.19 \\
\text { to } 0.79)\end{array}$ & $\begin{array}{l}94 \\
(1 \text { study })\end{array}$ & $\begin{array}{l}\oplus \oplus \bigcirc \bigcirc \\
\text { low }^{1,2}\end{array}$ & \\
\hline $\begin{array}{l}\text { BellyBra versus Tubigrip } \\
\text { - ADL }\end{array}$ & $\begin{array}{l}\text { The mean Bellybra versus } \\
\text { Tubigrip ability to perform } \\
\text { activities of daily living in } \\
\text { the control group was } 5 \text {. } \\
6 \text {, measured as a total of } \\
\text { several activities }\end{array}$ & $\begin{array}{l}\text { The mean Bellybra versus } \\
\text { Tubigrip ability to perform } \\
\text { activities of daily living } \\
\text { in the intervention group } \\
\text { was } 0.9 \text { lower } \\
\text { (1.81 lower to } 0.01 \\
\text { higher) }\end{array}$ & $\begin{array}{l}\text { MD }-0.90(95 \% \mathrm{Cl}-1.81 \\
\text { to } 0.01)\end{array}$ & $\begin{array}{l}94 \\
(1 \text { study })\end{array}$ & $\begin{array}{l}\oplus \oplus \bigcirc \bigcirc \\
\text { low }^{1,2}\end{array}$ & \\
\hline
\end{tabular}

*The basis for the assumed risk (e.g. the median control group risk across studies) is provided in footnotes. The corresponding risk (and its $95 \%$ confidence interval) is based on the assumed risk in the comparison group and the relative effect of the intervention (and its $95 \% \mathrm{Cl}$ ).

Cl: Confidence interval; MD: mean difference

GRADE Working Group grades of evidence

High quality: Further research is very unlikely to change our confidence in the estimate of effect.

Moderate quality: Further research is likely to have an important impact on our confidence in the estimate of effect and may change the estimate.

Low quality: Further research is very likely to have an important impact on our confidence in the estimate of effect and is likely to change the estimate.

Very low quality: We are very uncertain about the estimate. 


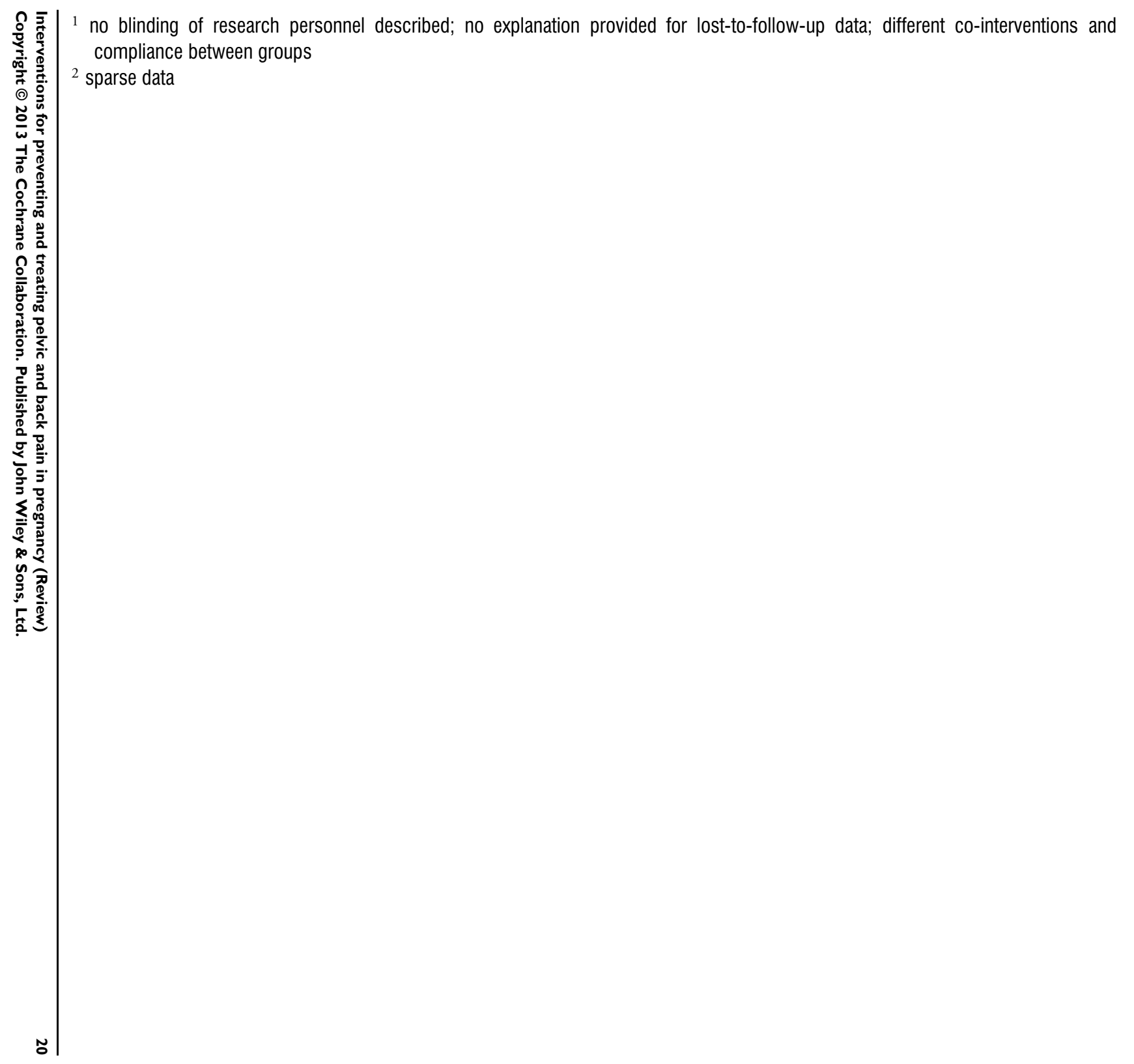


Pelvic pain: deep versus superficial acupuncture for preventing and treating pelvic and back pain in pregnancy

Patient or population: pregnant women with pelvic pain

Intervention: Pelvic pain: deep versus superficial acupuncture

\begin{tabular}{|c|c|c|c|c|c|c|}
\hline \multirow[t]{3}{*}{ Outcomes } & \multicolumn{2}{|c|}{ Illustrative comparative risks* $(95 \% \mathrm{Cl})$} & \multirow{3}{*}{$\begin{array}{l}\text { Relative effect } \\
(95 \% \text { Cl) }\end{array}$} & \multirow{3}{*}{$\begin{array}{l}\text { No of Participants } \\
\text { (studies) }\end{array}$} & \multirow{3}{*}{$\begin{array}{l}\text { Quality of the evidence } \\
\text { (GRADE) }\end{array}$} & \multirow[t]{3}{*}{ Comments } \\
\hline & Assumed risk & Corresponding risk & & & & \\
\hline & Control (superficial) & Intervention (deep) & & & & \\
\hline \multirow{2}{*}{$\begin{array}{l}\text { evening pain, reported } \\
\text { as better, based on } \\
\text { women's report on Vi- } \\
\text { sual Analogue Scale }\end{array}$} & Study population & & \multirow{2}{*}{$\begin{array}{l}\text { RR } 1.06 \\
(0.73 \text { to } 1.54)\end{array}$} & \multirow{2}{*}{$\begin{array}{l}47 \\
\text { (1 study) }\end{array}$} & \multirow{2}{*}{$\begin{array}{l}\oplus \oplus \bigcirc \bigcirc \\
\text { low }^{1,2}\end{array}$} & \\
\hline & 682 per 1000 & $\begin{array}{l}723 \text { per } 1000 \\
(498 \text { to } 1000)\end{array}$ & & & & \\
\hline
\end{tabular}

*The basis for the assumed risk (e.g. the median control group risk across studies) is provided in footnotes. The corresponding risk (and its $95 \%$ confidence interval) is based on the assumed risk in the comparison group and the relative effect of the intervention (and its $95 \% \mathrm{Cl}$ ).

Cl: Confidence interval; RR: Risk ratio;

GRADE Working Group grades of evidence

High quality: Further research is very unlikely to change our confidence in the estimate of effect.

Moderate quality: Further research is likely to have an important impact on our confidence in the estimate of effect and may change the estimate.

Low quality: Further research is very likely to have an important impact on our confidence in the estimate of effect and is likely to change the estimate.

Very low quality: We are very uncertain about the estimate.

${ }^{1}$ randomisation process and attrition rate/explanations not described

${ }^{2}$ sparse data 
Pelvic + low-back pain: any exercises + usual prenatal care versus usual prenatal care for preventing and treating pelvic and back pain in pregnancy

Patient or population: pregnant women with, or at risk of developing, pelvic and back pain

Intervention: Pelvic + low-back pain: any exercises + usual prenatal care versus usual prenatal care

\begin{tabular}{|c|c|c|c|c|c|c|}
\hline \multirow[t]{3}{*}{ Outcomes } & \multicolumn{2}{|c|}{ Illustrative comparative risks* $(95 \% \mathrm{Cl})$} & \multirow{3}{*}{$\begin{array}{l}\text { Relative effect } \\
(95 \% \mathrm{CI})\end{array}$} & \multirow{3}{*}{$\begin{array}{l}\text { No of Participants } \\
\text { (studies) }\end{array}$} & \multirow{3}{*}{$\begin{array}{l}\text { Quality of the evidence } \\
\text { (GRADE) }\end{array}$} & \multirow[t]{3}{*}{ Comments } \\
\hline & Assumed risk & Corresponding risk & & & & \\
\hline & $\begin{array}{l}\text { Control (usual prenatal } \\
\text { care) }\end{array}$ & $\begin{array}{l}\text { Any exercises }+ \text { usual } \\
\text { prenatal care }\end{array}$ & & & & \\
\hline \multirow{2}{*}{$\begin{array}{l}\text { Number of women who } \\
\text { reported pain on Visual } \\
\text { Analogue Scale }\end{array}$} & \multicolumn{2}{|l|}{ Study population } & \multirow{2}{*}{$\begin{array}{l}\text { RR } \mathbf{0 . 8 5} \\
-(0.73 \text { to } 1)\end{array}$} & \multirow{2}{*}{$\begin{array}{l}1344 \\
\text { (4 studies) }\end{array}$} & \multirow{2}{*}{$\begin{array}{l}\oplus \oplus \oplus \bigcirc \\
\text { moderate }{ }^{1}\end{array}$} & \\
\hline & 747 per 1000 & $\begin{array}{l}\mathbf{6 3 5} \text { per } 1000 \\
\text { (546 to } 747)\end{array}$ & & & & \\
\hline \multirow{2}{*}{$\begin{array}{l}\text { Number of women who } \\
\text { reported LBP/PGP-re- } \\
\text { lated sick leave }\end{array}$} & Study population & & \multirow{2}{*}{$\begin{array}{l}\text { RR } 0.76 \\
-(0.62 \text { to } 0.94)\end{array}$} & \multirow{2}{*}{$\begin{array}{l}1062 \\
\text { (2 studies) }\end{array}$} & \multirow{2}{*}{$\begin{array}{l}\oplus \oplus \oplus \bigcirc \\
\text { moderate }^{2}\end{array}$} & \\
\hline & 288 per 1000 & $\begin{array}{l}219 \text { per } \mathbf{1 0 0 0} \\
(178 \text { to } 270)\end{array}$ & & & & \\
\hline
\end{tabular}

*The basis for the assumed risk (e.g. the median control group risk across studies) is provided in footnotes. The corresponding risk (and its $95 \%$ confidence interval) is based on the assumed risk in the comparison group and the relative effect of the intervention (and its $95 \% \mathrm{Cl}$ ).

Cl: Confidence interval; RR: Risk ratio;

GRADE Working Group grades of evidence

High quality: Further research is very unlikely to change our confidence in the estimate of effect.

Moderate quality: Further research is likely to have an important impact on our confidence in the estimate of effect and may change the estimate.

Low quality: Further research is very likely to have an important impact on our confidence in the estimate of effect and is likely to change the estimate.

Very low quality: We are very uncertain about the estimate.

${ }^{1}$ there was a mix of potential biases among the four studies: no allocation concealment (1); no blinding of research personnel (all);

poor/no description of drop-outs, co-interventions and baseline inequality (mixed)

2 no blinding of research personnel; poor description of attrition; some differences in co-interventions 
Pelvic + low-back pain: acupuncture + usual prenatal care versus usual prenatal care for preventing and treating pelvic and back pain in pregnancy

Patient or population: pregnant women with, or at risk of developing, pelvic and back pain

Intervention: Pelvic + low-back pain: acupuncture + usual prenatal care versus usual prenatal care

\begin{tabular}{|c|c|c|c|c|c|c|}
\hline \multirow[t]{3}{*}{ Outcomes } & \multicolumn{2}{|c|}{ Illustrative comparative risks* $(95 \% \mathrm{Cl})$} & \multirow{3}{*}{$\begin{array}{l}\text { Relative effect } \\
(95 \% \mathrm{Cl})\end{array}$} & \multirow{3}{*}{$\begin{array}{l}\text { No of Participants } \\
\text { (studies) }\end{array}$} & \multirow{3}{*}{$\begin{array}{l}\text { Quality of the evidence } \\
\text { (GRADE) }\end{array}$} & \multirow[t]{3}{*}{ Comment } \\
\hline & Assumed risk & Corresponding risk & & & & \\
\hline & Control & $\begin{array}{l}\text { Pelvic + low-back pain: } \\
\text { acupuncture }+ \text { usual } \\
\text { prenatal care versus } \\
\text { usual prenatal care }\end{array}$ & & & & \\
\hline \multirow{2}{*}{$\begin{array}{l}\text { Number of women who } \\
\text { reported decreased pain }\end{array}$} & \multicolumn{2}{|c|}{ Study population } & \multirow{2}{*}{$\begin{array}{l}\text { RR } 4.16 \\
-(1.77 \text { to } 9.78)\end{array}$} & \multirow{2}{*}{$\begin{array}{l}72 \\
\text { (1 study) }\end{array}$} & \multirow{2}{*}{$\begin{array}{l}\oplus \oplus \bigcirc \bigcirc \\
\text { low }^{1,2}\end{array}$} & \\
\hline & 143 per 1000 & $\begin{array}{l}594 \text { per } 1000 \\
(253 \text { to } 1000)\end{array}$ & & & & \\
\hline
\end{tabular}

*The basis for the assumed risk (e.g. the median control group risk across studies) is provided in footnotes. The corresponding risk (and its $95 \%$ confidence interval) is based on the assumed risk in the comparison group and the relative effect of the intervention (and its $95 \% \mathrm{CI}$ ).

Cl: Confidence interval; RR: Risk ratio;

GRADE Working Group grades of evidence

High quality: Further research is very unlikely to change our confidence in the estimate of effect.

Moderate quality: Further research is likely to have an important impact on our confidence in the estimate of effect and may change the estimate.

Low quality: Further research is very likely to have an important impact on our confidence in the estimate of effect and is likely to change the estimate.

Very low quality: We are very uncertain about the estimate.

${ }^{1}$ no blinding of research personnel, over $20 \%$ attrition, different co-interventions

${ }^{2}$ sparse data 
Pelvic + low-back pain: acupuncture + usual prenatal care versus individualised physio + usual prenatal care for preventing and treating pelvic and back pain in pregnancy

Patient or population: pregnant women with, or at risk of developing, pelvic and back pain

Intervention: Pelvic + low-back pain: acupuncture + usual prenatal care versus individualised physio + usual prenatal care

\begin{tabular}{|c|c|c|c|c|c|c|}
\hline \multirow[t]{3}{*}{ Outcomes } & \multicolumn{2}{|c|}{ Illustrative comparative risks* $(95 \% \mathrm{Cl})$} & \multirow{3}{*}{$\begin{array}{l}\text { Relative effect } \\
(95 \% \mathrm{Cl})\end{array}$} & \multirow{3}{*}{$\begin{array}{l}\text { No of Participants } \\
\text { (studies) }\end{array}$} & \multirow{3}{*}{$\begin{array}{l}\text { Quality of the evidence } \\
\text { (GRADE) }\end{array}$} & \multirow[t]{3}{*}{ Comments } \\
\hline & Assumed risk & Corresponding risk & & & & \\
\hline & $\begin{array}{l}\text { Control (individualised } \\
\text { physio + usual prenatal } \\
\text { care) }\end{array}$ & $\begin{array}{l}\text { acupuncture }+ \text { usual } \\
\text { prenatal care }\end{array}$ & & & & \\
\hline \multirow{2}{*}{$\begin{array}{l}\text { Numbers of women rat- } \\
\text { ing treatment as good or } \\
\text { excellent }\end{array}$} & Study population & & \multirow{2}{*}{$\begin{array}{l}\text { RR } 1.24 \\
-(0.96 \text { to } 1.6)\end{array}$} & \multirow{2}{*}{$\begin{array}{l}46 \\
\text { (1 study) }\end{array}$} & \multirow{2}{*}{$\begin{array}{l}\oplus \oplus \bigcirc \bigcirc \\
\mathbf{l o w}^{1,2}\end{array}$} & \\
\hline & 778 per 1000 & $\begin{array}{l}964 \text { per } 1000 \\
\text { (747 to } 1000)\end{array}$ & & & & \\
\hline
\end{tabular}

*The basis for the assumed risk (e.g. the median control group risk across studies) is provided in footnotes. The corresponding risk (and its $95 \%$ confidence interval) is based on the assumed risk in the comparison group and the relative effect of the intervention (and its $95 \% \mathrm{Cl}$ ).

Cl: Confidence interval; RR: Risk ratio;

\section{GRADE Working Group grades of evidence}

High quality: Further research is very unlikely to change our confidence in the estimate of effect.

Moderate quality: Further research is likely to have an important impact on our confidence in the estimate of effect and may change the estimate.

Low quality: Further research is very likely to have an important impact on our confidence in the estimate of effect and is likely to change the estimate.

Very low quality: We are very uncertain about the estimate.

${ }^{1}$ no description of randomisation process, no blinding of research personnel described, uneven attrition (12 dropped out of physio

group, while none dropped out of the acupuncture group) and co-interventions between groups

${ }^{2}$ sparse data 


\section{ISCUSSION}

\section{Summary of main results}

We included 26 randomised trials examining 4093 pregnant women in this updated review, a substantial increase over Pennick 2007 (eight RCTs; 1305 participants). Eleven trials examined LBP $(\mathrm{N}=1312$ randomised/1164 analysed); four looked at pelvic pain $(\mathrm{N}=661 \mathrm{randomised} / 572$ analysed); and 11 examined women with both LBP and pelvic pain ( $\mathrm{N}=2120$ randomised/1918 analysed). Overall, $89 \%$ of the women were included in the analyses; the number of women lost to follow-up ranged from none reported to over $20 \%$.

In summary, for $\mathbf{L B P}$, low-quality evidence suggested that exercise (land- or water-based) significantly reduced pain, disability and LBP-related absenteeism more than usual prenatal care by itself. Very low-quality evidence suggested that a specially-designed pillow that supports the pregnant abdomen in bed reduced the intensity of backache at night better than a regular pillow.

Low-quality evidence from single trials suggested there was no significant difference in pain or women's ability to perform activities of daily living when comparing two types of pelvic support belt; in pain relief between osteopathic manipulation (OMT) and usual care; or in pain relief and back-related function when OMT was compared with sham US.

In summary, for pelvic pain, moderate quality evidence suggested that acupuncture was better than stabilising exercises at reducing evening pain and both of them were better than usual prenatal care.

Low-quality evidence from single trials suggested that acupuncture improved activities of daily living, including work, better than sham acupuncture; exercise alone or with the use of a rigid belt significantly reduced average pain, but not functional status. There was no statistical difference in functional status or average pain between groups who exercised with a non-rigid belt; in pain between acupuncture and sham acupuncture or in evening pain between women who received deep or superficial acupuncture.

In summary, for lumbo-pelvic pain, moderate quality evidence suggested that an eight- to 20 -week exercise training program significantly reduced the risk of women reporting lumbo-pelvic pain, and a 12-week training program reduced the risk of women reporting lumbo-pelvic-related sick leave and improved functional status.

Low-quality evidence from single trials suggested that OMT significantly reduced pain and improved disability; women who received a multi-modal intervention that included manual therapy, exercise and education (MOM) reported improved pain and physical function; and acupuncture reduced pain better than usual prenatal care. Acupuncture started at 26 weeks' gestation reduced pain and disability better than acupuncture started at 20 weeks'; and acupuncture significantly reduced pain and improved func- tional status better than either physiotherapy, sham acupuncture or usual care.

Prevention: four trials also sought an effective intervention to prevent back or pelvic pain. One provided the results of a numbers needed to treat analysis for improvement in pain and disability following participation in an exercise training program for pelvic and LBP, but no measures of variability (Mørkved 2007); another suggested that a 16 - to 20 -week training program was no more successful than usual prenatal care at preventing pelvic pain or LBP (Eggen 2012); Thomas 1989 measured women's overall impressions of a special pillow for preventing backache, but there were no data to support this impression; and finally Sedaghati 2007 only provided data on treatment effects, not primary prevention.

\section{Overall completeness and applicability of evidence}

The studies included in this updated review were conducted in Iran, Brazil, USA, Sweden, Thailand, Australia, New Zealand, Norway, South Africa and Germany, which would suggest that the women who participated broadly represented pregnant women in general. However, women entered the studies at various times in their pregnancies and were diagnosed with pelvic, back pain or both using a variety of methods ranging from self-reported symptoms to different diagnostic tests (depending on the study), making the internal validity and reliability of the classification of each condition questionable.

Primary outcomes of interest for this review were pain, disability, absenteeism from work and adverse events. While pain was measured in all the studies, disability and functional status were not, nor was absenteeism from work or adverse events. Only four studies (Elden 2008; Kihlstrand 1999; Mørkved 2007; Stafne 2012) reported on the positive impact of the interventions on the women's absenteeism from work due to their back or pelvic pain. Considering the number of women who now participate in the paid workforce, this is a limitation that should be addressed in future studies.

Women who participated in additional exercise programs, received acupuncture or OMT, or used a pillow or abdominal support generally expressed satisfaction with the interventions and felt they would consider them in subsequent pregnancies. In general, women in the studies who received more than usual prenatal care appeared to experience some pain relief, although the results varied. Three pooled estimates of effect were moderate (SMD 0.5 to $<0.8$, Analysis 1.2; or large in size (SMD $\geq 0.8$; Analysis 1.1; Analysis 3.1; Cohen 1988) and would likely be considered clinically significant. On the other hand, had the potential for risks of bias been lower, the estimates of effect may also have been lower, since it has been shown that trials with lower risks of bias have lower effect sizes (Van Tulder 2009). This was bourne out by the sensitivity analyses and re-analyses of Analysis 1.1 and Analysis 1.2. Data from Gil 2011 and Suputtitada 2002 were clear out- 
liers in the meta-analyses, which raised the concern that standard errors had been inadvertently reported instead of standard deviations. With the original data, the results were SMD -2.04 (95\% CI -3.03 to -1.04$)$ for pain and SMD -1.86 (95\% CI -4.63 to $0.91)$ for disability. Removing them from the analyses resulted in smaller estimates of effect: SMD -0.75 (95\% CI -1.10 to -0.40$)$ for pain and SMD -0.49 (95\% CI -0.87 to -0.12 ) for disability; re-calculating the standard deviation and using the new values in the meta-analyses resulted in less heterogeneity and more modest estimates of effect that were closer to the sensitivity analyses (SMD -0.80 ; $95 \%$ CI -1.07 to -0.53 for pain and SMD -0.56 ; $95 \%$ CI -0.89 to -0.23 for disability).

Considering the quality of the evidence in this review, these results must be considered with caution and generalising the results to all pregnant women is likely premature.

Incorporating the evidence into clinical practice may be challenging since 'usual prenatal care' and 'standard physiotherapy' are not described in sufficient detail in the trials and are likely to vary across jurisdictions. Similarly, there were insufficient details provided about other interventions that would make it difficult to replicate in another clinical setting.

\section{Quality of the evidence}

No outcomes were supported by high-quality evidence and only three by moderate-quality evidence (acupuncture for pelvic pain, exercise for lumbo-pelvic pain and lumbo-pelvic work absenteeism). Overall, there was low-quality evidence for outcomes because of high risks of bias and sparse data. Trials were generally small (range 30 to 855 women; with only three trials including over 300 women, the GRADE rule of thumb for imprecision/ sparse data; Schünemann 2009). Clinically heterogeneous populations, interventions, comparisons and outcome measures precluded pooling the results to arrive at overall estimates of effect in all but the exercise interventions for LBP and combined pelvic and back pain. Inclusion criteria were quite different across studies; women were admitted at different points in their pregnancy, 'diagnoses' of LBP and pelvic pain ranged from self-report of symptoms to clinical interpretation of the results of special tests, such as the posterior pelvic pain provocation test, resulting in a heterogenous population. Pain and disability were measured in a variety of ways; pain was measured as intensity, presence, change in pain within groups, numbers or percentage who reported improvement, and disability was measured as back-specific function, general function, ability to perform activities of daily living, change in abilities within groups, numbers or percentage who reported improved function, time off work and sleep disturbance. Outcomes were measured daily, weekly, in the morning, in the evening, over the course of the pregnancy and during the postpartum period; the latter outcomes were outside the scope of this review.

Besides the paucity of usable data, the risks of bias contribute to the lack of confidence we have in the results. Overall, the trial re- ports were poorly written and it was difficult to follow some of the analyses, although more recent trials tended to be more complete. We only included RCTs (one of which used a cross-over design) in this review, but in 13 of the trials, the methods of randomisation were unclear and in 14, the methods of allocation concealment were unclear. On the other hand, we excluded eight trials because the techniques they described for randomisation were at high risk for bias, or allocation procedures were simply unclear. Current wisdom suggests that randomisation and concealment of allocation are key study characteristics that reduce the potential for bias. Blinding of personnel remains difficult in non-pharmaceutical trials, a reality that increases the risk of bias, especially in self-reported measures of symptoms. Some of the more recent trials did attempt to minimise bias by recruiting, for example, only participants who were naive to acupuncture (Elden 2005; Elden 2008) or by conducting credibility checks (Wang 2009a) to determine the participants' expectations of the study interventions they were offered. In Gil 2011, Martins 2005 and Ekdahl 2010, baseline pain was different in the two groups. In Wedenberg 2000, 12 of 30 women dropped out of the physiotherapy group, while none withdrew from the acupuncture group (although two were excluded from analysis due to receiving both treatments), leading to potential attrition bias. Based on baseline data, there were no obvious reasons for the difference in withdrawals between the two groups.

For this update, we decided not to use the data from Thomas 1989, the cross-over study looking at the effects of different pillows. Rather than comparing the results from each phase separately, they had calculated the outcomes from all of the women when they were using the Ozzlo pillow against their outcomes when they were using the standard pillow, making it look as if there were 184 women analysed in the study instead of just 92 . In addition, the study design did not allow the effects of one pillow to subside before starting to use the second, and women in group two were one week further into their pregnancy. While this is not a long time, many women report that back pain increases as pregnancy progresses making this a notable study design flaw which puts the two groups at a different risk for back pain. The authors did report that there were no differences in the main outcomes between the two weeks, however if future cross-over studies are included, it would be important to divide the results from the two phases.

There were only minor, transient adverse effects reported in this review by those who received acupuncture (small subcutaneous hematomas at insertion site) in Wedenberg 2000 and Wang 2009a. A systematic review on the safety profile of acupuncture for back pain concluded, from reports on over 100,000 patients from the US, UK, and Sweden, that reported incidents from acupuncture were, on the whole, minor and transient. They listed fainting (10 patients), unexpected exacerbation of symptoms (12 patients), pain at site of needle (six patients), needle left in place (five patients), seizure after needle insertion (one patient with known epilepsy), slurred speech (one patient), pneumothorax (two pa- 
tients), broken needle (two patients) and minor bleeding at site (15\% of treatments) as the most notable problems (Cherkin 2003). More recently Moffatt 2013 has concluded that there is no firm evidence to suggest that acupuncture treatment can cause detrimental effects for the fetus or the maintenance of pregnancy. Therefore, provided that certain points that supply the cervix and uterus are avoided Vermani 2010, the current evidence would suggest that acupuncture is relatively safe for pregnant women with no other complications.

\section{Potential biases in the review process}

This review was updated using the updated Cochrane methodology for assessing risk of bias and quality of the evidence. The international literature was searched and trials in languages other than English were retrieved. However, while the English articles were identified and assessed by two review authors independently, the four non-English reports were only reviewed by one person (Bandpei 2010; Gil 2011; Martins 2005; Peters 2007); Gil 2011 was also translated using Google Translate (Google Translate). Three non-English reports were also excluded by one person only (Chitryniewicz 2010; Momoi 1999; Zand 2011). This has the potential to lead to some errors, but considering the lack of overall data in the English reports, this is not likely to make a substantial change in the results or quality of the evidence.

\section{Agreements and disagreements with other studies or reviews}

Pennick 2007 included eight RCTs (1305 women with pelvic, back pain or both) and found that adding pregnancy-specific exercises, physiotherapy, acupuncture and pillows to usual prenatal care reduced pain intensity, disability, and absenteeism. However, seven of the eight trials had moderate to high risks of bias and readers were advised to view the results with caution.

A number of non-Cochrane systematic reviews have been published since Pennick 2007. While they do have different foci and different search dates, Ee 2008; Kanakaris 2011; Richards 2012; Vermani 2010 and this current review are essentially in agreement for the aspects of overlap. Field 2008 reviewed research on the effectiveness of complementary and alternative medicine for pregnancy and labour and concluded that the evidence suggests they are effective for reducing pregnancy-related back and leg pain, amongst other symptoms and bio-markers outside the scope of this review, but 'the research has several methodological limitations'. Anderson 2005 investigated the effectiveness of complementary and alternative medicine in obstetrics and included two of the trials included in this review that examined the effects of acupuncture on pregnancy-related LBP (Kvorning 2004; Wedenberg 2000). They came to the same conclusions as we did.

\section{A U THORS'CONCLUSIONS}

\section{Implications for practice}

Moderate quality evidence suggested that acupuncture or exercise, tailored to the stage of pregnancy, significantly reduced evening pelvic pain or lumbo-pelvic pain more than usual care alone; acupuncture was significantly more effective than exercise for reducing evening pelvic pain and a 16 - to 20 -week training program was no more successful than usual prenatal care at preventing pelvic or LBP. Low-quality evidence suggested that exercise significantly reduced pain and disability from LBP.

There was low-quality evidence from single trials for other outcomes because of high risk of bias and sparse data; clinical heterogeneity precluded pooling. Publication bias and selective reporting cannot be ruled out.

Physiotherapy, OMT, acupuncture, a multi-modal intervention, or the addition of a rigid pelvic belt to exercise relieved pelvic or back pain more than usual care alone. Acupuncture was more effective than physiotherapy at relieving evening lumbo-pelvic pain and disability and improving pain and function when it was started at 26- rather than at 20-weeks' gestation, although the effects were small.

There was no significant difference in low-back pain and function for different support belts, exercise, neuro emotional technique or spinal manipulation, or in evening pelvic pain between deep and superficial acupuncture.

Very low-quality evidence suggested a specially-shaped pillow may reduce night-time LBP.

Further research is very likely to have an important impact on our confidence in the estimates of effect and is likely to change the estimates.

\section{Implications for research}

Given the high incidence of back and pelvic pain in pregnancy and the distress this causes many women in late pregnancy, more research would be helpful to inform the advice given by prenatal practitioners. Future studies would benefit from an agreed classification system for categorising women according to their presenting symptoms. Possible foci of future research might include: developing and validating a classification system for pregnancy-related back and pelvic pain, patient-education during early pregnancy on specially-adapted exercises, the efficacy and safety of analgesics in late pregnancy, and standardisation of outcome assessment. More and better designed studies that build on the current evidence, investigating the effects of physiotherapy, acupuncture and other conservative and complementary treatments already being used by pregnant women (Wang 2004) are also needed. Preventive studies beginning early in pregnancy would be welcome to see if any of these interventions will really prevent the development of back 
and pelvic pain. In order to establish the safety of interventions we recommend that future studies measure the presence or absence of adverse events. In addition, by incorporating validated outcome measures into study designs that include work-related absence along with pain and general disability, future reviews may use meta-analyses to help determine the most effective interventions.

\section{ACKNOWLEDGEMENTS}

The authors would like to thank the Scientific Foundation Board of the Royal College of General Practitioners for the grant which made the 2002 updating of this review possible. Gavin Young would like to thank Paul Shekelle of the Cochrane Back Review Group for helping with the 2002 analyses and Victoria Pennick would like to thank Andrea Furlan for her helpful comments and help with translation in the 2007 version.

We would like to acknowledge the contributions made by David Jewell to the first two versions of this review and Gavin Young for his contributions to the first three versions. We were able to exclude trials and include data from non-English trials due to the gracious assistance of Andrea Furlan, Ivan Steenstra, Jacob Etches, Ayako Kitta, Reza Yousefi-Nooraie and Tomasz Kotwicki. Thanks also to Kelly An who helped with 'Risk of bias' assessment and data extraction, and Lynn Hampson and Rachel Couban who helped identify and obtain copies of the studies.

A special thank you goes to Stephanie McKeown whose encouragement and support made it possible for Dianne Liddle to participate in this review.

As part of the pre-publication editorial process, this review has been commented on by three peers (an editor and two referees who are external to the editorial team), a member of the Pregnancy and Childbirth Group's international panel of consumers and the Group's Statistical Adviser.

The National Institute for Health Research (NIHR) is the largest single funder of the Cochrane Pregnancy and Childbirth Group. The views and opinions expressed therein are those of the authors and do not necessarily reflect those of the NIHR, NHS or the Department of Health.

\section{R E F E R N C E S}

\section{References to studies included in this review}

Bandpei 2010 \{published data only\}

Bandpei MAM, Ahmadshirvani M, Fakhri M, Rahmani N.

The effect of an exercise program and ergonomic advices on treatment of pregnancy-related low back pain: a randomized controlled clinical trial. Journal of Mazandaran University of Medical Sciences 2010;20(77):10-9.

Depledge 2005 \{published data only\}

Depledge J, McNair PJ, Keal-Smith C, Williams M. Management of symphysis pubis dysfunction during pregnancy using exercise and pelvic support belts. Physical Therapy 2005;85(12):1290-300.

Eggen 2012 \{published data only\}

* Eggen MH, Stuge B, Mowinckel P, Jensen KS, Hagen KB. Can supervised group exercises including ergonomic advice reduce the prevalence and severity of low back pain and pelvic girdle pain in pregnancy? A randomized controlled trial. Physical Therapy 2012;92(6):781-90.

Hagen KB. Can tailored exercises in pregnancy prevent low back and pelvic girdle pain? A randomised controlled trial. http://www.controlled-trials.com/isrctn/pf/95014448 (accessed 15 August 2012) 2010.

Ekdahl 2010 \{published data only\}

Ekdahl L, Petersson K. Acupuncture treatment of pregnant women with low back and pelvic pain--an intervention study. Scandinavian Journal of Caring Sciences 2010;24(1): $175-82$.
Elden 2005 \{published data only\}

Elden H, Hagberg H, Olsen MF, Ladfors L, Ostgaard HC. Regression of pelvic girdle pain after delivery: follow-up of a randomised single blind controlled trial with different treatment modalities. Acta Obstetricia et Gynecologica Scandinavica 2008;87(2):201-8.

* Elden H, Ladfors L, Olsen MF, Ostgaard HC, Hagberg H. Effects of acupuncture and stabilising exercises as adjunct to standard treatment in pregnant women with pelvic girdle pain: randomised single blind controlled trial. BMJ 2005; 330:761. [DOI: 10.1136/bmj.38397.507014]

Elden H, Ostgaard HC, Fagevik-Olsen M, Ladfors L, Hagberg H. Treatments of pelvic girdle pain in pregnant women: adverse effects of standard treatment, acupuncture and stabilising exercises on the pregnancy, mother, delivery and the fetus/neonate. BMC Complementary and Alternative Medicine 2008;8:34.

Ladfors L, Elden H, Olsen MF, Ostgaard HC. Effects of acupuncture and specific stabilizing exercises among women with pregnancy-related pelvic pain: a randomised single blind controlled trial [abstract]. American Journal of Obstetrics and Gynecology 2004;191(6 Suppl 1):S77.

Elden 2008 \{published data only\}

* Elden H, Fagevik-Olsen M, Ostgaard HC, Stener-Victorin E, Hagberg $\mathrm{H}$. Acupuncture as an adjunct to standard treatment for pelvic girdle pain in pregnant women: randomised double-blinded controlled trial comparing acupuncture with non-penetrating sham acupuncture. BJOG: An International Journal of Obstetrics and Gynaecology 
2008;115(13):1655-68.

Hagberg H. Acupuncture as a complement to standard treatment for the treatment of well-defined pelvic girdle pain in pregnant women. http://www.controlled-trials.com/ ISRCTN11374571 (accessed 15 February 2007).

Garshasbi 2005 \{published data only\}

Garshasbi A, Faghih Zadeh S. The effect of exercise on the intensity of low back pain in pregnant women. International Journal of Gynecology \& Obstetrics 2005;88:271-5.

Gil 2011 \{published data only\}

Gil VFB, Osis MJD, Faúndes A. Lumbar pain during pregnancy: efficacy of Global Postural Reeducation (GPR) treatment [Portuguese] [Lombalgia durante a gestação: eficácia do tratamento com Reeducação Postural Global (RPG)]. Fisioterapia e Pesquisa 2011;18(2):164-70.

Gross 2012 \{published data only\}

Gross G, George JW, Thompson PA, Nelson DM, Skaggs C. A randomized controlled trial comparing a multi-modal intervention and standard obstetrical care for low back and pelvic pain in pregnancy. American Journal of Obstetrics and Gynecology 2012;206(Suppl 1):S360.

Kalus 2007 \{published data only\}

* Kalus SM, Kornman L, Quinlivan JA. Managing back pain in pregnancy using a support garment: a randomised trial. BJOG: An International Journal of Obstetrics and Gynaecology 2007;115:68-75.

Kalus SM, Kornman LH, Quinlivan JA. Evaluating the impact of the belly bra on back pain in pregnancy. Perinatal Society of Australia and New Zealand 10th Annual Congress; 2006 April 3-6; Perth, Australia. 2006:219. Quinlivan J, Kornman L. Evaluating the impact of a belly bra on back pain in pregnancy. Australian Clinical Trials Register. http://www.actr.org.au (accessed 6 December 2005).

Kashanian 2009 \{published data only\} Kashanian M, Akbari Z, Alizadeh MH. The effect of exercise on back pain and lordosis in pregnant women. International Journal of Gynecology \& Obstetrics 2009;107 (2):160-1.

Kihlstrand 1999 \{published data only\}

Kihlstrand M, Stenman B, Nilsson S, Axelsson O. Watergymnastics reduced the intensity of back/low back pain in pregnant women. Acta Obstetricia et Gynecologica Scandinavica 1999;78(3):180-5.

Kluge 2011 \{published data only\}

Kluge J, Hall D, Louw Q, Theron G, Grove D. Specific exercises to treat pregnancy-related low back pain in a South African population. International Journal of Gynecology \& Obstetrics 2011;113(3):187-91.

Kvorning 2004 \{published data only\} Kvorning N, Holmberg C, Grennert L, Aberg A, Akeson $\mathrm{J}$. Acupuncture relieves pelvic and low-back pain in late pregnancy. Acta Obstetricia et Gynecologica Scandinavica 2004;83:246-50.
Licciardone 2010 \{published data only\}

Licciardone JC. Study of the effectiveness of osteopathic manipulative treatment in pregnant women. ClinicalTrials.gov (http://clinicaltrials.gov/) (accessed 21 June 2007).

* Licciardone JC, Buchanan S, Hensel KL, King HH, Fulda KG, Stoll ST. Osteopathic manipulative treatment of back pain and related symptoms during pregnancy: a randomized controlled trial. American Journal of Obstetrics and Gynecology 2010;202(1):43.e1-8.

Lund 2006 \{published data only\}

Lund I, Lundeberg T, Lonnberg L, Svensson E. Decrease of pregnant women's pelvic pain after acupuncture: a randomized controlled single-blind study. Acta Obstetricia et Gynecologica Scandinavica 2006;85(1):12-9.

Martins 2005 \{published data only\}

Martins R, Pinto e Silva JL. An exercise method for the treatment of lumbar and posterior pelvic pain in pregnancy [Tratamento da lombalgia 3 dor pelvica posterior na gestacao por um metodo de exercisios]. Revista Brasileira de Ginecologia y Obstetricia 2005;27(5):275-82.

Mørkved 2007 \{published data only\}

Mørkved S, Salvesen KA, Schei B, Lydersen S, Bø K. Does group training during pregnancy prevent lumbopelvic pain? A randomized clinical trial. Acta Obstetricia et Gynecologica Scandinavica 2007;86(3):276-82.

Peters 2007 \{published data only\}

* Peters R, Van der Linde M. Osteopathic treatment of women with back pain during pregnancy. A randomised controlled study [Osteopathische Behandlung von Frauen mit Ruckenschmerzen wahrend der Schwangerschaft. Eine randomisierte kontrollierte Studie]. Osteopathische Medizin 2007;8(1):26.

Peters R, Van der Linde M. Osteopathic treatment of women with low back pain during pregnancy. A randomized controlled trial. Osteopathy Today, 9th International Congress of the German Osteopathic Association (VOD); 2006 October 5-8; Schlangenbad, Wiesbaden, Germany. Wiesbaden: German Academy of Osteopathy, 2006:7.

Peterson 2012 \{published data only\}

Peterson D, Haas M, Gregory T. A pilot randomized controlled trial comparing the efficacy of exercise, spinal manipulation, and Neuro Emotional Technique for the treatment of pregnancy related low back pain. Chiropractic \& Manual Therapies 2012;20(1):18. [DOI: 10.1186/ 2045-709X-20-18]

\section{Sedaghati 2007 \{published data only\}}

Sedaghati P, Ziaee V, Ardjmand A. The effect of an ergometric training program on pregnants weight gain and low back pain. Gazzetta Medica Italiana Archivio per le Scienze Mediche 2007;166(6):209-13.

Stafne 2012 \{published data only\}

Stafne SN, Salvesen KA, Romundstad PR, Stuge B, Morkved S. Does regular exercise during pregnancy influence lumbopelvic pain? A randomized controlled trial. 
Acta Obstetricia et Gynecologica Scandinavica 2012 May;91

(5):552-9.

Suputtitada 2002 \{published data only\}

Suputtitada A, Wacharapreechanont T, Chaisayan P. Effect of the "sitting pelvic tilt exercise" during the third trimester in primigravidas on back pain. Journal of the Medical Association of Thailand 2002;85 Suppl 1:S170-9.

Thomas 1989 \{published data only\} Thomas IL, Nicklin J, Pollock H, Faulkner K. Evaluation of a maternity cushion (Ozzlo pillow) for backache and insomnia in late pregnancy. Australian and New Zealand Journal of Obstetrics and Gynaecology 1989;29:133-8.

Wang 2009a \{published data only\}

Wang SM. Acupuncture and low back pain during pregnancy. National Centre for Complementary \& Alternative Medicine. http://nccam.nih.gov/research/ extramural/awards/2005/ (accessed 31 March 2006). Wang SM. Use ear acupuncture as treatment for low back pain during pregnancy. ClinicalTrials.gov (http:// clinicaltrials.gov/) (accessed 20 February 2008).

Wang SM, Caldwell-Andrews AA, Fermo L, Sevarino F, Kain ZN. Auricular acupuncture as a treatment for gestational low back pain: preliminary findings [abstract]. Anesthesiology 2002;96 Suppl:A1025.

* Wang SM, Dezinno P, Lin EC, Lin H, Yue JJ, Berman $\mathrm{MR}$, et al.Auricular acupuncture as a treatment for pregnant women who have low back and posterior pelvic pain: a pilot study. American Journal of Obstetrics and Gynecology 2009; 201(3):271.e1-9.

Wang SM, Lin E, Braveman F, Kain Z. Auricular acupuncture as a treatment for posterior pelvic pain during pregnancy: a RCT. Anesthesiology 2007;107:Abstract no: A277.

Wedenberg 2000 \{published data only\} Wedenberg K, Moen B, Norling A. A prospective randomized study comparing acupuncture with physiotherapy for low-back and pelvic pain in pregnancy. Acta Obstetricia et Gynecologica Scandinavica 2000;79: $331-5$.

\section{References to studies excluded from this review}

\section{Beyaz 2011 \{published data only\}}

Beyaz EA, Ozcan E, Ketenci A, Beyaz MM. The effectiveness of pregnancy rehabilitation: Effects on low back pain and calf cramps during pregnancy and pregnancy outcome. Nobel Medicus 2011;7(2):67-74.

Chitryniewicz 2010 \{published data only\}

Chitryniewicz J, Kulis A. The influence of physical activity and massage on low back pain in pregnant women [Wplyw aktywnosci ruchowej i zabiegow masazu na dolegliwosci bolowe kregoslupa ledz wiowego u kobiet w ciazy]. Ginekologia Praktyczna 2010;18(2):17-22.

Ciardi 2002 \{published data only\} Ciardi S, Gozzo V, Wilmarth MA. Pregnant women's response to a prenatal body mechanics and exercise program for the prevention of low back pain: report on a pilot study. Journal of the Section on Women's Health 2002;26(4):17-22.

da Silva 2004 \{published data only\}

da Silva JBG, Nakamura MU, Cordeiro JA, Kulay L Jr. Acupuncture for low back pain in pregnancy - a prospective, quasi-randomised, controlled study. Acupuncture in Medicine 2004;22(2):60-7.

de Jonge-Vors 2011 \{published data only\} de Jonge-Vors C. Reducing the pain: midwifery acupuncture service audit in Birmingham. Practising Midwife 2011 Nov; 14(10):22-6.

Field 1999a \{published data only\}

Field T, Hernandez-Reif M, Hart S, Theakston H, Schanberg S, Kuhn C. Pregnant women benefit from massage therapy. Journal of Psychosomatic Obstetrics and Gynaecology 1999;20:31-8.

Field 2012 \{published data only\} Field T, Diego M, Hernandez-Reif M, Medina L, Delgado J, Hernandez A. Yoga and massage therapy reduce prenatal depression and prematurity. Journal of Bodywork and Movement Therapies 2012;16(2):204-9.

Foxcroft 2011 \{published data only\} Foxcroft KF, Rowlands IJ, Byrne NM, McIntyre HD, Callaway LK. Exercise in obese pregnant women: the role of social factors, lifestyle and pregnancy symptoms. $B M C$ Pregnancy \& Childbirth 2011;11(4):2011.

Granath 2006 \{published data only\} Granath AB, Hellgren MS, Gunnarsson RK. Water aerobics reduces sick leave due to low back pain during pregnancy. JOGNN: Journal of Obstetric, Gynecologic, \& Neonatal Nursing 2006;35(4):465-71.

Haugland 2006 \{published data only\} Haugland KS, Rasmussen S, Daltveit AK. Group intervention for women with pelvic girdle pain in pregnancy. A randomized controlled trial. Acta Obstetricia et Gynecologica Scandinavica 2006;85(11):1320-6.

Kohama 2006 \{published data only\} Kohama T, Inoue M. Pycnogenol alleviates pain associated with pregnancy. Phytotherapy Research 2006;20(3):232-4.

Ladefoged 2012 \{published data only\} Ladefoged ML, Bor P, Svendlund R, Sondergaard N, Hojgaard A. The effect of introducing regular exercise during pregnancy and postpartum in physically inactive women. Acta Obstetricia et Gynecologica Scandinavica 2012; 39(Suppl 159):102-3.

\section{Mens 2012 \{published data only\}} Mens JMA, Huis V, Pool-Goudzwaard A. The Active Straight Leg Raise test in lumbopelvic pain during pregnancy. Manual Therapy 2012;17(4):364-8.

\section{Momoi 1999 \{published data only\}}

Momoi M. Evaluation research on the use of the foot bath for pregnant women experiencing low back pain. Nihon Kangoka Gakkaishi (Journal of Japan Academy of Nursing Science) 1999;19(1):31-41. 
Nilsson-Wikmar 2005 \{published data only\}

* Nilsson-Wikmar L, Holm K, Oijerstedt R, HarmsRingdahl K. Effect of three different physical therapy treatments on pain and activity in pregnant women with pelvic girdle pain: a randomized clinical trial with 3, 6, and 12 months follow-up postpartum. Spine 2005;30(8): $850-6$.

Nilsson-Wikmar L, Holm K, Oijerstedy R, HarmsRingdahl K. Effects of different treatments on pain and on functional activities in pregnant women with pelvic pain [abstract]. Third Interdisciplinary World Congress On Low Back \& Pelvic Pain; 1998 Nov 19-21; Vienna, Austria. 1998:330-1.

Ostgaard 1994 \{published data only\}

Ostgaard HC, Zetherstrom G, Roos Hansson E. Back pain in relation to pregnancy: a 6-year follow-up. Spine 1997;22 (24):2945-50.

* Ostgaard HC, Zetherstrom G, Roos-Hansson E, Svanberg B. Reduction of back and posterior pelvic pain in pregnancy. Spine 1994;19:894-900.

Schoenfeld 2011 \{published data only\}

Schoenfeld B. Resistance training during pregnancy: safe and effective program design. Strength \& Conditioning Journal (Allen Press) 2011;33(5):67-75.

Singh 2008 \{published data only\} Singh N, Desai OP. Prevention and management of low backache in pregnant women through the use of exercise program and education booklet. Indian Journal of Occupational Therapy 2008;39(3):65-72.

Thorell 2012 \{published data only\}

Thorell E, Kristiansson P. Pregnancy related back pain, is it related to aerobic fitness? A longitudinal cohort study. BMC Pregnancy and Childbirth 2012;12 Article 30:1-8.

Torstensson 2009 \{published data only\}

Torstensson T, Lindgren A, Kristiansson P. Corticosteroid injection treatment to the ischiadic spine reduced pain in women with long-lasting sacral low back pain with onset during pregnancy: a randomized, double blind, controlled trial. Spine 2009;34(21):2254-8.

Zand 2011 \{published data only\}

Zand S, Rafiei M, Zamani A. The effect of simple exercises and correct daily activities on backache and dependent variables during pregnancy period. Iranian Journal of Obstetrics, Gynecology and Infertility 2011;14(2):48-53.

\section{References to ongoing studies}

Abolhasani 2010 \{published data only\}

Abolhasani M. Comparison between two types of treatment in pelvic girdle pain in pregnancy: abdomino lumbo pelvic belt and exercise therapy. IRCT Iranian Registry of Clinical Trials (www.irct.ir) (accessed 6 December 2010).

Greene 2009 \{published data only\}

Greene RA. Randomised controlled trial for the treatment of pelvic girdle pain in pregnancy. www.controlled-trials.com/ (accessed 8 March 2012).

\section{Hensel 2008 \{published data only\}}

Hensel K. Osteopathic manipulative medicine in pregnancy: physiologic and clinical effects. ClinicalTrials.gov (http:// clinicaltrials.gov/) (accessed 8 March 2012).

Moholdt 2011 \{published data only\} Moholdt TT, Salvesen K, Ingul CB, Vik T, Oken E, Morkved S. Exercise training in pregnancy for obese women (ETIP): Study protocol for a randomised controlled trial. Trials 2011;12:Article Number: 154.

\section{Additional references}

\section{ACSM 2006}

American College of Sports Medicine. ACSM's Guidelines for Exercise Testing and Prescription. 7th Edition. Philadelphia, PA: Lippincott, Williams \& Wilkins, 2006.

\section{Airaksinen 2006}

Airaksinen O, Brox JI, Cedraschi C, Hildebrandt J, KlaberMoffett J, Kovacs F, et al.Chapter 4: European guidelines for the management of chronic non-specific low back pain. European Spine Journal 2006;March 15(Suppl 2): S192-300.

\section{Albert 2006}

Albert HB, Godskesen M, Korsholm L, Westergaard JG. Risk factors in pregnancy-related pelvic joint pain. Acta Obstetricia et Gynecologica Scandinavica 2006;85(5): 539-44.

\section{American Osteopathic Association}

American Osteopathic Association. Osteopathic Medicine and your health. AOA Website; http:// www.osteopathic.org/osteopathic-health/treatment/Pages/ default.aspx (Accessed May 22, 2013).

\section{Anderson 2005}

Anderson FWJ, Johnson CT. Complementary and alternative medicine in obstetrics. International Journal of Gynaecology and Obstetrics 2005;91:116-24.

\section{Bombardier 2001}

Bombardier C, Hayden J, Beaton DE. Minimal clinically important difference. Low-back pain: outcome measures. Journal of Rheumatology 2001;28:431-8.

\section{Cherkin 2003}

Cherkin DC, Sherman KJ, Deyo RA, Shekelle PG. A review of the evidence for the effectiveness, safety and costs of acupuncture, massage therapy and spinal manipulation for back pain. Annals of Internal Medicine 2003;138:898-906.

\section{Cohen 1988}

Cohen J. Statistical Power Analysis for the Behavioral Sciences. 1st Edition. New York, SanFrancisco, London: Academic press, 1988.

\section{Ee 2008}

Ee CC, Manheimer E, Pirotta MV, White AR. Acupuncture for pelvic and back pain in pregnancy: a systematic review. American Journal of Obstetrics \& Gynecology 2008;198(3): 254-9.

\section{Elden 2008b}

Elden H, Hagberg H, Olsen MF, Ladfors L, Ostgaard HC. Regression of pelvic girdle pain after delivery: follow-up of 
a randomised single blind controlled trial with different treatment modalities. Acta Obstetricia et Gynecologica Scandinavica 2008;87(2):201-8.

\section{Elden 2008c}

Elden H, Ostgaard HC, Fagevik-Olsen M, Ladfors L, Hagberg $\mathrm{H}$. Treatments of pelvic girdle pain in pregnant women: adverse effects of standard treatment, acupuncture and stabilising exercises on the pregnancy, mother, delivery and the fetus/neonate. BMC Complementary and Alternative Medicine 2008;8:34.

\section{Field 2008}

Field T. Pregnancy and labor alternative therapy research. Alternative Therapies in Health and Medicine 2008;14(5): $28-34$.

\section{Google Translate}

Google Inc; available at https://translate.google.ca/?hl=en\& tab=wT. Google Translate (https://translate.google.ca/). Mountain View, CA 94043: Google Inc; available at https:/ /translate.google.ca/?hl=en\&tab=wT, (Accessed August 8, 2012).

\section{Greenwood 2001}

Greenwood CJ, Stainton MC. Back pain / discomfort in pregnancy: invisible and forgotten. Journal of Perinatal Education 2001;10(1):1-12.

\section{Hagberg 2007}

Hagberg H. Acupuncture as a complement to standard treatment for the treatment of well-defined pelvic girdle pain in pregnant women (ongoing trial). http://controlledtrials.com (Accessed 15 February 2007).

\section{Hagen 2010}

Hagen KB. Can tailored exercises in pregnancy prevent low back and pelvic girdle pain? A randomised controlled trial. http://www.controlled-trials.com/isrctn/pf/95014448 (Accessed 15 August 2012) 2010.

\section{Higgins 2011}

Higgins JPT, Green S, editors. Cochrane Handbook for Systematic Reviews of Interventions. Version 5.1.0 [updated March 2011]. The Cochrane Collaboration, 2011. Available from www.cochrane-handbook.org.

\section{Kalus 2006}

Kalus SM, Kornman LH, Quinlivan JA. Evaluating the impact of the belly bra on back pain in pregnancy. Perinatal Society of Australia and New Zealand 10th Annual Congress; 2006 April 3-6; Perth, Australia. 2006:219.

\section{Kanakaris 2011}

Kanakaris NK, Roberts CS, Giannoudis PV. Pregnancyrelated pelvic girdle pain: an update. BMC Medicine 2011; 9:15.

Licciardone 2007

Licciardone JC. Study of the effectiveness of osteopathic manipulative treatment in pregnant women. ClinicalTrials.gov (http://clinicaltrials.gov/) (Accessed 21 June 2007).

\section{Lile 2003}

Lile J, Perkins J, Hammer RL, Loubert PV. Diagnostic and management strategies for pregnant women with back pain. Journal of the American Academy of Physician Assistants 2003; 16:31-44.

\section{Lin 2008}

Lin JG, Chen WL. Acupuncture analgesia: a review of its mechanisms of actions. American Journal of Chinese Medicine 2008;36(4):635-45.

Maigne 2003

Maigne JY, Vautravers P. Mechanism of action of spinal manipulative therapy. Joint Bone Spine 2003;70(5):336-41.

\section{Mens 2006}

Mens JMA, Damen L, Snijders CJ, Stam HJ. The mechanical effect of a pelvic belt in patients with pregnancyrelated pelvic pain. Clinical Biomechanics 2006;21(2): $122-7$.

Mens 2009

Mens JM, Pool-Goudzwaard A, Stam HJ. Mobility of the pelvic joints in pregnancy-related lumbopelvic pain: a systematic review. Obstetrical \& Gynecological Survey 2009; 64:200-8.

Moffatt 2013

Moffatt M, Flynn M. Safety of acupuncture in pregnancy. Journal of the Acupuncture Association of Chartered Physiotherapists 2013;Spring:41-50.

\section{Mogren 2005}

Mogren IM, Pohjanen A. Low back pain and pelvic pain during pregnancy. Spine 2005;30(8):983-91.

\section{Mogren 2006}

Mogren IM. Perceived health, sick leave, psychosocial situation, and sexual life in women with low-back and pelvic pain during pregnancy. Acta Obstetricia et Gynecologica Scandinavica 2006;85:647-56.

Mousavi 2007

Mousavi SJ, Parnianpour M, Vleeming A. Pregnancy related pelvic girdle pain and low back pain in an Iranian population. Spine 2007;32(3):E100-4.

\section{Ostelo 2008}

Ostelo RW, Deyo RA, Stratford P, Waddell G, Croft P, von Korff $M$, et al.Interpreting change scores for pain and functional status in low back pain: towards international consensus regarding minimal important change. Spine 2008;33:90-4.

\section{RevMan 2006}

The Nordic Cochrane Centre, The Cochrane Collaboration. Review Manager (RevMan). Version 4.3. Copenhagen: The Nordic Cochrane Centre, The Cochrane Collaboration, 2006.

\section{RevMan 2012}

The Nordic Cochrane Centre, The Cochrane Collaboration. Review Manager (RevMan). Version 5.2. Copenhagen: The Nordic Cochrane Centre, The Cochrane Collaboration, 2012. 
Richards 2012

Richards E, van Kessel G, Virgara R, Harris P. Does antenatal physical therapy for pregnant women with low back pain or pelvic pain improve functional outcomes? A systematic review. Acta Obstetrica et Gynecologica Scandinavica 2012;91:1038-45.

\section{Riley 2011}

Riley RD, Gates S, Neilson J, Alfirevic Z. Statistical methods can be improved within Cochrane pregnancy and childbirth reviews. Journal of Clinical Epidemiology 2011;64:608-18. [DOI: 10.1016/j.jclinepi.2010.08.002]

\section{Rost 2006}

Rost CC, Jacqueline J, Kaiser A, Verhagen AP, Koes BW. Prognosis of women with pelvic pain during pregnancy: a long-term follow-up study. Acta Obstetricia et Gynecologica Scandinavica 2006;85(7):771-7.

\section{Schulz 2010}

Schulz KF, Altman DG, Moher D, for the CONSORT Group. CONSORT 2010 Statement: Updated Guidelines for Reporting Parallel Group Randomised Trials. PLoS Medicine 2010;7(3):e1000251. [DOI: 10.1371/ journal.pmed.1000251]

\section{Schünemann 2009}

Schünemann H, Broż ek J, Oxman A (editors). GRADE handbook for grading quality of evidence and strength of recommendation. Version 3.2 [updated March 2009]. The GRADE Working Group. Available from www.cc-ims.net/ gradepro 2009.

Skaggs 2007

Skaggs CD, Prather H, Gross G, George JW, Thompson PA, Nelson DM. Back and pelvic pain in an underserved United States pregnant population. Journal of Manipulative and Physiological Therapeutics 2007;30(2):130-4.

Van de Pol 2007

Van de Pol G, Van Brummen HJ, Bruinse HW, Heintz APM, Van der Vaart H. Pregnancy-related pelvic girdle pain in the Netherlands. Acta Obstetricia et Gynecologica Scandinavica 2007;86(4):416-22.

Van Tulder 2009

Van Tulder MW, Suttorp M, Morton S, Bouter LM, Shekelle P. Empirical evidence of an association between internal validity and effect size in randomized controlled trials of low back pain. Spine 2009;34(16):1685-92.

Vermani 2010

Vermani E, Mittal R, Weeks A. Pelvic girdle pain and low back pain in pregnancy: a review. Pain Practice 2010;10(1): $60-71$.

Vleeming 2008

Vleeming A, Albert HB, Ostgaard HC, Sturesson B, Stuge B. European guidelines for the diagnosis and treatment of pelvic girdle pain. European Spine Journal 2008;17(6): 794-819.

\section{Wang 2004}

Wang SM, Dezinno P, Maranets I, Berman MR, CaldwellAndrews AA, Kain ZN. Low back pain during pregnancy: prevalence, risk factors, and outcomes. Obstetrics \& Gynecology 2004;104:65-70.

Wang 2007

Wang SM, Lin E, Braveman F, Kain Z. Auricular acupuncture as a treatment for posterior pelvic pain during pregnancy: a RCT. Anesthesiology 2007;107:Abstract no: A277.

\section{Wang 2008}

Lin E. Use ear acupuncture as treatment for low back pain during pregnancy. ClinicalTrials.gov (http:// clinicaltrials.gov/) (Accessed 20 February 2008).

\section{Wang 2009b}

Wang SM, Dezinno P, Lin EC, Lin H, Yue JJ, Berman MR, et al.Auricular acupuncture as a treatment for pregnant women who have low back and posterior pelvic pain: a pilot study. American Journal of Obstetrics and Gynecology 2009; 201(3):271.e1-9.

Wu 2004 Wu WH, Meijer OG, Uegali K, Mens JMA, van Dieen $\mathrm{JH}$, Wuisman PI, et al.Pregnancy-related pelvic girdle pain (PPP) i: terminology, clinical presentation, and prevalence. European Spine Journal 2004;13:575-89.

\section{References to other published versions of this review}

\section{Pennick 2007}

Pennick V, Young G. Interventions for preventing and treating pelvic and back pain in pregnancy. Cochrane Database of Systematic Reviews 2007, Issue 2. [DOI: 10.1002/14651858.CD001139.pub2]

Young 1995

Young GL. Special vs standard pillow for backache in late pregnancy [revised 13 May 1993]. In: Enkin MW, Keirse MJNC, Renfrew MJ, Neilson JP, Crowther C (eds.) Pregnancy and Childbirth Module. In: The Cochrane Pregnancy and Childbirth Database [database on disk and CDROM]. The Cochrane Collaboration; Issue 2, Oxford: Update Software; 1995.

\section{Young 1998}

Young G, Jewell D. Interventions for preventing and treating pelvic and back pain in pregnancy. Cochrane Database of Systematic Reviews 1998, Issue 3. [DOI: 10.1002/14651858.CD001139]

\section{Young 2002}

Young G, Jewell D. Interventions for preventing and treating pelvic and back pain in pregnancy. Cochrane Database of Systematic Reviews 2002, Issue 1. [DOI: 10.1002/14651858.CD001139]

* Indicates the major publication for the study 


\title{
CHARACTERISTICS OF STUDIES
}

\section{Characteristics of included studies [ordered by study ID]}

\author{
Bandpei 2010
}

Methods

'following ethical approval and through a randomised controlled clinical trial, 120 pregnant women with LBP were recruited into experimental and control groups.'

Conducted in Iran; no funding source stated.

Participants

\section{Inclusion criteria:}

Gestational age: 17 to 22 weeks.

History of at least 12 weeks back pain during pregnancy.

\section{Exclusion criteria:}

Contraindications of physical activity according to ACOG committee guidelines

History of exercise before pregnancy.

History of spinal surgery, spinal tumours, hip fracture, vertebral malformations, osteoporosis, and multiple sclerosis

\begin{tabular}{|c|c|}
\hline Interventions & $\begin{array}{l}\text { Experiment group: } \mathbf{N}=\mathbf{6 0} \\
\text { - Illustrated booklet on the exercises and ergonomic principles. } \\
\text { - } 5 \text { educational workshops, } 20 \text { min each, on the abdominal and back muscles, } \\
\text { strengthening and stretching exercises; led by an expert midwife and a physiotherapist. } \\
\text { - Follow-up telephone calls to assure the sustainability of intervention. } \\
\text { Control group: } \mathbf{N}=\mathbf{6 0} \\
\text { No intervention. }\end{array}$ \\
\hline Outcomes & $\begin{array}{l}\text { Pain (VAS) and disability (Oswestry disability questionnaire) were measured in both } \\
\text { groups. But in the results, only the baseline and the difference from baseline, with no } \\
\text { report of SD, was reported in each study group } \\
\text { The comparison of all changes between } 2 \text { study groups were statistically significant with } \\
\mathrm{P}<0.0001\end{array}$ \\
\hline Low-back pain & $\mathrm{X}$ \\
\hline \multicolumn{2}{|l|}{ Pelvic pain } \\
\hline \multicolumn{2}{|l|}{ Low-back pain and pelvic pain } \\
\hline Notes & $\begin{array}{l}\text { Change score from immediately after treatment was subtracted from the baseline pain } \\
\text { score for an 'immediately after treatment' VAS score; reported lost to follow-up was } \\
\text { assumed to have happened during treatment; RevMan calculator was used to calculate } \\
\text { SD to allow results to be included in meta-analysis for 'any exercise vs usual prenatal } \\
\text { care', analysis } 1.1 \\
\text { - translated from Arabic by single Iranian researcher. } \\
\text { Funding = no information provided. }\end{array}$ \\
\hline
\end{tabular}

\section{Risk of bias}

Interventions for preventing and treating pelvic and back pain in pregnancy (Review)

Copyright @ 2013 The Cochrane Collaboration. Published by John Wiley \& Sons, Ltd. 
Bandpei 2010 (Continued)

\begin{tabular}{|c|c|c|}
\hline Bias & Authors' judgement & Support for judgement \\
\hline $\begin{array}{l}\text { Random sequence generation (selection } \\
\text { bias) }\end{array}$ & Low risk & $\begin{array}{l}\text { Block randomisation with matching (strat- } \\
\text { ification?) for age, gestational age, and BMI }\end{array}$ \\
\hline Allocation concealment (selection bias) & Unclear risk & Not mentioned in paper. \\
\hline $\begin{array}{l}\text { Blinding of participants and personnel } \\
\text { (performance bias) } \\
\text { All outcomes }\end{array}$ & High risk & $\begin{array}{l}\text { Patients were not blinded. Nothing men- } \\
\text { tioned about blinding of providers }\end{array}$ \\
\hline $\begin{array}{l}\text { Blinding of outcome assessment (detection } \\
\text { bias) } \\
\text { All outcomes }\end{array}$ & High risk & $\begin{array}{l}\text { Nothing mentioned about blinding of out- } \\
\text { come assessors. }\end{array}$ \\
\hline $\begin{array}{l}\text { Incomplete outcome data (attrition bias) } \\
\text { All outcomes }\end{array}$ & Low risk & $\begin{array}{l}120 \text { patients were enrolled ( } 60 \text { in each } \\
\text { group). } 3 \text { patients in intervention group, } 5 \\
\text { in control group missed. In all cases the re- } \\
\text { searchers lost track of the patients due to } \\
\text { the change in living location }\end{array}$ \\
\hline Selective reporting (reporting bias) & Unclear risk & $\begin{array}{l}\text { The outcomes were also measured at } 6^{\text {th }} \\
\text { month and } 1 \text { year after delivery. But only } \\
\text { the results for immediately after treatment, } \\
\text { and } 3 \text { months after delivery were reported } \\
\text { Pain (VAS) and disability (Oswestry dis- } \\
\text { ability questionnaire) were measured in } \\
\text { both groups. But in the results, only the } \\
\text { baseline and the difference from baseline, } \\
\text { with no report of SD, was reported in each } \\
\text { study group } \\
\text { The comparison of all changes between } 2 \\
\text { study groups were statistically significant } \\
\text { with P }<0.0001\end{array}$ \\
\hline Other bias & Low risk & Nothing noted in the paper. \\
\hline
\end{tabular}


Methods
- 'randomised masked prospective experimental clinical trial.'

- 106 consecutive women referred for management of symphysis pubic problems were asked to participate.

- Those who met the inclusion criteria were assesses by 1 of 4 therapists who were identically trained; 36 withdrew prior to randomisation because they did not meet the inclusion criteria.

- To see a small to medium effect size (0.35) on a modified RMDQ, with power set at 0.8 and alpha at $0.05,30$ participants were needed per group.

- Number randomised $=90$; number analysed $=87$.

\section{Participants}

Interventions

\section{Inclusion criteria:}

Pregnant women referred to the National Women's Hospital, Auckland, New Zealand physical therapy outpatient department for treatment

Have pain (insidious onset) and tenderness on palpation in the symphysis pubis, with or without radiation to the groin

Have a positive ASLR test result. A positive test result required the participant to experience pain or difficulty with this movement. (See study's Appendix 1 for more description)

Exclusion criteria:

Medical conditions preventing the use of pelvic support belts. For example, some types of placenta previa

Posterior (sacroiliac joint or lumbar spine) pain that was considered by the woman to be worse than the symphysis pubis pain

\begin{tabular}{l} 
1. Exercise plus non-rigid support belt: $\mathrm{N}=29$. \\
- Participants received same information and exercises as the control group. \\
- Received a non-rigid neoprene support belt (Smiley Belt). \\
- Received a logbook for recording number of hours the belt was worn and number \\
of times exercises done. \\
2. Exercise plus rigid support belt: $\mathrm{N}=28$. \\
- Participants received same information and exercises as the control group. \\
- Received a rigid belt (Lifecare Pubic Belt). \\
- Received a logbook for recording number of hours the belt was worn and number \\
of times exercises done. \\
Control group: Exercise only: $\mathrm{N}=30$. \\
Participants received an exercise booklet with 5 exercises aimed to increase the stability \\
of the pelvic bones. A trained physical therapist demonstrated the exercises and checked \\
that they were being performed correctly \\
Exercise needed to be completed 3 times daily for 1 week. Participants were given logbook \\
to record the frequency they exercised \\
$\begin{array}{l}\text { Participants also received verbal and written education about the anatomy and pathology } \\
\text { of symphysis pubis dysfunction and self-help management. (See study's Appendix } 2 \text { and } \\
3 \text { for specific exercises and self-help management techniques.) }\end{array}$ \\
$\begin{array}{l}\text { Average and worst pain in last week - VAS (0-100); days off work; modified Roland } \\
\text { Morris Disability Questionnaire; Patient Specific Functional Scale; measured at baseline, } \\
\text { after treatment }\end{array}$ \\
\hline Outcomes
\end{tabular}

\section{Experiment group:}

1. Exercise plus non-rigid support belt: $\mathrm{N}=29$.

- Participants received same information and exercises as the control group.

- Received a non-rigid neoprene support belt (Smiley Belt). of times exercises done.

Exercise plus rigid support belt: $\mathrm{N}=28$.

- Participants received same information and exercises as the control group.

- Received a rigid belt (Lifecare Pubic Belt)

fimes exercises done.

Control group: Exercise only: $\mathrm{N}=30$. that they were being performed correctly

Exercise needed to be completed 3 times daily for 1 week. Participants were given logbook to record the frequency they exercised

Participants also received verbal and written education about the anatomy and pathology of symphysis pubis dysfunction and self-help management. (See study's Appendix 2 and

Low-back pain

Interventions for preventing and treating pelvic and back pain in pregnancy (Review) 


\section{Depledge 2005 (Continued)}

\begin{tabular}{l|l}
\hline Pelvic pain & $\mathrm{X}$ \\
\hline Low-back pain and pelvic pain & \\
\hline Notes & $\begin{array}{l}\text { There were no significant differences between the groups in adherence to their exercise } \\
\text { program or belt wearing. The adherence rate is acceptable (average for all participants: } \\
\text { Exercises }=16.5 / 21 \text { times, Number of hours belt worn/week }=44.2) \\
\text { Funding }=\text { Maurice and Phyllis Paykel Trust for a Research Scholarship }\end{array}$ \\
\hline
\end{tabular}

\section{Risk of bias}

\section{Bias}

Random sequence generation (selection Low risk bias)

\section{Support for judgement}

Quote: 'Randomization process involved the use of a table of 3 randomly permuted blocks'
Not specifically mentioned: patients assigned to groups by independent person (not connected to study) but unclear how this was actually done

Patients not blinded; therapists providing exercise therapy were unaware of the intervention groups to which participants were assigned. However, unclear as to who distributed the belts

Authors did not specify who collected the outcomes (outcomes were self-report measures)

All outcomes
Incomplete outcome data (attrition bias) Low risk All outcomes

No withdrawals in the control group.

1 woman in the non-rigid support belt group delivered her baby before the postintervention assessment

2 women in the rigid support belt group delivered their babies before their post-intervention assessment

1 woman refused to be in the study as she was 'not prepared to be in the exercise-only group'

No exclusions mentioned.

Selective reporting (reporting bias) Low risk
Study reported all outcomes it said it would report in methods 
Depledge 2005 (Continued)

\begin{tabular}{|c|c|c|}
\hline Other bias & Low risk & $\begin{array}{l}\text { Groups similar at baseline; adherence simi- } \\
\text { lar between groups; outcomes taken at same } \\
\text { time for each group, co-interventions likely } \\
\text { to be similar }\end{array}$ \\
\hline
\end{tabular}

Eggen 2012

Methods

Participants
Observer-blinded randomised controlled trial.

257 women were randomised.

\section{Inclusion criteria:}

Healthy Norwegian speaking women between 18 to 40 years from 2 Maternity Care Units (within the Norwegian Public Health System)

\section{Exclusion criteria:}

1. Pregnant women carrying twins.

2. Inflammatory rheumatic disorders.

3. Risk factors for miscarriage.

\section{Intervention group $(\mathrm{N}=129 / 106$ analysed):}

- Participants, referred to 1 of 2 specially trained physical therapists, will receive tailored supervised group exercise once a week, along with advice to do daily home exercise.

- Specific attention to body awareness and ergonomic advice in real-life situations; the main focus of the intervention being the specific training of the transversely oriented abdominal muscles with co-activation of the lumbar multifidus at the lumbosacral region, and stretching the hip abductors.

- Intervention will take place for a maximum of 16 weeks, between 20-36 weeks' gestation, with no follow-up after 36 weeks' gestation.

Control group $(\mathrm{N}=128 / 107$ analysed):

Usual prenatal care.

1. Functional status measured with the modified Roland Morris Disability Questionnaire $(0-24)$

2. Low-back and lumbo-pelvic pain measured using the VAS scale (0-10)

3. Health related quality of life measured with the SF-8 Health Survey

All outcomes measured at 24, 28, 32, and 36 weeks' gestation.

Low-back pain

Pelvic pain 
Eggen 2012 (Continued)

\begin{tabular}{|c|c|c|}
\hline Notes & \multicolumn{2}{|c|}{$\begin{array}{l}\text { Funding/sponsor: Norwegian Fund for Postgraduate Training in Physiotherapy (Nor- } \\
\text { way) } \\
\text { Lead author contacted to clarify the number analysed in intervention group; she con- } \\
\text { firmed that it should be 106, not } 103 \text { as stated in the Figure and tables }\end{array}$} \\
\hline \multicolumn{3}{|l|}{ Risk of bias } \\
\hline Bias & Authors' judgement & Support for judgement \\
\hline $\begin{array}{l}\text { Random sequence generation (selection } \\
\text { bias) }\end{array}$ & Low risk & $\begin{array}{l}\text { 'randomisation procedure was computer } \\
\text { generated by the statistician not involved } \\
\text { in data collection.' }\end{array}$ \\
\hline Allocation concealment (selection bias) & Low risk & $\begin{array}{l}\text { 'group allocation was concealed in consecu- } \\
\text { tively numbered, sealed, opaque envelopes. }\end{array}$ \\
\hline $\begin{array}{l}\text { Blinding of participants and personnel } \\
\text { (performance bias) } \\
\text { All outcomes }\end{array}$ & High risk & Participants not blinded. \\
\hline $\begin{array}{l}\text { Blinding of outcome assessment (detection } \\
\text { bias) } \\
\text { All outcomes }\end{array}$ & High risk & $\begin{array}{l}\text { Outcomes were self-reported, therefore not } \\
\text { blinded; however the midwives who dis- } \\
\text { tributed the questionnaires to the women } \\
\text { were not aware of their group allocation }\end{array}$ \\
\hline $\begin{array}{l}\text { Incomplete outcome data (attrition bias) } \\
\text { All outcomes }\end{array}$ & Low risk & $\begin{array}{l}\text { Treatment group lost } 22 / 129(17.8 \%) \text { and } \\
\text { the control group lost } 21 / 128(16.4 \%) \text { by } \\
\text { the end of follow-up at } 36 \text { weeks' gestation }\end{array}$ \\
\hline Selective reporting (reporting bias) & Low risk & $\begin{array}{l}\text { Results provided for all the outcomes } \\
\text { outlined in the trial registration (IS- } \\
\text { RCTN95014448) }\end{array}$ \\
\hline Other bias & Low risk & $\begin{array}{l}\text { Groups were similar at baseline except that } \\
\text { the training group had significantly higher } \\
\text { BMI; almost twice as many women in the } \\
\text { training group had experienced moderate } \\
\text { to severe PGP in a previous pregnancy but } \\
\text { this was adjusted for in the outcome analy- } \\
\text { ses; adherence to exercises did not seem to } \\
\text { vary between groups, nor did consultation } \\
\text { with healthcare providers }\end{array}$ \\
\hline
\end{tabular}

Interventions for preventing and treating pelvic and back pain in pregnancy (Review)

Copyright @ 2013 The Cochrane Collaboration. Published by John Wiley \& Sons, Ltd. 
Methods
Participants

- $\mathrm{N}=40$ pregnant women 'from the same demographic area' in Sweden; $\mathrm{N}=20$ in each group (group 1 and 2).

- After diagnosis with pelvic and LBP, women were referred to the acupuncturist at the hospital 'where randomisation was carried out; women were phoned to give them the dates for their acupuncture; baseline data were collected when they came for treatment'.

Inclusion: healthy pregnant women with low-back and pelvic pain diagnosed using posterior pain provocation test

Exclusion: treatment with cortisone, anticoagulants or immunosuppressive drugs, heart disease, diabetes, pacemakers, epilepsy, hepatitis, HIV or AIDS, acute infection, psychiatric disease, haematological disorders, renal disease, premature contractions, needle phobia

Interventions

Both groups received the same treatment; 8 acupuncture treatments over a 6 week period ( 2 treatments per week in the first 2 weeks and once per week thereafter) with first treatment lasting 20 minutes and number of needles limited to 5, and remainder 30 minutes with maximum 10 needles

Group 1 (mean age 28.6 yrs) started treatment at 20 weeks' gestation and Group 2 (mean age 27.9 yrs) at 26 weeks' gestation.

No control group - acupuncture intervention was started either at 20 (group 1) or 26 weeks (group 2) gestation

Outcomes

Short Form Health survey questionnaire (SF-36), Short Form Magill Pain Questionnaire (MPQ), Pain-o-meter, Foetal sound measured at baseline, at 4th and 8th treatment sessions, at same times for each group; qualitative data collected via telephone interviews 2-3 months after delivery

Both groups had similar experience of acupuncture (from qualitative interviews). Small number of study participants acknowledged by authors. Non compliance in both groups reported

Low-back pain

Pelvic pain

Low-back pain and pelvic pain $\quad \mathrm{X}$

Notes

Funding = Council of Research and Development (FoU-centrum), Landstinget Kronoberg, Sweden

\section{Risk of bias}

\section{Bias}

Random sequence generation (selection Unclear risk bias)

\section{Authors' judgement}

\section{Support for judgement}

Insufficient information given about sequence generation; in the discussion it states that 'the women were chosen randomly' 
Ekdahl 2010 (Continued)

\begin{tabular}{|c|c|c|}
\hline Allocation concealment (selection bias) & Low risk & Telephone allocation. \\
\hline $\begin{array}{l}\text { Blinding of participants and personnel } \\
\text { (performance bias) } \\
\text { All outcomes }\end{array}$ & Low risk & $\begin{array}{l}\text { 'both groups had similar experience with } \\
\text { acupuncture when asked at end of treat- } \\
\text { ment'; unclear if acupuncturists were in- } \\
\text { formed of gestation, or if they were able } \\
\text { to determine by observation, however, the } \\
\text { difference was only } 20 \text { to } 26 \text { weeks, there- } \\
\text { fore likely not a big issue }\end{array}$ \\
\hline $\begin{array}{l}\text { Blinding of outcome assessment (detection } \\
\text { bias) } \\
\text { All outcomes }\end{array}$ & Unclear risk & $\begin{array}{l}\text { Insufficient information provided on who } \\
\text { collected the self-report outcomes }\end{array}$ \\
\hline $\begin{array}{l}\text { Incomplete outcome data (attrition bias) } \\
\text { All outcomes }\end{array}$ & Low risk & $\begin{array}{l}\text { Both groups had } 4 \text { drop-outs with reasons } \\
\text { given - did not appear to be related to in- } \\
\text { tervention }\end{array}$ \\
\hline Selective reporting (reporting bias) & Low risk & $\begin{array}{l}\text { Qualitative data supports quantitative data } \\
\text { - however the telephone interviews were } \\
\text { completed by the study author }\end{array}$ \\
\hline Other bias & Low risk & $\begin{array}{l}\text { Co-interventions and adherence similar } \\
\text { across groups, timing of outcome assess- } \\
\text { ment same across groups, mean pain inten- } \\
\text { sity was significantly lower in group } 1 \text { than } \\
\text { group } 2 \text { at baseline }\end{array}$ \\
\hline
\end{tabular}

Elden 2005

Methods

386 women consecutively selected by doctors and midwives and randomised to 3 groups by distribution of pre-sealed opaque envelopes, with group assignment by computergenerated random table to determine the allocation sequence before the study.

Participants and caregiver not blinded; assessor blinded.

Acupuncture group: randomised $=125$; analysed $=110(88 \%)(10$ declined treatment, 1 declined visit, 5 had early delivery).

Stabilising exercises group: randomised $=131$; analysed $=112(85.5 \%)(9$ declined treatment, 1 moved from area, 4 had early delivery, 5 declined visit).

Standard treatment group (control); randomised $=130$; analysed $=108(83.0 \%)(15$

declined treatment, 3 had early delivery, 3 declined visit, 1 moved from area)

Intention to treat: those who finished the trial were analysed in the group to which they had been assigned

Participants

Location: East Hospital, Sahlgrenska Academy and 27 maternity care centres in the hospital's reference area in Gothenburg, Sweden; 2000-2002.

Inclusion criteria: healthy women at 12 to 31 weeks' gestation, fluent in Swedish, singleton fetuses, had defined pregnancy-related pelvic girdle pain.

Exclusion criteria: those with other pain conditions, systemic disorders, contraindications

Interventions for preventing and treating pelvic and back pain in pregnancy (Review)

Copyright $\odot 2013$ The Cochrane Collaboration. Published by John Wiley \& Sons, Ltd. 


\begin{tabular}{|c|c|}
\hline Interventions & $\begin{array}{l}\text { Experiment group } 1 \text { - acupuncture. } \\
\text { General information about the condition, anatomy of the back and pelvis, advice about } \\
\text { activities of daily living, given a pelvic belt and a home exercise program by physiothera- } \\
\text { pist + acupuncture treatment given twice a week over } 6 \text { weeks using } 10 \text { local acupuncture } \\
\text { points in sensitive spots + } 7 \text { extra-segmental points - needles inserted to evoke De Qi - } \\
\text { left in situ for } 30 \text { minutes, stimulated every } 10 \text { minutes - given by } 2 \text { experienced medical } \\
\text { acupuncturists } \\
\text { Experiment group } 2 \text { - stabilising exercises. } \\
\text { General information about the condition, anatomy of the back and pelvis, advice about } \\
\text { activities of daily living, given a pelvic belt and a home exercise program by physiothera- } \\
\text { pist + individual stabilising exercises (modified for pregnancy) for a total of } 6 \text { hours over } \\
6 \text { weeks - given by } 2 \text { experienced physiotherapists } \\
\text { Control group: standard treatment. } \\
\text { General information about the condition, anatomy of the back and pelvis, advice about } \\
\text { activities of daily living, given a pelvic belt and a home exercise program by physiother- } \\
\text { apist - given by } 3 \text { experienced physiotherapists }\end{array}$ \\
\hline Outcomes & $\begin{array}{l}\text { Measured at } 1 \text { week post-treatment: self-report pain each a.m. - } 100 \mathrm{~mm} \text { VAS; examiner } \\
\text { assessment of recovery from symptoms - positive pain drawing; examiner assessment of } \\
\text { recovery from symptoms - posterior pelvic pain provocation test; examiner assessment } \\
\text { of recovery from symptoms - pain when turning in bed } \\
\text { Adverse events: none reported for any of the } 3 \text { groups. }\end{array}$ \\
\hline \multicolumn{2}{|l|}{ Low-back pain } \\
\hline Pelvic pain & $\mathrm{X}$ \\
\hline \multicolumn{2}{|c|}{ Low-back pain and pelvic pain } \\
\hline Notes & $\begin{array}{l}\text { Funding = The Vardal Foundation, the Dagmar Foundation, the Trygg-Hansa Insurance } \\
\text { Company, the Sahlgrenska University Foundation } \\
14 \text { March } 2012 \text { - email \& LinkedIn message sent to Dr Elden to clarify number of } \\
\text { participants in Table 3; response received - clarified that there were } 130 \text { in the standard } \\
\text { group and } 131 \text { in the exercise group; other data are correct }\end{array}$ \\
\hline
\end{tabular}

\section{Risk of bias}

$\begin{array}{lll}\text { Bias } & \text { Authors' judgement } & \text { Support for judgement }\end{array}$

Random sequence generation (selection Low risk bias)

Allocation concealment (selection bias) Low risk
Computer-generated random table to determine the allocation sequence before the study

Pre-sealed opaque envelopes. 
Blinding of participants and personnel High risk (performance bias)

All outcomes

Blinding of outcome assessment (detection Low risk bias)

All outcomes

Incomplete outcome data (attrition bias) Low risk All outcomes
Participants and providers were not blinded.

'Results coded and entered by personnel from independent institution; Statistician blinded to group and treatment.'

Standard treatment group; randomised = 130; analysed $=108$ [83.0\%] (lost to follow-up: declined treatment $\mathrm{N}=15$, early delivery $\mathrm{N}=3$, declined visit $\mathrm{N}=3$, moved from area $\mathrm{N}=1$ )

Acupuncture group: randomised $=125$; analysed $=110$ [88\%] (lost to follow-up: declined treatment $\mathrm{N}=10$, declined visit $\mathrm{N}=1$, early delivery $\mathrm{N}=5$ )

Stabilising exercises: randomised $=131$; analysed $=112$ [85.5\%] (lost to follow-up: declined treatment $\mathrm{N}=9$, moved from area $\mathrm{N}=1$, early delivery $\mathrm{N}=4$, declined visit $\mathrm{N}=5$ )

ITT: analysed participants measured one week post-treatment against those randomised

Selective reporting (reporting bias) Low risk

Low risk
Data presented for a priori determined outcomes.

Table 3 seems to have the number of women reversed between 'Standard' and 'Exercise' groups. Author clarified this to be so

Elden 2008

Methods

Participants
- 'randomised double-blinded controlled trial.'

- Women recruited between June 2006 and May 2007 from 25 units within the Västra Götaland region, Sweden.

- $\mathrm{N}=115$ randomised; $\mathrm{N}=58$ to standard treatment plus acupuncture; $\mathrm{N}=57$ to standard treatment plus non-penetrating acupuncture.

\section{Inclusion criteria:}

Pregnant women.

Clinical diagnosis of pelvic girdle pain (according to Ostgaards criteria).

Experienced evening pain of more than $50-\mathrm{mm}$ on a $100-\mathrm{mm}$ VAS during baseline week. Acupuncture-naive.

Singleton fetuses at 12 to 29 completed gestational weeks. 
Elden 2008 (Continued)

Must speak Swedish fluently.

Exclusion criteria:

Women with other pain conditions, history of orthopaedic disease or surgery in the spine or pelvic girdle, systemic disorders, coagulation disturbances or increased risk of infection

Interventions

Experiment group: standard treatment + penetrating acupuncture

Standard treatment: general information about condition and anatomy of back and pelvis and a pelvic belt, gave advice and home programme exercised designed to increase strength in the abdominal and gluteal muscles. Information was supplemented by a leaflet. Also instructed to avoid other treatments during intervention period

Penetrating acupuncture: see study methods for exact acupuncture points used. Sterilised disposable needles were used and inserted intramuscularly to depth of $15-50 \mathrm{~mm}$. Needles were left in situ for 30 minutes and manually stimulated every 10 minutes.

Control group: Standard treatment + non-penetrating acupuncture

Standard treatment: identical to experimental group

Non-penetrating acupuncture: used a validated sham acupuncture device (which looks like real acupuncture needles but the tip of needle is blunted). The shaft of the sham needle did not penetrate the skin, it collapsed into the handle and creates an illusion of insertion. Needles were left in situ for 30 minutes and manually stimulated every 10 minutes.

Outcomes

EQ-5d questionnaire and EQ-5d VAS; VAS - Pain (0-100) in the morning \& evening; Oswestry Disability Index (back specific function); frequency of sick leave; Disability Rating Index (DRI) measured at baseline, after treatment and 1 week follow-up

Adverse events: transient, tingling, needle pain, slight bleeding, fainting, sleepiness

Low-back pain

Pelvic pain $\quad \mathrm{X}$

Low-back pain and pelvic pain

Notes

Pain severity diagnosed with ASLR test and posterior pain provocation test. $\mathrm{N}=165$ women assessed for eligibility ( $\mathrm{N}=50$ did not meet inclusion criteria). All women acupuncture naive $\&$ singleton fetus. No serious adverse events reported. Same contact time, manual contact during search and stimulation of needles, interaction between patient and therapist in both groups. Drop-outs reported with reasons

Funding = grants from the Foundation of the Health and Medical care committee of the Region of Västra Götaland (Sweden), grants from the Swedish Medical Reserach Council and Swedish government grants to researchers in the public health service

Risk of bias

Bias

Random sequence generation (selection Low risk bias)
Authors' judgement

\section{Support for judgement}

Quote: 'Computer-generated random table was used'. 
Elden 2008

Allocation concealment (selection bias) Low risk (performance bias)

All outcomes
Statistician who was not involved in the study administered pre-coded numbered identical opaque envelopes to assign participants to the intervention groups

Participants: low risk - only LI4 (on hand) not blinded

'Women were blinded to whether they were receiving sham or active treatment.'

Therapist remained neutral for both groups.

Women were treated in a prone position (i. e. unable to see the needles except ones on hand).

Sham needle collapses into a handle to create illusion of insertion.

Reported that most participants believed they received the penetrating acupuncture Providers: high risk

Not blinded.

Same therapist administered sham and active treatments.

Blinding of outcome assessment (detection Low risk bias)

All outcomes

Incomplete outcome data (attrition bias) Low risk All outcomes

\section{Assessors: low risk}

Blinded to treatment allocation, doctors handling decisions about sick-listing were also blinded

Dropouts: 2 in treatment and 5 in control dropped intervention because it 'violated protocol'

At follow-up: 3 drop-outs in treatment group due to early birth and declined visit, 2 in control group due to declined visit Low drop-out rate, and similar reasons between the groups.

No exclusions mentioned.

Numbers add up.

For missing data and those who withdrew, ITT analysis applied to outcome data using last recorded data

Low risk: attrition and drop-outs reported and reasons, numbers at each stage add up, ITT - last value carried forward

Study reported all outcomes it said it would report in methods. All outcome data are found in tables 
Elden 2008 (Continued)

Other bias

Low risk

Randomisation procedure successful (however more in control group on sick leave?)

Garshasbi 2005

Methods

266 randomised: those who could not exercise were excluded from the exercise group, but it's unclear why 54 people dropped out of exercise group and none out of control.

Excluded before randomisation $=14$ with UTI, threatened abortion, lack of time, leaving 266 to be randomised.

Randomised to exercise group $=161,54$ who could not participate in exercises $=107$.

Randomised to control group $=105$.

Participants and caregiver not blinded; assessor-blinded.

Analysis of pain and flexibility measures were conducted on those who completed the intervention in the group to which they had been randomised

Participants

280 women invited to participate from those registered at Hazrat Zaynab Hospital prenatal clinic in Tehran, Iran (no details about how they were selected from the 2358 who had registered at the clinic during the study period).

Inclusion criteria: primigravida, 20 to 28 years old, 17 to 22 weeks' gestation, housewives, high school graduates.

Exclusion criteria: women with contraindications to aerobic exercise during pregnancy according to ACOG guidelines, history of exercise before pregnancy, history of orthopaedic disease or surgery, those who missed 3 exercise sessions

Baseline characteristics.

2 groups similar in age, weight, height, BMI.

Exercise group $=73$ women $(68 \%)$ had LBP during pregnancy.

Control group $=78$ women $(70.5 \%)$ had LBP during pregnancy.

Interventions

Experiment group.

Exercises recommended by Tarbiat Modares Faculty of Sport and tested for pregnant women by physiotherapists, to strengthen abdominal muscles, hamstring muscles and increase traction of iliopsoas and para vertebral muscles.

15 movements in 60 minutes: 5 minutes of slow walking, 5 minutes of extension movements, 10 minutes of general warming up, 15 minutes anaerobic exercise, 20 minutes of specific exercise, 5 minutes return to the 1 st position - offered to exercise 3 times a week - supervised by midwife - intensity of exercises controlled by maternal pulse rate stopped if $>140 /$ minute

Control group: no treatment.

Outcomes

Adverse events: none reported.

No scales/units given for outcomes measured, but 1 may assume they are reporting the group mean, measured on the KEBEK questionnaire (range 0 to 100 , higher $=$ worse pain); change scores do not appear to be included, the degree of lordosis and degree of flexibility of the spine

Low-back pain

$\mathrm{X}$

Pelvic pain

Interventions for preventing and treating pelvic and back pain in pregnancy (Review)

Copyright $\odot 2013$ The Cochrane Collaboration. Published by John Wiley \& Sons, Ltd. 
Garshasbi 2005 (Continued)

Low-back pain and pelvic pain

Notes
All numbers do not add up; there are contradictions in text; we tried unsuccessfully to
clarify data with lead author during the 2007 update
Funding: not stated.

Risk of bias

\begin{tabular}{|c|c|c|}
\hline Bias & Authors' judgement & Support for judgement \\
\hline $\begin{array}{l}\text { Random sequence generation (selection } \\
\text { bias) }\end{array}$ & Unclear risk & $\begin{array}{l}\text { 'prospective randomised study' but method } \\
\text { of randomisation not described }\end{array}$ \\
\hline Allocation concealment (selection bias) & Low risk & Sealed envelopes. \\
\hline $\begin{array}{l}\text { Blinding of participants and personnel } \\
\text { (performance bias) } \\
\text { All outcomes }\end{array}$ & High risk & $\begin{array}{l}\text { Participants and providers were not } \\
\text { blinded. }\end{array}$ \\
\hline $\begin{array}{l}\text { Blinding of outcome assessment (detection } \\
\text { bias) } \\
\text { All outcomes }\end{array}$ & Low risk & $\begin{array}{l}\text { Report states that the outcome assessor was } \\
\text { blinded. }\end{array}$ \\
\hline $\begin{array}{l}\text { Incomplete outcome data (attrition bias) } \\
\text { All outcomes }\end{array}$ & High risk & $\begin{array}{l}\text { Difficult to assess since numbers do not add } \\
\text { up; appears that } 14 \text { withdrew prior to ran- } \\
\text { domisation; about } 20 \% \text { withdrew/dropped } \\
\text { out after randomisation; it appears that } 54 \\
\text { dropped out of the intervention group and } \\
\text { none out of the control group. }\end{array}$ \\
\hline Selective reporting (reporting bias) & High risk & $\begin{array}{l}\text { Results are difficult to interpret and appear } \\
\text { to be reversed }\end{array}$ \\
\hline Other bias & Low risk & Nothing more to add. \\
\hline
\end{tabular}

\section{Gil 2011}

Methods

Potential women were identified through obstetric records and approached, in person or by phone, to determine if they met the inclusion criteria

41 women were invited to attend; 4 declined, 3 did not attend the first follow-up

34 women randomised to either Global Postural Re-education (GPR) treatment or usual prenatal care

Participants

Women selected from those receiving prenatal care in 3 health centres and those who attended lectures in preparation for birth at a private hospital in Campinas, Brazil Both groups of women were similar in most of the characteristics studied on admission to the study: in the GPR group 10 women came from a private hospital and 7 from a health (publish) centres, in the control group there were 6 women coming from the

Interventions for preventing and treating pelvic and back pain in pregnancy (Review)

Copyright $\odot 2013$ The Cochrane Collaboration. Published by John Wiley \& Sons, Ltd. 


\begin{tabular}{ll} 
& $\begin{array}{l}\text { private hospital and } 11 \text { health (public) centres } \\
\text { Inclusion criteria: LBP, nulliparity, low-risk singleton pregnancy, gestational age be- } \\
\text { tween } 20 \text { to } 25 \text { weeks, aged } 18 \text { to } 40 \text { years, absence of obstetric or medical illness, ab- } \\
\text { sence of pre-existing spinal pathologies. Differentiation made between LBP and poste- } \\
\text { rior pelvic pain at baseline physiotherapy assessment }\end{array}$ \\
\hline Interventions & $\begin{array}{l}\text { Global Postural Re-education }(\mathbf{G P R}) \text { treatment }(\mathbf{n}=\mathbf{1 7}) \\
\text { Weekly } 40 \text {-minute sessions for } 8 \text { weeks. } \\
\text { Stretching of the muscles of the posterior chain - angle closure coxo-femoral and abduc- } \\
\text { tion of the upper limbs \& closing angle coxo-femoral with adduction of the upper limbs } \\
\text { Control group }(\mathbf{n}=\mathbf{1 7}) \\
\text { Regular prenatal care. }\end{array}$ \\
\hline
\end{tabular}

Outcomes

GPR group

Intensity of LBP, measured with VAS (0-10) at baseline, before/after each treatment session

Back-related function, measured with the RMDQ at baseline, before/after each session

Control group

Intensity of LBP and back-related function were measured at baseline, at 4 and 8 weeks of the study

Use of pain medication collected for both study groups.

Low-back pain $\quad \mathrm{x}$

Pelvic pain

Low-back pain and pelvic pain

Notes

Used Google Translate to translate from Portuguese; verified by single Portuguese researcher

Paper stated that there was no external funding.

Data needed for the meta-analyses appeared to be incorrectly reported in the paper and were re-analysed

\section{Risk of bias}

\begin{tabular}{|c|c|c|}
\hline Bias & Authors' judgement & Support for judgement \\
\hline $\begin{array}{l}\text { Random sequence generation (selection } \\
\text { bias) }\end{array}$ & Low risk & $\begin{array}{l}\text { 'randomisation was performed by using a } \\
\text { list of random numbers generated by com- } \\
\text { puter.' }\end{array}$ \\
\hline
\end{tabular}

Allocation concealment (selection bias) Unclear risk

No mention in translated version of allocation concealment.

Blinding of participants and personnel High risk (performance bias)

All outcomes 'these professionals had lagged randomisation, so did not know to which group each woman was allocated' ... however, those 
Gil 2011 (Continued)

who provided the exercise therapy and those who received it would have known to which group they were allocated

Blinding of outcome assessment (detection High risk bias)
All outcomes

'at the end of the participation on each woman in the study, they conducted a professional full re-evaluation of LBP' ... however, the women were the ones who reported their symptoms via the VAS and RMDQ

Incomplete outcome data (attrition bias) Unclear risk All outcomes

Selective reporting (reporting bias)

Low risk

3 participants are reported as lost to followup; there is no real clarification of their initial group - it could be control group, but the 17 in each group do not seem to take any losses into consideration

Data provided for baseline and after intervention outcome measures for pain and disability

Other bias $\quad$ High risk

Gross 2012

Methods

Prospective randomised controlled trial - 169 pregnant women

Study tested the hypothesis the hypothesis that a multi-modal approach of manual therapy, exercise and education for LBP/PP in pregnancy is superior to standard obstetric care for the reduction of pain, impairment and disability

Enrollment to the study between 24 and 28 weeks' gestation with follow-up at 33 weeks' gestation and 3 months postpartum

Participants

Pregnant women with LBP/PP at enrolment (24 to 28 weeks' gestation). No other criteria provided

Interventions

Experimental group $(\mathbf{n}=\mathbf{8 7})$ : multi-modal musculoskeletal and obstetric management (MOM) - standard obstetric care PLUS a chiropractic specialist provided manual therapy, stabilisation exercises and patient education - no details on number of treatments 
Gross 2012 (Continued)

Control group $(\mathbf{n}=\mathbf{8 2})$ : Standard Obstetric Care (STOB).

\begin{tabular}{|c|c|}
\hline Outcomes & $\begin{array}{l}\text { Pain intensity (NRS), Disability (Quebec Disability Questionnaire - QDQ), Personal } \\
\text { Pain History (PPH), SLR, P4 }\end{array}$ \\
\hline \multicolumn{2}{|l|}{ Low-back pain } \\
\hline \multicolumn{2}{|l|}{ Pelvic pain } \\
\hline Low-back pain and pelvic pain & $\mathrm{X}$ \\
\hline Notes & $\begin{array}{l}\text { This was a poster presentation at the 32nd Annual Meeting for the Society for Maternal- } \\
\text { Fetal Medicine with only the abstract published in a supplement of the journal, so further } \\
\text { biases are difficult to assess; there was no reference to other publications on this trial and } \\
\text { none were identified by a Google and MEDLINE search on } 16 \text { Aug } 2012 \\
\text { August 27, 2012: email sent to Dr Gross requesting data, via Saint Louis University } \\
\text { School of Medicine, Division of Maternal-Fetal Medicine general email since unable to } \\
\text { find individual email; as of November 2nd, } 2012 \text { there has been no response } \\
\text { Assume study conducted in US, since all PIs list American university affiliations } \\
\text { Grant number: R18HP07640. }\end{array}$ \\
\hline
\end{tabular}

Risk of bias

\begin{tabular}{|c|c|c|}
\hline Bias & Authors' judgement & Support for judgement \\
\hline $\begin{array}{l}\text { Random sequence generation (selection } \\
\text { bias) }\end{array}$ & Unclear risk & $\begin{array}{l}\text { No information provided on method of } \\
\text { generating allocation sequence apart from } \\
\text { 'randomised' stated in the title and study } \\
\text { design section }\end{array}$ \\
\hline Allocation concealment (selection bias) & Unclear risk & Details not provided. \\
\hline $\begin{array}{l}\text { Blinding of participants and personnel } \\
\text { (performance bias) } \\
\text { All outcomes }\end{array}$ & Unclear risk & $\begin{array}{l}\text { Insufficient detail provided - Chiroprac- } \\
\text { tic specialist performing baseline evalua- } \\
\text { tion and follow-up exams 'single masked' }\end{array}$ \\
\hline $\begin{array}{l}\text { Blinding of outcome assessment (detection } \\
\text { bias) } \\
\text { All outcomes }\end{array}$ & Unclear risk & $\begin{array}{l}\text { Insufficient detail provided - Chiroprac- } \\
\text { tic specialist performing baseline evalua- } \\
\text { tion and follow-up exams 'single masked' }\end{array}$ \\
\hline $\begin{array}{l}\text { Incomplete outcome data (attrition bias) } \\
\text { All outcomes }\end{array}$ & Unclear risk & $\begin{array}{l}\text { Insufficient detail provided - only number } \\
\text { in each arm of trial provided in results sec- } \\
\text { tion }\end{array}$ \\
\hline Selective reporting (reporting bias) & Unclear risk & $\begin{array}{l}\text { Limited data provided; e.g. results section } \\
\text { states that there was a significant reduction } \\
\text { in NRS, QDQ, PPH and SLR scores in the } \\
\text { experimental group at } 33 \text { weeks' gestation }\end{array}$ \\
\hline
\end{tabular}

Interventions for preventing and treating pelvic and back pain in pregnancy (Review)

Copyright (๑) 2013 The Cochrane Collaboration. Published by John Wiley \& Sons, Ltd. 
Gross 2012 (Continued)

whilst the control group only showed an improvement in QDQ, however on both occasions only $\mathrm{P}$ values given $(\mathrm{P}<0.05)$

Other bias $\quad$ Unclear risk

Groups were demographically similar and baseline evaluation showed no differences in pain, disability or physical assessments between groups however no data provided pre versus post intervention

Kalus 2007

\begin{tabular}{ll}
\hline Methods & $\mathrm{N}=115$ women randomised (N=55 to Bellybra and $\mathrm{N}=60$ to Tubigrip) \\
\hline Participants & Inclusion criteria: \\
& Women between 20 and 36 weeks pregnancy with lumbar back or posterior pelvic pain \\
& Exclusion criteria: \\
& Women with high back pain or symphysiolysis but with no concomitant lumbar back \\
& or posterior pelvic pain. \\
& Complicated pregnancy. \\
& Non-English speaking. \\
\hline
\end{tabular}

Interventions

Experiment group: BellyBra

A nylon/spandex undergarment worn like a vest, has a 1-way stretch panel across the thoracolumbar back that is designed to provide support and assisted by the involvement of shoulder straps, to improve posture. A wide elastic band sits below the abdomen supporting the uterus and lifting weight off the pelvis.

Worn for 3 weeks, did not specify how often to be worn.

Control group: Tubigrip

More generic form of support. Worn as a double layer and extends from the mid-thoracic spine to the sacral spine and pelvis.

Worn for 3 weeks, did not specify how often to be worn.

Outcomes

VAS $(0-10 \mathrm{~cm})$, physical activity including work, satisfaction with life survey (SWLS) , use of analgesic medication, usefulness of garment at baseline, completion of 3-week intervention, 'on a return visit to the antenatal clinic' - ? timing

Low-back pain

$\mathrm{X}$

Pelvic pain

Low-back pain and pelvic pain

Notes

Although the primary aim was to assess the severity of LBP and posterior pelvic pain, the pelvic pain was primarily due to pain in the sacroiliac joint Australia

Funding $=$ no funding or support was provided for any of the authors; Furtile Mind Pty Ltd (retailers for maternity and postpartum clothes, supplies) provided the BellyBras

Interventions for preventing and treating pelvic and back pain in pregnancy (Review)

Copyright $\Subset 2013$ The Cochrane Collaboration. Published by John Wiley \& Sons, Ltd. 
Kalus 2007 (Continued)

used in the trial

Risk of bias

\begin{tabular}{|c|c|c|}
\hline Bias & Authors' judgement & Support for judgement \\
\hline $\begin{array}{l}\text { Random sequence generation (selection } \\
\text { bias) }\end{array}$ & Low risk & $\begin{array}{l}\text { Quote: 'Participants were randomised...by } \\
\text { means of computer-generated numbered, } \\
\text { sealed, opaque envelopes' }\end{array}$ \\
\hline
\end{tabular}

Allocation concealment (selection bias) Low risk

Opaque sealed envelopes used.

Blinding of participants and personnel High risk

(performance bias)

No blinding of participants, providers

All outcomes

mentioned.

Blinding of outcome assessment (detection High risk

bias)

All outcomes
Incomplete outcome data (attrition bias) High risk

All outcomes
No blinding of assessors mentioned.

9 participants (16\%) in intervention group were lost at follow-up (2 delivered within study period, 7 failed to attend appointment and could not be contacted)

12 participants in control group (20\%) were lost at follow-up (3 delivered within study period, 9 failed to attend their follow-up appointment and could not be contacted)

No exclusions mentioned; $14 \%$ were lost to follow-up with no reason

Selective reporting (reporting bias) Low risk

Study reported all outcomes it said it would report in methods

Other bias

High risk
11 women $(23.9 \%)$ in intervention group and 23 women $(47.9 \%)$ in control group reported the use of other treatments for their back pain during the study period, including the use of analgesic medication, physiotherapy, acupuncture, massage, etc. (co-interventions make it difficult to attribute change to the intervention)

Most noticeably, 3 in the intervention and 14 in the control group used analgesic medication during the study period $44(95.7 \%)$ women in intervention group stated that they wore the garment at least once a week compared with $33(68.8 \%)$ in 
Kalus 2007

the control group

High risk - co-interventions and compliance different.

Kashanian 2009

\begin{tabular}{ll} 
Methods & 30 women 'randomly assigned' to study group $(\mathrm{N}=15)$ or control group $(\mathrm{N}=15)$ \\
\hline Participants & $\begin{array}{l}\text { Inclusion: women between } 20 \text { and } 30 \text { years, back pain, nulliparous, } 16 \text { weeks' gestation, } \\
\text { no regular exercise prior to entering study } \\
\text { Exclusion: pelvic pain, any systemic disorder or drug use, previous trauma, surgery, } \\
\text { damage to spine or lower limbs, any pregnancy complications, } \geq 3 \text { missed treatments }\end{array}$
\end{tabular}

Interventions

Exercise group $=1$ hour introduction session with 7 exercises and relaxation movements taught. Each exercise session lasted 30 minutes x 3 / week x 8 weeks. Exercise included warm up (4.5 minutes) walking, stretching (spine extensors, hamstrings, thigh adductors, lumbar paravertebral muscles), strengthening (thigh extensors and abdominal obliques) x 21 minutes, relaxation $\mathrm{x} 4.5$ minutes

Control = routine prenatal care - did not perform any of the study exercises

Outcomes

Roland Morris Disability Questionnaire; lumbar lordosis using flexible ruler and formula measured at baseline, after 1 and 2 months

Low-back pain $\quad \mathrm{X}$

Pelvic pain

Low-back pain and pelvic pain

Notes

This was part of the journal's 'brief communication' section only, so further biases are difficult to assess; there was no reference to other publications on this trial and none were identified during a Google search 13 March 2012

14 March 2012 - email \& Linked-In message sent to lead author, requesting more information $=>$ as of November 2nd, 2012, no response

Assume the study was carried out in Iran, since all authors were affiliated with Iranian universities

\section{Risk of bias}

\begin{tabular}{l|ll}
\hline Bias & Authors' judgement & Support for judgement \\
\hline $\begin{array}{l}\text { Random sequence generation (selection } \\
\text { bias) }\end{array}$ & Unclear risk & 'randomly assigned' - details not provided. \\
\hline Allocation concealment (selection bias) & Unclear risk & Details not provided.
\end{tabular}


Kashanian 2009 (Continued)

\begin{tabular}{|c|c|c|}
\hline $\begin{array}{l}\text { Blinding of participants and personnel } \\
\text { (performance bias) } \\
\text { All outcomes }\end{array}$ & Unclear risk & Details not provided. \\
\hline $\begin{array}{l}\text { Blinding of outcome assessment (detection } \\
\text { bias) } \\
\text { All outcomes }\end{array}$ & Unclear risk & Details not provided. \\
\hline $\begin{array}{l}\text { Incomplete outcome data (attrition bias) } \\
\text { All outcomes }\end{array}$ & Low risk & $\begin{array}{l}\text { Details not provided, but number ran- } \\
\text { domised are included in the results table }\end{array}$ \\
\hline Selective reporting (reporting bias) & High risk & $\begin{array}{l}\text { Limited data provided; e.g. states that } \\
\text { RMDQ was used, but no values given; pain } \\
\text { outcome measure not identified, while pain } \\
\text { results provided }\end{array}$ \\
\hline
\end{tabular}

$\begin{array}{ll}\text { Other bias } \quad \text { Unclear risk } & \end{array}$

This was part of the journal's 'brief communication' section only, so further biases are difficult to assess; there was no reference to other publications on this trial and none were identified during a Google search 13 March 2012

Kihlstrand 1999

Methods

Participants
Preventive randomised controlled trial.

329 women invited to participate, 258 were randomised 'using sealed envelopes'. Enrolment was done in segments of time, since only 60 women could participate in the pool program at the same time

Women registering at 1 of 6 maternity clinics run by Falun County Health Care Board in Sweden and had their ultrasound between gestational age 15 to 18 weeks.

329 women invited to study, from 967 who registered. 60 invitees declined because they could not participate in water gymnastics.

258 randomised to 2 groups of 129 each.

Inclusion criteria

Gestational age less than 19 weeks; fluent in Swedish; expectations of a normal pregnancy Exclusion criteria

Women with epilepsy, a previous preterm birth before week 32, younger than 18 years, women already participating in a water gymnastics program

Drop-outs due to inability to participate in water gymnastics, recurrent UTIs, shift work, baby-sitting problems, miscarriage, intrauterine death, lack of time, invited to participate after date of closure

Interventions

\section{Intervention group:}

20 1-hour weekly water gymnastics classes involving exercise (tested for pregnant women) and relaxation in water (32 to 34 degrees).

First 10 sessions with exercises suitable for early pregnancy; last 10 sessions with exercises suitable for later pregnancy. 
Kihlstrand 1999 (Continued)

Hour session divided into 30 minutes exercise +30 minutes relaxation

Control group: no treatment.

Back pain - VAS; number of days taken as sick leave because of back pain in pregnancy
Adverse effects: no excess risk for pregnancy associated with water gymnastics observed:
no differences with gyn/UTI infections, maternal weight gain, gestational age at delivery,
weight/height of neonate, delivery characteristics

Low-back pain $\quad \mathrm{X}$

Pelvic pain

Low-back pain and pelvic pain

Notes

Funding: Dalarna Research Institute; Local Insurance Office.

Risk of bias

\begin{tabular}{l|l|l}
\hline Bias & Authors' judgement & Support for judgement \\
\hline $\begin{array}{l}\text { Random sequence generation (selection } \\
\text { bias) }\end{array}$ & Unclear risk & $\begin{array}{l}\text { 'Preventive randomised controlled trial' } \\
\text { randomised 'using sealed envelopes' -actual } \\
\text { method of randomisation not described, } \\
\text { but it was conducted 'by a mid-wife when } \\
\text { the women had their ultrasound.' }\end{array}$ \\
\hline $\begin{array}{l}\text { Allocation concealment (selection bias) } \\
\begin{array}{l}\text { Blinding of participants and personnel } \\
\text { (performance bias) } \\
\text { All outcomes }\end{array}\end{array}$ & Low risk risk & Adequate - sealed envelopes. \\
\hline
\end{tabular}

Blinding of outcome assessment (detection Unclear risk

Assessor blinding unclear.

bias)

All outcomes

Incomplete outcome data (attrition bias) High risk

All outcomes

Participants who completed the study were analysed in the groups to which they were randomised; less than 5\% reported as lost to follow-up; numbers do not always add up - query if $\mathrm{N}$ for outcomes are based on those who answered specific questions on follow-up?

Selective reporting (reporting bias) High risk

Not enough data were given to allow use of the VAS; pain data provided in graphs from which one cannot extract exact values. Difficult to follow the path of recruitment, drop-outs since numbers given in text do

Interventions for preventing and treating pelvic and back pain in pregnancy (Review)

Copyright $\odot 2013$ The Cochrane Collaboration. Published by John Wiley \& Sons, Ltd. 
Kihlstrand 1999 (Continued)

not add up

\begin{tabular}{lll}
\hline Other bias & Low risk & Nothing noted.
\end{tabular}

Kluge 2011

\begin{tabular}{ll} 
Methods & Randomised controlled trial - 50 women. \\
\hline Participants & $\begin{array}{l}\text { South African women of } 20 \text { to } 40 \text { years between } 16 \text { and } 24 \text { weeks' gestation; LBP/PP } \\
\text { (with or without radiation to the knee) that had started during current pregnancy (72\% } \\
\text { of sample had LBP) }\end{array}$ \\
\hline
\end{tabular}

Interventions

Exercise group ( $\mathbf{N}=\mathbf{2 6 / 2 4}$ analysed): 1 formal exercise class lasting 30-45 minutes with warm-up and cool down periods incorporated. Handout illustrating and explaining the exercise program which consisted of postural, transversus abdominis and pelvic floor exercises to train correct isolation and isometric contraction. Exercises then individually progressed to increase level of difficulty and facilitate co-contraction of transversus abdominis and pelvic floor muscles with gluteals, quadriceps and other muscle groups. Follow-up class every second week for 10 weeks. Women also asked to complete a daily home exercise programme and record their goals in their training diary. Verbal information on basic back care and posture during pregnancy and an information pamphlet Control group $(\mathbf{N}=\mathbf{2 4 / 2 2}$ analysed): verbal information on basic back care and posture during pregnancy and an information pamphlet as for exercise group but no specific instructions given to participants regarding whether to perform any exercise

Outcomes

Pain intensity (NRS 0-10); functional ability (Likert modified Roland Morris Disability Questionnaire (RMDQ)

Low-back pain

Pelvic pain

Low-back pain and pelvic pain $\quad \mathrm{X}$

Notes

Neurological exam was completed at assessment along with erector spinae palpation, sacroiliac palpation, P4 test and passive SLR however, apart from erector spinae palpation eliciting LBP symptoms, the positive yield of these tests for subtyping of symptoms was low

Funding not reported.

Risk of bias

Bias

Authors' judgement

Support for judgement

Random sequence generation (selection Low risk bias)

Computer-generated random numbers in balanced blocks of 20 .

Interventions for preventing and treating pelvic and back pain in pregnancy (Review)

Copyright $\Subset 2013$ The Cochrane Collaboration. Published by John Wiley \& Sons, Ltd. 


\section{Kluge 2011 (Continued)}

\begin{tabular}{|c|c|c|}
\hline Allocation concealment (selection bias) & Low risk & Sealed numbered opaque envelopes. \\
\hline $\begin{array}{l}\text { Blinding of participants and personnel } \\
\text { (performance bias) } \\
\text { All outcomes }\end{array}$ & High risk & Unblinded. \\
\hline $\begin{array}{l}\text { Blinding of outcome assessment (detection } \\
\text { bias) } \\
\text { All outcomes }\end{array}$ & High risk & Unblinded. \\
\hline $\begin{array}{l}\text { Incomplete outcome data (attrition bias) } \\
\text { All outcomes }\end{array}$ & Low risk & $\begin{array}{l}\text { ITT analysis completed; less than } 10 \% \text { of } \\
\text { sample lost to follow-up }\end{array}$ \\
\hline Selective reporting (reporting bias) & Low risk & Outcomes reported as specified. \\
\hline Other bias & Low risk & $\begin{array}{l}\text { Groups similar at baseline regarding most } \\
\text { important prognostic indicators; outcomes } \\
\text { assessed at same time for both groups; com- } \\
\text { pliance reported in detail }\end{array}$ \\
\hline
\end{tabular}

\section{Kvorning 2004}

Methods

Participants
100 women, enrolled and randomised to 1 of 2 groups. The code for group allocation was obtained in advance by throwing dice in pairs of 10 , and enclosed in advance in an envelope, marked with the order number of inclusion and opened consecutively by midwife on inclusion to the study.

Participants and caregiver not blinded; assessor blinded.

Those who finished the trial were analysed in the assigned groups.

Lost to follow-up: 1 ward closed to recruitment after 12 months because women no longer wished to be included in the study.

Acupuncture group $=$ randomised 50, analysed 37; (lost 6 due to clinic closure, 3 delivered, 2 did not like acupuncture, 1 did not complete assessment correctly, 1 lost due to vacation of midwife).

Control group $=$ randomised 50, analysed 35 (lost 6 due to clinic closure, 5 did not complete forms correctly, 3 insisted on acupuncture, 1 was admitted to hospital for pain management and rest)

Study in Sweden.

No mention of funding.

Length of study or follow-up not given.

Inclusion criteria: 3rd trimester of pregnancy, presented at the maternity ward centres in southern Sweden, complaining of pelvic girdle or LBP.

Exclusion criteria: those participating in study for less than 3 weeks.

Baseline.

2 groups did not differ significantly in age $(30 \pm 5.0$ years $)$; gestational week at first visit $(30 \pm 4.2$ weeks); employed (75\%); had acupuncture before (20\%); negative attitude to acupuncture (20\%).

Pain in sacroiliac region or over symphysis with no motor or sensory disturbances: $\mathrm{A}=$ 
$78 \% ; \mathrm{C}=80 \%$.

Duration of pain: $\mathrm{A}=8.8 \pm 5.6$ weeks; $\mathrm{C}=6.0 \pm 3.8$ weeks $(\mathrm{P}<0.001)$.

Duration of pain in past 24 hours: $A=9.8 \pm 7.1$ hours; $C=9.2 \pm 7.4$ hours.

Number of participants on analgesics: $\mathrm{A}=1 ; \mathrm{C}=0$.

Interventions $\quad$ Experiment group.

Acupuncture given according to written instructions and periosteal stimulation.

Started with LR3 and GV20 points + local tender points, added BL60, SI3 and 1 of lumbar and sacral bladder points (BL22-26) if needed; stimulated to De Qi, needles left in place for increasing length of time.

Time: patient received acupuncture twice a week during first 2 weeks; after this, they only received it once a week (note - no total duration of treatment time given)

Control group: no treatment.

Outcomes

Pain increased, pain unchanged, pain decreased, no pain during last 3 weeks of pregnancy, pain on activity decreased, Visits to maternity centres, number of participants who used analgesics, number of participants who used TENS, number of participants who used sacroiliac belt, number of participants who used physiotherapy, baby's birthweight, baby's Apgar at $1 / 5 / 10$ minutes

Adverse effects: reported by $38 \%$ of acupuncture group - local pain (6); heat or sweating (5); local haematoma (2); tiredness (2); nausea (2); weakness (1)

Low-back pain

Pelvic pain

Low-back pain and pelvic pain $\quad \mathrm{X}$

Notes No mention of funding.

Risk of bias

\begin{tabular}{|c|c|c|}
\hline Bias & Authors' judgement & Support for judgement \\
\hline $\begin{array}{l}\text { Random sequence generation (selection } \\
\text { bias) }\end{array}$ & Low risk & $\begin{array}{l}\text { 'code for group obtained in advance by } \\
\text { throwing dice in pairs of } 10 . \text {.' }\end{array}$ \\
\hline
\end{tabular}

Allocation concealment (selection bias) Low risk

'Predetermined code enclosed in advance in envelop, marked with the order number of inclusion and opened consecutively by midwife on inclusion.'

Blinding of participants and personnel High risk (performance bias)

All outcomes

No explicit mention in the report, but it seems unlikely that either the women, midwives or acupuncturists were unaware of inclusion into the acupuncture or control group

Interventions for preventing and treating pelvic and back pain in pregnancy (Review)

Copyright $\odot 2013$ The Cochrane Collaboration. Published by John Wiley \& Sons, Ltd. 


\section{Kvorning 2004 (Continued)}

Blinding of outcome assessment (detection Low risk

bias)

All outcomes 'two blinded investigators independently assessed the development of the patients' individual VAS scoring over time with a kappa coefficient of $0.68 \%$ (95\% CI 0.54 to 0.83$)^{\prime}$

Incomplete outcome data (attrition bias) High risk All outcomes

Over 20\% lost to follow-up in each group. 1 ward closed to recruitment after 12 months because women no longer wished to be included in the study $=>$ excluded 12 participants who had been enrolled by this clinic, leaving 44 in each group

Acupuncture group - lost 3 because they delivered, 2 did not like acupuncture, 1 did not complete assessment correctly, 1 lost due to vacation of midwife (7) - analysed $37 / 50$

Control group - lost 5 - did not complete forms correctly, 3 insisted on acupuncture, 1 was admitted to hospital for pain management and rest (9) - analysed 35/50

Selective reporting (reporting bias) High risk

Data provided on outcomes listed in methods section but at times they are difficult to follow and not presented in a fashion that allow analyses

Other bias

High risk
Variety of other treatments used by the women to relieve symptoms (analgesics, TENS, pelvic belt, physio); length of study unclear

\section{Licciardone 2010}

Methods

Participants

Interventions
$\mathrm{N}=146$ randomised (group 1: $\mathrm{N}=49$; group 2: $\mathrm{N}=48$; group 3; $\mathrm{N}=49$ ). Participants stratified by age and gravida

Inclusion: obstetric patients with back pain up to 30 weeks' gestation; exclusion: intent to deliver outside study site, high-risk pregnancy, including gestational diabetes, preeclampsia, placenta previa, abruptio placenta

Group 1: usual obstetric care plus osteopathic manipulative treatment (OMT)

Group 2: usual obstetric care plus sham ultrasound (Sham US).

Group 3 (controls): usual obstetric care. 7 treatments each lasting 30 minutes at 30, 32, 34, 36, 37, 38, 39 weeks' gestation

OMT = included any of the following modalities: soft tissue, myofascial release, muscle energy, range of motion mobilisations used in a systematic manner by all providers*

Sham US = using a non-functional ultrasound therapy unit that provided both visible 
Licciardone 2010 (Continued)

and auditory cues provided by a normal ultrasound unit

Usual obstetric care during pregnancy - no study treatments provided (7 visits in total: at $30,32,34,36,37,38,39$ weeks' gestation)

Outcomes

VAS $(0-10 \mathrm{~cm})$ - average back pain experienced; Roland Morris Disability Questionnaire (back-specific function) measured at baseline and after 7th (last) treatment session; at same times for each group

Low-back pain $\quad \mathrm{X}$

Pelvic pain

Low-back pain and pelvic pain

Notes

*Treatment providers met regularly to ensure consistency in duration, type, anatomic location and manner of OMT provided. OMT and Sham US provided by same physicians with same amount of attention given to both groups. 2 from each treatment group missed more than $50 \%$ of treatments. Compliance best in control group

Funding = grants from the Osteopathic Heritage Foundation and the National Center for Complementary and Alternative Medicine at the National Institutes of Health

\section{Risk of bias}

Bias

Random sequence generation (selection Unclear risk bias)

\section{Authors' judgement}

\section{Support for judgement}

Patients randomly assigned and stratified by age and gestation, but no other information given about the sequence generation

Allocation concealment (selection bias) Unclear risk Insufficient information given.

Blinding of participants and personnel High risk (performance bias)

All outcomes

Blinding of outcome assessment (detection High risk bias)

All outcomes

Incomplete outcome data (attrition bias) High risk All outcomes
Not possible to blind patients or care providers.

Outcome measures were by self-report, but high risk because patients not blinded

ITT analysis = 144 participants; last observation carried forward, attrition and exclusions reported $(23$ (16\%) withdrew before visit 7; 60 (42\%) withdrew due to delivery) ... but query the reliability of imputing over $1 / 2$ of the data (actual data for $146-83=$ 63) 
Licciardone 2010 (Continued)

Selective reporting (reporting bias) Low risk

Several approaches used to decrease risk of bias from last observation carried forward method

Other bias

Low risk

Similar compliance in treatment groups, baseline measurements similar, co-interventions controlled, outcomes taken at same time points

Lund 2006

Methods

- Prospective randomised controlled single-blind study.

- Women recruited from 2 different maternity healthcare departments and randomised to superficial or deep acupuncture.

- 106 women examined; 70 women randomised; 23 dropped out; analyses conducted on 47 who completed the study.

Participants

\section{Inclusion criteria:}

Gestational age: 22 to 36 weeks.

Duration of pain: $\geq 2$ weeks.

Pain intensity last week, rated on VAS, 0-100: $\geq 60$.

Increased pelvic pain in walking, turning from 1 side to the other in bed, or rising from sitting to standing.

Physical examination confirming provoked pelvic pain:

(i) In 1 of 3 tests: posterior pelvic pain provocation test (P4), standing on 1 leg, Patrick's Fabere test;

(ii) In palpating tissue over: the sacroiliac joints, the symphysis pubis, or $\mathrm{mm}$. Gluteus maximus/medius

Exclusion criteria:

Earlier experience of acupuncture treatment.

Fear of needles.

Urogenital infections.

Symptoms of lingering pelvic pain due to earlier pregnancy.

Interventions

Experiment group: Deep stimulation acupuncture $(\mathrm{N}=25)$

10 acupuncture treatments of 30 minutes each, given twice weekly for 5 weeks by a registered physiotherapist. See study for exact location of acupuncture points used.

Longer and thicker needles were inserted intramuscularly. Needles were stimulated 5 times during the treatment sessions by manually twirling the needles $180^{\circ}$ back and forth until patient reported sensations of de qi.

Control group: Superficial stimulation acupuncture $(\mathrm{N}=22)$

10 acupuncture treatments of 30 minutes each, given twice weekly for 5 weeks by a registered physiotherapist. See study for exact location of acupuncture points used.

Shorter and thinner needles were inserted subcutaneously and left in place until end of treatment. To mimic the procedure of deep stimulation, therapist sat down by patient 4 additional times during treatment without manipulating the needles

Interventions for preventing and treating pelvic and back pain in pregnancy (Review)

Copyright $\Subset 2013$ The Cochrane Collaboration. Published by John Wiley \& Sons, Ltd. 


\section{Lund 2006 (Continued)}

Outcomes $\quad$ VAS pain (at rest and during 3 daily activities); Nottingham Health Profile measured 5 days prior to and 5 days after treatment; at same time for both groups

Low-back pain

Pelvic pain $\quad \mathrm{X}$

Low-back pain and pelvic pain

Notes

Funding $=$ research grants from Praktikertjänst $\mathrm{AB}$ and the National Security in Sweden

Risk of bias

\begin{tabular}{l|l|l}
\hline Bias & Authors' judgement & Support for judgement \\
\hline $\begin{array}{l}\text { Random sequence generation (selection } \\
\text { bias) }\end{array}$ & Unclear risk & $\begin{array}{l}\text { 'women ... were randomised ...' but ran- } \\
\text { domisation procedure not described } \\
\text { Unclear risk - as above, randomisation pro- } \\
\text { cedure not explained }\end{array}$ \\
\hline Allocation concealment (selection bias) & Low risk & $\begin{array}{l}\text { Quote: 'Sealed envelopes with labels for de- } \\
\text { termination of treatment were used in ran- } \\
\text { domisation provided by a statistician not } \\
\text { involved in the study' }\end{array}$ \\
\hline
\end{tabular}

Blinding of participants and personnel Low risk (performance bias)

All outcomes

bias)

All outcomes

Incomplete outcome data (attrition bias) High risk All outcomes
Both groups given acupuncture so could not tell difference as patients were acupuncture naive; care providers knew whether they gave superficial or deep acupuncture but acted the same towards the patient regardless

Self-reported outcomes collected from patients who were unaware of their treatment group

Dropout rate: 23 participants out of 70 (13 in Superficial group, 10 in Deep group) Reasons for drop-outs listed; reasons similar for both groups

It does not seem that the grouping affected the drop-out reasons, and although almost $1 / 3$ dropped out from each group, the over-riding reason was non-compliance with completing pain diaries

No excluded data mentioned - and it appears that analyses only done on complete data sets 


\section{Lund 2006 (Continued)}

\begin{tabular}{|c|c|c|}
\hline Selective reporting (reporting bias) & Low risk & $\begin{array}{l}\text { Study reported all outcomes it said it would } \\
\text { report in methods }\end{array}$ \\
\hline Other bias & Low risk & $\begin{array}{l}\text { No other } \\
\text { Women all acupuncture naive. Groups sim- } \\
\text { ilar at baseline. }\end{array}$ \\
\hline
\end{tabular}

\section{Martins 2005}

\begin{tabular}{|c|c|c|}
\hline Methods & \multicolumn{2}{|c|}{$\begin{array}{l}\text { The physiotherapist conducting the research randomised the women into } 2 \text { groups by } \\
\text { means of a 'raffle' or 'lottery'. } \\
\text { Exercise group = 33; control group = } 36 \text {. } \\
\text { There appeared to be no drop-outs and although analysis is unclear, there appears to be } \\
\text { no contamination of groups in analysis; outcomes for control group not reported }\end{array}$} \\
\hline Participants & \multicolumn{2}{|c|}{$\begin{array}{l}\text { Inclusion criteria: women with lumbar or pelvic pain, gestational age greater than } 12 \\
\text { weeks, live in city of Paulinia, Brazil. } \\
\text { Exclusion criteria: twin pregnancy, neurological symptoms in the lower limbs, restric- } \\
\text { tions for exercise, those already engaged in a physiotherapy program to ease symptoms }\end{array}$} \\
\hline Interventions & \multicolumn{2}{|c|}{$\begin{array}{l}\text { Experiment group: exercises in groups for 'global activity and stretching' } \\
\text { Control group: routine medical recommendations. }\end{array}$} \\
\hline Outcomes & \multicolumn{2}{|c|}{$\begin{array}{l}\text { Proportion of women with improvement, VAS after } 8 \text { weeks. } \\
\text { Adverse events: not reported. }\end{array}$} \\
\hline \multicolumn{3}{|l|}{ Low-back pain } \\
\hline \multicolumn{3}{|l|}{ Pelvic pain } \\
\hline Low-back pain and pelvic pain & \multicolumn{2}{|l|}{$\mathrm{X}$} \\
\hline Notes & \multicolumn{2}{|c|}{$\begin{array}{l}\text { Funding: not reported } \\
\text { translated from Portugese by single Portuguese researcher }\end{array}$} \\
\hline \multicolumn{3}{|l|}{ Risk of bias } \\
\hline Bias & Authors' judgement & Support for judgement \\
\hline $\begin{array}{l}\text { Random sequence generation (selection } \\
\text { bias) }\end{array}$ & Low risk & Used a 'Raffle' or 'lottery'. \\
\hline Allocation concealment (selection bias) & High risk & $\begin{array}{l}\text { Physiotherapist who was doing the research } \\
\text { allocated to groups }\end{array}$ \\
\hline
\end{tabular}


Martins 2005 (Continued)

\begin{tabular}{l|l}
$\begin{array}{l}\text { Blinding of participants and personnel Unclear risk } \\
\text { (performance bias) }\end{array}$ & $\begin{array}{l}\text { Description of blinding for participants, } \\
\text { caregiver not provided }\end{array}$ \\
\hline
\end{tabular}

Blinding of outcome assessment (detection Unclear risk

bias)

Description of blinding for assessors not provided.

All outcomes

Incomplete outcome data (attrition bias) High risk

All outcomes

Outcome table appears to indicate no dropouts; report appears to indicate that there is no contamination between groups, but none of this is clearly described

Selective reporting (reporting bias)

High risk

Results are incomplete (only intervention group's improvement reported, no data for control group)

Other bias

High risk

Other treatments not described; baseline data were not comparable: Exercise group $=48 \%$ greater than 5 on VAS $0-10$; Usual care group $=61 \%$ greater than 5 on VAS $0-10$

Mørkved 2007

Methods

Participants
- Pregnant women were recruited between October 1998 to May 2000.

- 1533 women in and around Trondheim, Norway were invited to join => 301 were randomised.

- Primary outcome was prevention and treatment of urinary incontinence; secondary outcome was prevention and treatment of pelvic and LBP.

\section{Inclusion criteria:}

Nulliparous.

$\geq 18$ years old.

Singleton live fetus at a routine ultrasound scan at 18 weeks of pregnancy

Exclusion criteria:

Pregnancy complications.

High risk of preterm labour.

Pain during PFM contractions.

Ongoing urinary tract infection or diseases that could interfere with participation.

Living too far from Trondheim to be able to attend weekly training groups
Experiment group: Exercise training group

Training with a physical therapist in groups of 10 to 15 women for 60 minutes once per week for 12 weeks, where training focused on PFM and other exercises.

Women were encouraged to perform 8 to 12 intensive PFM contractions twice per day at home. Motivation was strongly emphasised.

Each training sessions consisted of: 15 to 20 minutes aerobic activity, 30 to 35 minutes 
Outcomes

of exercises, 5 to 10 minutes of light stretching, body awareness, and breathing and relaxation exercises.

Women were given general advice related to ergonomics and daily life activities in pregnancy

\section{Control group:}

Women received customary information given by their midwife or general practitioner.

They were not discouraged from exercising on their own

\begin{tabular}{|c|c|}
\hline Outcomes & $\begin{array}{l}\text { Self-reported pain in the low-back area lasting for } \geq 1 \text { week; pain drawing, off sick due } \\
\text { to low-back/pelvic pain (yes/no); Disability Rating index; pelvic floor muscle strength } \\
\text { measured at baseline ( } 20 \text { weeks' gestation); } 36 \text { weeks' gestation, } 3 \text { months' postpartum }\end{array}$ \\
\hline Low-back pain & \\
\hline Pelvic pain & \\
\hline Low-back pain and pelvic pain & $\mathrm{X}$ \\
\hline Notes & $\begin{array}{l}\text { Adherence to training protocol was registered based on the women's personal training } \\
\text { diary (must do } 2 \text { sets of } 8 \text { to } 12 \text { contractions of PFM per day) and reports from the } \\
\text { physical therapists that led the group training (participation in ?6 group training sessions) } \\
120 \text { of the } 148 \text { women ( } 81 \% \text { ) in training group followed the training protocol } \\
\text { Funding = Norwegian Fund for Postgraduate Training in Physiotherapy and the Nor- } \\
\text { wegian Women's Public Health Association }\end{array}$ \\
\hline
\end{tabular}

\section{Risk of bias}

\begin{tabular}{|c|c|c|}
\hline Bias & Authors' judgement & Support for judgement \\
\hline $\begin{array}{l}\text { Random sequence generation (selection } \\
\text { bias) }\end{array}$ & Low risk & $\begin{array}{l}\text { Quote: 'Randomization was done in blocks } \\
\text { of } 32 \text { with the use of opaque sealed en- } \\
\text { velopes', did not specify method used to } \\
\text { select the blocks, but likely OK, given the } \\
\text { fact that they used other safeguards }\end{array}$ \\
\hline Allocation concealment (selection bias) & Low risk & $\begin{array}{l}\text { Opaque sealed envelopes used. } \\
\text { Quote: 'A secretary with no other involve- } \\
\text { ment in the trial prepared the envelopes. } \\
\text { Each woman opened } 1 \text { of the envelopes } \\
\text { herself and was enrolled by the secretary in } \\
\text { the secretary's office.' }\end{array}$ \\
\hline
\end{tabular}

Blinding of participants and personnel High risk (performance bias)

All outcomes
Participants and care providers were aware of treatments (exercise vs usual care) 
Mørkved 2007 (Continued)

\begin{tabular}{|c|c|c|}
\hline $\begin{array}{l}\text { Blinding of outcome assessment (detection } \\
\text { bias) } \\
\text { All outcomes }\end{array}$ & Unclear risk & $\begin{array}{l}\text { Quote: 'The principal investigator was not } \\
\text { involved in the training of the women and } \\
\text { was blinded to group allocation while mak- } \\
\text { ing the assessments and plotting the data'. } \\
\text { However, the outcomes were self-report } \\
\text { and the women were not blinded to their } \\
\text { treatment; unclear if those who received } \\
\text { usual care were aware of other options }\end{array}$ \\
\hline $\begin{array}{l}\text { Incomplete outcome data (attrition bias) } \\
\text { All outcomes }\end{array}$ & Low risk & $\begin{array}{l}7 \text { participants in control and } 5 \text { in training } \\
\text { group withdrew after the first assessment } \\
\text { Reasons for withdrawal were diseases con- } \\
\text { nected to pregnancy }(n=6) \text { or personal rea- } \\
\text { sons }(n=6) \text {. } \\
\text { It does not seem that the grouping affected } \\
\text { the drop-out reasons } \\
\text { No excluded data mentioned. }\end{array}$ \\
\hline Selective reporting (reporting bias) & Low risk & $\begin{array}{l}\text { Study reported all outcomes it said it would } \\
\text { report in methods }\end{array}$ \\
\hline Other bias & Unclear risk & $\begin{array}{l}\text { Unclear risk: Influence of co-interventions, } \\
\text { adherence not reported in results }\end{array}$ \\
\hline
\end{tabular}

\section{Peters 2007}

\begin{tabular}{l|l}
\hline Methods & $\begin{array}{l}- \text { 'Randomised controlled clinical trial in the classic 'waiting list' design. } \\
\text { C Carried out by } 2 \text { osteopaths in their offices in } \\
\text { ú berlingen and M } \\
\text { ú lheim, Germany. } \\
- \text { Women recruited from 'a number of midwives and gynaecologists'. }\end{array}$ \\
\hline Participants & $\begin{array}{l}\text { - } 60 \text { pregnant women with pelvic and/or low-back pain that had lasted at least a } \\
\text { week and was at least VAS > 3. } \\
\text { - Average age } 30 \text { years, mean gestation } 25 \text { weeks. }\end{array}$ \\
\hline Interventions & $\begin{array}{l}\text { Intervention group: received } 4 \text { osteopathic treatments in weekly intervals. } \\
\text { Waiting list comparison group, after } 5 \text { weeks on the waiting list they received osteo- } \\
\text { pathic treatment that was reported as 'having no relevance for the study' }\end{array}$ \\
\hline Outcomes & $\begin{array}{l}\text { Pain, measured with VAS; interference with ADL, measured with Quebec Back Pain } \\
\text { Disability Scale at baseline and end of first } 5 \text { weeks (end of treatment for intervention } \\
\text { group) }\end{array}$ \\
\hline Low-back pain & \\
\hline
\end{tabular}

Pelvic pain

Interventions for preventing and treating pelvic and back pain in pregnancy (Review)

Copyright @ 2013 The Cochrane Collaboration. Published by John Wiley \& Sons, Ltd. 
Peters 2007 (Continued)

\begin{tabular}{ll}
\hline Low-back pain and pelvic pain & $\mathrm{X}$ \\
\hline Notes & $\begin{array}{l}\text { Information taken from an abstract of an unpublished thesis that is available in German, } \\
\text { for a cost, from Akademie füf Osteopathie (AFO), Deutschland (funds not available to } \\
\text { obtain full manuscript) } \\
\text { Funding not reported. } \\
\text { Abstract initially translated from German by single German-speaking researcher, then } \\
\text { English abstract found on-line }\end{array}$ \\
\hline
\end{tabular}

Risk of bias

\begin{tabular}{|c|c|c|}
\hline Bias & Authors' judgement & Support for judgement \\
\hline $\begin{array}{l}\text { Random sequence generation (selection } \\
\text { bias) }\end{array}$ & Unclear risk & $\begin{array}{l}\text { 'Randomised controlled clinical trial' - } \\
\text { methodology not reported in abstract }\end{array}$ \\
\hline Allocation concealment (selection bias) & Unclear risk & $\begin{array}{l}\text { Waiting list comparison group, after } 5 \\
\text { weeks waiting list they get a treatment that } \\
\text { is reported as having no relevance for the } \\
\text { study }\end{array}$ \\
\hline $\begin{array}{l}\text { Blinding of participants and personnel } \\
\text { (performance bias) } \\
\text { All outcomes }\end{array}$ & Unclear risk & No mention of blinding in abstract. \\
\hline $\begin{array}{l}\text { Blinding of outcome assessment (detection } \\
\text { bias) } \\
\text { All outcomes }\end{array}$ & Unclear risk & No mention of blinding in abstract. \\
\hline $\begin{array}{l}\text { Incomplete outcome data (attrition bias) } \\
\text { All outcomes }\end{array}$ & Unclear risk & $\begin{array}{l}3 \text { patients in the control group dropped } \\
\text { out; no information provided on exclusions } \\
\text { or analyses }\end{array}$ \\
\hline Selective reporting (reporting bias) & Low risk & $\begin{array}{l}\text { Data provided for pain and Quebec Back } \\
\text { Pain Disability Scale }\end{array}$ \\
\hline Other bias & Unclear risk & $\begin{array}{l}\text { Difficult to assess since we were unable to } \\
\text { access the full thesis }\end{array}$ \\
\hline
\end{tabular}

Peterson 2012

Methods

Pilot randomised controlled trial - 57 participants randomised. All participants screened initially by phone and all treatments described prior to randomisation. No limit on what stage in pregnancy women could enter the trial. Before randomisation all participants identified their treatment preference 
Peterson 2012 (Continued)

Inclusion criteria: healthy pregnant women with singleton fetus and LBP of unknown
Prigin that began during pregnancy and was reproduced by manual palpation
Exclusion criteria: women with health conditions that contra-indicated exercise (in-
cluding heart disease, hypertension, BMI $>40$, diabetes, incompetent cervix, ruptured
membranes, decreased fetal movement) or manipulation (including unrelenting night
pain, loss of bladder or bowel control, progressive neurological deficit, cancer, spinal
fracture, unexplained weight loss, unrelenting fever)
Women who smoked, consumed alcohol, were taking anti-depressants or had Roland
Morris Disability Questionnaire score above 20 or below 4 . Women planning to move
during pregnancy, not willing to comply with study procedures and unable to read and
write English

Interventions

Exercise group (control; $\mathbf{N}=\mathbf{2 2}$ ): exercise booklet provided with specific exercises and recommendations for postural and movement patterns to alleviate LBP, and advice on when to stop exercising. Individualised stretching and strengthening exercises were prescribed, demonstrated and practiced at each study visit. Exercisies took approximately 15 minutes to perform and participants were asked to exercise $5 \mathrm{x} /$ week

Spinal manipulative therapy $(\mathbf{N}=\mathbf{1 5})$ : high velocity, low amplitude thrust applied to isolated joint to move it just past physiological end range in side-lying position. Direction, velocity and amplitude determined by the clinician from palpation findings

Neuro emotional technique (NET; $\mathbf{N}=\mathbf{2 0}$ ): Chiropractic mind-body technique using relaxed breathing and visualisation techniques with elements of traditional Chinese medicine (such as association of emotions with certain organs or meridians) and chiropractic medicine (adjustment of spinal levels innervating specific organs. The NET standard protocol was followed (Pablis et al., 2008)

Maximum number of treatments per participant $=8$ with very few in any group reaching this amount. Co-interventions controlled

Outcomes

Pain intensity (NRS 0-10), RMDQ (back-specific function), sick leave due to pregnancy related LBP (assessed but not listed as 1 of the outcomes)

Low-back pain

$\mathrm{X}$

Pelvic pain

Low-back pain and pelvic pain

Notes

138 participants screened; sick leave not listed in methods as 1 of the outcomes but reported in Table 2; higher drop-out from exercise group however adherence to exercise did not affect outcomes

Funding provided by The One Foundation, the research division of the NeuroEmotional Technique; 'The One Foundation did not contribute to the study in any other way' Conducted at Oregon Health \& Science University, USA.

Risk of bias

Bias

Authors' judgement

Support for judgement

Interventions for preventing and treating pelvic and back pain in pregnancy (Review)

Copyright $\Subset 2013$ The Cochrane Collaboration. Published by John Wiley \& Sons, Ltd. 
Peterson 2012 (Continued)

\begin{tabular}{|c|c|c|}
\hline $\begin{array}{l}\text { Random sequence generation (selection } \\
\text { bias) }\end{array}$ & Unclear risk & $\begin{array}{l}\text { The method used to generate the allocation } \\
\text { sequence was not described - 'before being } \\
\text { randomised, participants identified thei } \\
\text { treatment preference ... she would open } \\
\text { the consecutive envelope in her preference } \\
\text { strata in the presence of the researcher .. } \\
\text { women were randomly allocated into } 1 \text { o } \\
\text { three treatment groups' }\end{array}$ \\
\hline
\end{tabular}

Allocation concealment (selection bias) Low risk

'the randomisation schedule was completed prior to initiating the study and was concealed from all study staff by using consecutively numbered, sealed, opaque envelopes for each strata of preference group.'

Blinding of participants and personnel High risk (performance bias)

Participants and practitioners were not All outcomes blinded to treatment group after randomisation

Blinding of outcome assessment (detection High risk bias)

All outcomes

Incomplete outcome data (attrition bias) Low risk All outcomes

Participants were outcome assessors.

(1)

Selective reporting (reporting bias) Low risk

Last observation carried forward may limit data but carried out to replicate methods used in an earlier trial by Licciardone and colleagues (2010). Sensitivity analysis completed providing similar results to primary outcome analysis

Other bias

High risk

Participants randomised according to their treatment preference, entered the study at different gestational points, groups were not similar at baseline for all prognostic factors, and were paid to participate (USD\$20 per visit)

Interventions for preventing and treating pelvic and back pain in pregnancy (Review) 
Methods

Participants

Outcomes

Pelvic pain

Low-back pain and pelvic pain

Notes

Email to the corresponding author for clarification failed to elicit a response

Funding $=$ grant from Sports Medicine Research Center and Vice Chancellor for Research at Tehran University of Medical Sciences
100 women invited and divided into 2 groups; 10 withdrawn from exercise group prior to intervention $=>90$ analysed

\section{Inclusion criteria:}

Pregnant women in the second half of pregnancy referred to prenatal clinics of Qom province, Iran.

Participants were in 20 to 22 weeks of gestation.

\section{Exclusion criteria:}

Inability to perform exercises; excluded after missing 3 sessions

Experiment group: Exercise program $=40$

Program consisted of 15 minute warm up and cool down plus 30 minute cycling in the range of $55 \%$ to $65 \%$ of the maximal heart rate with respect to the age. Exercises were prescribed by a physical training specialist. The exercise sessions were 3 times a week for 8 weeks

\section{Control group: $\mathbf{=} \mathbf{5 0}$}

The study did not specify what the control group was.

Pain, measured with Quebec questionnaire, measured at baseline and 8 weeks after start of program; demographic data collected at baseline; $\mathrm{P}$ value $<0.05$ considered to be statistically significant

\section{Risk of bias}

\section{Bias}

Random sequence generation (selection Unclear risk bias)

\section{Authors' judgement}

\section{Support for judgement}

No description of sequence generation were described except 'the total numbers of 100 invited were divided into two exercise and control groups'

'Randomised' was only mentioned in the abstract.

Unclear risk: randomisation procedure not described.

Not mentioned. 


\section{Sedaghati 2007 (Continued)}

Blinding of participants and personnel High risk

Not mentioned, but assume not.

(performance bias)

All outcomes

Blinding of outcome assessment (detection Unclear risk

Not mentioned.

bias)

All outcomes

Incomplete outcome data (attrition bias) High risk

All outcomes
Quote: 'every woman missing three session of exercise was excluded from the study' but unclear how many this affected Drop-outs/withdrawals from study not mentioned, however, 10 women who were randomised did not proceed to the intervention because they were unable to participate in the exercises

Did not specify how they dealt with the missing/excluded data

Study reported all outcomes it said it would report in methods

Unclear risk: compliance not reported, nor co-interventions.

Stafne 2012

Methods

Participants

nterventions 2-armed, 2 centre randomised controlled trial - 855 women randomised

Inclusion criteria: aged 18 years or more, singleton live fetus and within 30 minute drive of hospital and able to attend weekly training

Exclusion criteria: high-risk pregnancy or diseases that could interfere with participation in exercise

Exercise group ( $\mathbf{N}=\mathbf{4 2 9 / 3 9 6}$ analysed): 60 -minute exercise sessions $1 x /$ week for 12 weeks between 20 to 36 weeks' gestation led by a physiotherapist in groups of 8 to 15 participants. Each session consisted of moderate intensity (13-14 on Borg scale) aerobic activity, strength training and balance exercises. 45 minute home exercise session $2 \mathrm{x} /$ week consisting of 30 minutes of aerobic activity and 15 minutes of strengthening and balance exercises. Adherence monitored throughout

Control group $(\mathrm{N}=426 / 365$ analysed $)$ : standard antenatal care; not discouraged from exercising

Both groups given written information on pelvic floor exercises, diet and pregnancy related lumbo-pelvic pain

Outcomes

Lumbopelvic pain - VAS (0-100) - morning and evening, sick leave due to lumbo-pelvic pain, Disability Rating Index (DRI), Fear avoidance Beliefs Questionnaire 
Stafne 2012 (Continued)

Low-back pain

Pelvic pain

Low-back pain and pelvic pain $\quad \mathrm{X}$

Notes

Additional outcomes related to a related study: gestational diabetes, glucose metabolism Approximately $60 \%$ of women who enrolled reported lumbo-pelvic pain at time of inclusion

Funding sources: Norwegian University of Sciences and Technology, Norweigian Fund for Postgraduate Training in Physiotherapy, Liason Committee for Central Norway Regional Health Authority

30 October 2012 - email sent to lead author to clarify correct number analysed in the intervention group - 396 or 397; author confirmed that there were 396 women in the intervention group

\section{Risk of bias}

\begin{tabular}{|c|c|c|}
\hline Bias & Authors' judgement & Support for judgement \\
\hline $\begin{array}{l}\text { Random sequence generation (selection } \\
\text { bias) }\end{array}$ & Low risk & Computerised randomisation. \\
\hline Allocation concealment (selection bias) & Low risk & $\begin{array}{l}\text { 'concealed randomisation' by a web-based } \\
\text { computerised procedure; ... personnel had } \\
\text { no influence over randomisation.' }\end{array}$ \\
\hline $\begin{array}{l}\text { Blinding of participants and personnel } \\
\text { (performance bias) } \\
\text { All outcomes }\end{array}$ & High risk & $\begin{array}{l}\text { While personnel had no influence over the } \\
\text { process of randomisation, the physiother- } \\
\text { apists who delivered the programmes were } \\
\text { aware of the end results ... i.e. they were } \\
\text { providing the participants with the inter- } \\
\text { vention }\end{array}$ \\
\hline
\end{tabular}

Blinding of outcome assessment (detection High risk bias)

All outcomes
Outcomes were self-reported symptoms, therefore the women were the outcome assessors and they knew whether they were receiving exercise therapy or not
Incomplete outcome data (attrition bias) High risk All outcomes
Exercise group $=8 \%$ drop-out $/$ loss to follow-up; control group $=14 \%$ drop-out $/$ loss to follow-up with a large proportion of these giving no reason and not included in the analysis

All outcomes reported as specified in methods. 
Stafne 2012 (Continued)

Other bias

Low risk
Groups similar at baseline even when not including those lost to follow-up. Cointerventions avoided or similar between groups and compliance with exercise assessed against specified level of $3 \mathrm{x} /$ week. Timing of outcome assessment same for both groups

Suputtitada 2002

Methods

74 women were allocated to experimental or control groups by using a 'random sampling technique' (no description).

Exercise group: randomised $=37$; analysed $=32(76.2 \%)$.

Control group: randomised $=37$; analysed $=35(83.3 \%)$.

Lost to follow-up: toxemia (3), would not deliver at hospital (3), preterm labour due to oligohydramnios (1), group membership not noted, nor the reasons for the other losses

Participants

Inclusion criteria: primigravida, healthy - no underlying disease, 20 to 35 years old, 26 to 30 weeks' gestation, at least $140 \mathrm{~cm}$ tall, BMI before becoming pregnant less than $25 \mathrm{~kg} / \mathrm{m}^{2}$, non-smoker, no previous severe back and pelvic pain, no contraindication for exercise during pregnancy, did not exercise regularly ( $<1 /$ week), attending prenatal clinic and intend to deliver at King Chulalongkorn Memorial Hospital, Bangkok, fluent in Thai, willing to participate in study regimen

Exclusion criteria:

Underlying disease that would effect exercise, pregnancy and labour, e.g. heart disease, diabetes mellitus, thyrotoxicosis, hypertension, infection, unable to follow exercise program 5 days/week for 8 weeks, weight gain more than $25 \mathrm{~kg}$ or less than $10 \mathrm{~kg}$, do not intend to deliver at King Chulalongkorn Memorial Hospital

Women were similar at baseline for all factors except job activities: exercise group sat more often at work $(\mathrm{N} / \mathrm{S})$; control group stood more often at work and income: exercise group were in higher paid jobs than the control $(\mathrm{P}=0.008)$

Interventions

Experiment group.

Sitting pelvic tilt exercise: week 1 = do 4 cycles (hold position for 5 seconds then relax for 5 seconds) of exercises each morning and evening; increase by 2 cycles/session in weeks 2 to 4 , until you are doing 10 cycles/session, then continue at this level for the next 4 weeks.

Exercises should be done twice a day, 5 days/week (twice under supervision of exercise instructor at the hospital; 3 times unsupervised at home) for a total of 8 weeks.

Record kept of exercises done; instructor checked agility and overall fitness when at clinic

Control group: no treatment (nothing noted in article).

Outcomes

Pain improved, pain worsened, pain measured with VAS, gestational age at birth, baby's Apgar score at 1 minute, baby's Apgar score at 5 minutes

Adverse events: 'no negative effects on mother or fetus; no preterm labour; no premature rupture of membranes' 
Suputtitada 2002 (Continued)

\begin{tabular}{l|l}
\hline Low-back pain & $\mathrm{X}$ \\
\hline Pelvic pain & \\
\hline Low-back pain and pelvic pain & \begin{tabular}{l} 
Numbers are not consistently reported throughout the article; total number of partici- \\
pants seems to range from 73 to 84 , with most mention of 74 randomised, which is the \\
number we used. Data needed for the meta-analyses appeared to be incorrectly reported \\
in the paper and were re-analysed \\
\hline Funding: not mentioned.
\end{tabular} \\
\hline
\end{tabular}

\section{Risk of bias}

Bias

Authors' judgement

Random sequence generation (selection Unclear risk bias)

\section{Support for judgement}

'random sampling technique' but not described; in discussion section, the authors state 'the inclusion and exclusion criteria were used to match these two groups as closely as possible and scrutinize the variables that may contribute to the impact of physical conditioning or pregnancy outcomes'... which doesn't sound like 'randomisation'..

Unclear - 'allocated to experimental or control groups'.

No blinding of participants or providers.

Blinding of participants and personnel High risk (performance bias)

Unclear risk

Unclear about outcome assessors.

Blinding of outcome assessment (detection Unclear risk bias)

All outcomes

Incomplete outcome data (attrition bias) High risk All outcomes

$17 \%$ loss of participants from control group; $24 \%$ loss of participants from intervention group; details for withdrawals not clearly described. Analysis on 67 completers only

Selective reporting (reporting bias) Low risk

Reported on LBP for mothers, 1-minute and 5-minute Apgar scores and birthweight of babies 
Suputtitada 2002 (Continued)

\begin{tabular}{|c|c|c|}
\hline Other bias & Unclear risk & $\begin{array}{l}\text { Exercise diary kept and checked by exercise } \\
\text { instructor; co-interventions not described }\end{array}$ \\
\hline
\end{tabular}

Thomas 1989

Methods

Cross-over trial: order of use of pillows being 'randomly assigned' -- further details on randomisation not given.

109 women recruited; 92 women finished the 2-week observational period.

Analysis unclear (cross-over study) - analysed results of everyone who had one intervention against the results of those who received the 2 nd intervention

Participants

Inclusion criteria.

36 weeks' gestation, attending an antenatal clinic in Brisbane, Australia.

Low-risk pregnancy.

Drop-outs related to delivery, failure to present to clinic for assignment of 2 nd pillow,

failure to return completed questionnaires

Interventions

Provision of 2 different types of pillow to support the pregnant abdomen when lying in a lateral position. The pillows were taken home and used for 1 week each, consecutively. The Ozzlo pillow was a locally designed, curved, sloping, soft cushion conforming to the shape of the abdomen; the control pillow was a standard hospital pillow

Outcomes

Numbers of women reporting moderate improvement in backache or better. Numbers of women reporting relief of insomnia

No adverse effected noted.

Low-back pain $\quad \mathrm{X}$

Pelvic pain

Low-back pain and pelvic pain

Notes

There was no comparison with no treatment. We contacted the authors in 1999 and the Ozzlo pillow seems no longer to be made

Funding source not noted.

Risk of bias

Bias

Random sequence generation (selection Unclear risk bias)

Allocation concealment (selection bias)

Unclear risk
Authors' judgement

Support for judgement

Cross-over trial: order of use of pillows being 'randomly assigned' -- further details on randomisation not given

Unclear. 
Thomas 1989 (Continued)

\begin{tabular}{|c|c|c|}
\hline $\begin{array}{l}\text { Blinding of participants and personnel } \\
\text { (performance bias) } \\
\text { All outcomes }\end{array}$ & High risk & $\begin{array}{l}\text { Participants and personnel did not seem to } \\
\text { be blinded. }\end{array}$ \\
\hline $\begin{array}{l}\text { Blinding of outcome assessment (detection } \\
\text { bias) } \\
\text { All outcomes }\end{array}$ & High risk & $\begin{array}{l}\text { Outcome assessors did not appear to be } \\
\text { blinded. }\end{array}$ \\
\hline $\begin{array}{l}\text { Incomplete outcome data (attrition bias) } \\
\text { All outcomes }\end{array}$ & High risk & $\begin{array}{l}84 \% \text { of women completed study; women } \\
\text { acted as their own control but there was } \\
\text { no 'wash-out period' provided between pil- } \\
\text { lows }\end{array}$ \\
\hline Selective reporting (reporting bias) & High risk & $\begin{array}{l}\text { Data were measured for all women when } \\
\text { they used } 1 \text { pillow and all women when } \\
\text { they used the second one, rather than pro- } \\
\text { viding data at the end of the first phase of } \\
\text { the trials, before the cross-over }\end{array}$ \\
\hline Other bias & Unclear risk & $\begin{array}{l}\text { Daily worksheets describing sleep patterns, } \\
\text { pain, etc handed in end of each week; co- } \\
\text { interventions not mentioned }\end{array}$ \\
\hline
\end{tabular}

\section{Wang 2009a}

Methods
- Randomised controlled trial, conducted at Yale-New Haven Hospital, USA.

- Women recruited by prenatal healthcare providers in the area; women called the hotline and spoke with the research assistant.

$159 \mathrm{R} / 152 \mathrm{~A}$

Inclusion: pregnant women between 25-38 weeks' gestation) with LBP and/or posterior PP

Exclusion: associated nerve root syndrome, neurologic deficit, fever, abdominal pain, other systematic manifestations, active uterine contractions

$\mathrm{N}=159$ randomised. $\mathrm{AA}=58$; Sham $\mathrm{AA}=54 ; \mathrm{WL}=47$.

All patients acupuncture naive. Drop-outs and exclusions reported with reasons

Interventions

Group 1: auricular (ear) acupuncture x 7 days plus self-care (AA). $N=58$. Used specific acupuncture points (kidney, analgesia, shenmen)

Group 2: sham auricular (ear) acupuncture x 7 days plus self-care (Sham AA). N = 54 . used non-specific points (shoulder, wrist, extra auricular point)

Group 3: self-care only waiting list control (WL). $N=47$.

Self care only. No acupuncture treatment received. Women just given advice

NB: All women given advice to rest if desired, take $650 \mathrm{mg}$ acetaminophen every 6 hours if needed, use hot/cold compress as desired

Outcomes

VAS - Pain (0-100 mm); Disability Rating Index (DRI) - functional status; State Trait Anxiety Index (STAI), measured at baseline, after 7 days of continuous AA or Sham AA 
and at 1 week post treatment (for both groups)

Days off work not included in outcomes.

Low-back pain

Pelvic pain

Low-back pain and pelvic pain $\quad \mathrm{X}$

Notes $\quad$ Funding = national Center for the Complementary and Alternative Medicine Grant

Risk of bias

Bias

Random sequence generation (selection Low risk bias)

Allocation concealment (selection bias) Unclear risk

Blinding of participants and personnel Low risk (performance bias)

All outcomes

Authors' judgement

All outcomes
Blinding of outcome assessment (detection Low risk bias)

All outcomes

Incomplete outcome data (attrition bias) Low risk All outcomes

Selective reporting (reporting bias) Low risk

Other bias

Low risk

\section{Support for judgement}

'randomly assigned to one of the three treatment groups based on a computer generated randomisation sheet.'

No information provided on allocation concealment.

Women had no previous experience with acupuncture and were asked to complete a credibility questionnaire after the removal of the needles

While not blinded, acupuncturist was skilled and trained and followed a strict script during treatment to avoid any nuances being picked up by the participants

Assessors and statisticians were blinded; women who gave self-reports were also blinded

Attrition and exclusions reported, numbers add up in the analysis, authors indicate how they managed missing values in their analysis

Study reported all outcomes as indicated in the methods section

Similar co-interventions; groups similar at baseline, timing of outcome assessment same across groups and compliance acceptable across groups 
Wedenberg 2000

\begin{tabular}{|c|c|}
\hline Methods & Randomised controlled trial - 60 women. \\
\hline Participants & Swedish women with pelvic or back pain arising before 32 weeks' gestation \\
\hline Interventions & $\begin{array}{l}\text { Acupuncture. } \\
3 \text { times/week for } 2 \text { weeks, then } 2 \text { times/week for } 2 \text { weeks = total 10; each session = } 30 \\
\text { minutes. } \\
2 \text { to } 10 \text { needles used, started with fossa triangularis points in ear adding body points, } \\
\text { local points as needed; needles were gently tapped or rotated } 15 \text { minutes after insertion } \\
\text { until De Qi reached } \\
\text { Physiotherapy. } \\
1 \text { to } 2 \text { times/week within } 6 \text { to } 8 \text { weeks = total } 10 \text { physiotherapy group sessions; } 50 \\
\text { minutes each. } \\
\text { Individualised treatment based on assessment }+ \text { trochanter-belt for pelvic support, } \\
\text { warmth, massage, soft-tissue mobilisation if needed. } \\
\text { All were offered water gymnastics according to a defined program }\end{array}$ \\
\hline Outcomes & $\begin{array}{l}\text { VAS (pain), disability rating indices and rating of overall effect all assessed by the women } \\
\text { in the trial } \\
\text { Adverse effects: no serious adverse effects reported, but } 2 \text { women reported small subcu- } \\
\text { taneous hematomas in the ear from acupuncture }\end{array}$ \\
\hline \multicolumn{2}{|l|}{ Low-back pain } \\
\hline \multicolumn{2}{|l|}{ Pelvic pain } \\
\hline Low-back pain and pelvic pain & $\mathrm{X}$ \\
\hline Notes & $\begin{array}{l}\text { There was no comparison with no treatment. } \\
\text { The pain and disability scales were not used in this review because of insufficient data } \\
\text { Study funded by the Council of Research and Development of Vrinnevi Hospital, Nor- } \\
\text { rkoping, Sweden }\end{array}$ \\
\hline
\end{tabular}

\section{Risk of bias}

Bias

Random sequence generation (selection Unclear risk bias)
Authors' judgement

Allocation concealment (selection bias)

Low risk

\section{Support for judgement}

60 women who accepted invitation to join study 'drew a closed envelope from a box to randomise to either the acupuncture or physiotherapy group', but method of randomisation not described

'drew a closed envelope from a box.'

Blinding of participants and personnel High risk Participants and caregiver not blinded.

(performance bias)

All outcomes 
Wedenberg 2000 (Continued)

Blinding of outcome assessment (detection Unclear risk

bias)

All outcomes

Incomplete outcome data (attrition bias) High risk

All outcomes
Aassessor blinding unclear.

Analysed those who completed the intervention in the group to which they had been randomised

2 of 30 women were not analysed in the acupuncture group since they had both inadvertently received both acupuncture and physiotherapy.

12 of 30 women in the physiotherapy group dropped out: preterm contractions (3), delivered during study (1), pre-eclampsia (1), no pain-diary notes (1), failed to attend (3) , inconvenient treatment hours (3)

Data for pain and disability outcomes not provided with sufficient detail to include in analyses

Other bias

High risk
Statistically significant difference in the distribution of type of pain at baseline, women pursued different co-treatments to relieve symptoms

ACOG: American College of Obstetricians and Gynecologists

ASLR: active straight leg raise

ADL: activities of daily living

BMI: body mass index

CI: confidence interval

gyn: gynaecological

ITT: intention-to-treat

$\mathrm{kg} / \mathrm{m}^{2}:$ kilogram $/$ meters squared

LBP: low-back pain

NRS: numerical rating scale

N/S: not significant

P4: Posterior Pelvic Pain Provocation Test

PGP: pelvic girdle pain

PP: pelvic pain

PFM: pelvic floor muscles

RMDQ: Roland Morris Disability Questionnaire

SD: standard deviation

SLR: straight leg raise test

UTI: urinary tract infection

VAS: visual analogue scale 


\begin{tabular}{ll}
\hline Study & Reason for exclusion \\
\hline Beyaz 2011 & CCT - participants not randomised. \\
\hline Chitryniewicz 2010 & $\begin{array}{l}\text { QRCT - participants not randomised. } \\
\text { Translated from Polish by one Polish-speaking researcher. }\end{array}$ \\
\hline Ciardi 2002 & QRCT - pilot study of 8 women assigned to groups based on ability to attend classes \\
\hline da Silva 2004 & $\begin{array}{l}\text { QRCT - women assigned to groups based on the day they attended the prenatal clinic - Tuesday and } \\
\text { Thursday were assigned to study group; Monday and Wednesday were assigned to control group }\end{array}$
\end{tabular}

de Jonge-Vors 2011 Not a clinical trial; publication reports on an audit/evaluation of a Midwifery Acupuncture Service.

Field 1999a Trial studied the effect of massage on stress reduction in pregnancy; back pain was measured, but only as a stressor that was managed with massage, not as an outcome of real interest. Attempts to contact 1st author for clarification were unsuccessful

Field 2012 Intervention designed to study the effect of yoga or massage compared to standard prenatal care on depressed pregnant women; back and leg pain was measured but not an outcome of real interest and not listed as 1 of the outcomes in methods section

Foxcroft $2011 \quad$ Participants not randomised. Secondary analysis of intervention to prevent gestational diabetes

\begin{tabular}{ll}
\hline Granath 2006 & QRCT - Randomisation was by date of birth. \\
\hline Haugland 2006 & Intervention was started during pregnancy, but goal and outcomes measured 6 and 12 weeks postpartum \\
\hline Kohama 2006 & $\begin{array}{l}\text { CCT - sequence generation not described '...140 women were included in the study...80 patients were } \\
\text { enrolled into the treatment group ... Pregnant women with the same pregnancy-related pains were observed } \\
\text { without Pycnogenol@ treatment as a control group' }\end{array}$ \\
\hline
\end{tabular}

Ladefoged 2012 QRCT - described as a 'Prospective controlled trial', with no details given for allocation. Report of conference proceedings, but unable to locate trial register (http://apps.who.int/trialsearch/Default.aspx; accessed 15 August 2012)

Mens 2012

Cross-sectional study to determine the sensitivity and specificity of specific tests for LBP/PP. No intervention involved

Momoi 1999

CCT - sequence generation not described - attempts to contact the author for clarification unsuccessful

Translated from Japanese by one Japanese-speaking researcher and a native Japanese non-researcher

Nilsson-Wikmar 2005 QRCT - women stratified by previous pregnancies, then assigned to 1 of 3 treatment groups in sequence (1st primigravida to group 1, 2nd primigravida to group 2, 3rd primigravida to group 3, etc)

Ostgaard 1994

QRCT - 3 groups divided by whether date of birth was 1st to10th day in the month, 11th to 20th or 21st to 31 st 
(Continued)

\begin{tabular}{ll}
\hline Schoenfeld 2011 & Not a trial but an overview of the benefits of exercise in pregnancy \\
\hline Singh 2008 & $\begin{array}{l}\text { Article is described as a 'Single center, prospective, randomised ,experimental study', but there are no details } \\
\text { of allocation, the control group(s), or comparison of outcomes between groups. Results are provided for } 15 \\
\text { participants who appear to be the only ones entered into the study }\end{array}$ \\
\hline Thorell 2012 & $\begin{array}{l}\text { Longitudinal cohort study that assessed peak oxygen uptake and incidence of back pain during and after } \\
\text { pregnancy }\end{array}$ \\
\hline Torstensson 2009 & Women were not pregnant at the time of intervention, just at the inception of the LBP \\
\hline Zand 2011 & $\begin{array}{l}\text { Not a RCT - recruited pregnant women were allocated into study groups using block technique (AABB); } \\
\text { acronym (AABB) implies that the block allocation was not probably random. Translated from Farsi by one } \\
\text { Farsi-speaking researcher }\end{array}$ \\
\hline
\end{tabular}

CCT: controlled clinical trial

LBP: low-back pain

PP: pelvic pain

RCT: randomised controlled trial

QRCT: quasi-randomised controlled trial

\section{Characteristics of ongoing studies [ordered by study ID]}

\section{Abolhasani 2010}

\begin{tabular}{l|l} 
Trial name or title & $\begin{array}{l}\text { Comparison between } 2 \text { types of treatment for pelvic girdle pain in pregnancy: Abdomino lumbo pelvic belt } \\
\text { and exercise therapy }\end{array}$ \\
\hline Methods & Participants will be allocated to 3 groups, including 2 interventions and 1 control, through randomisation \\
\hline Participants & $\begin{array}{l}132 \text { healthy pregnant women with pelvic girdle pain and pregnancy date } 20 \text { - } 32 \text { weeks will be recruited. Other } \\
\text { eligibility criteria: } 1 \text { - Mono fetus. 2- Pelvic girdle pain had been diagnosed with history, physical examination } \\
\text { and specific tests } \\
\text { Exclusion criteria: contraindications of exercise in pregnancy, Systemic diseases such as: restrictive lung diseases, } \\
\text { heart disease; if participants do not come back after } 3 \text { and } 6 \text { weeks of intervention; If participants do not use } \\
\text { belt or exercise regularly }\end{array}$
\end{tabular}

Interventions Participants will be prescribed exercise plus educational pamphlet, abdominal lumbo pelvic belt with educational pamphlet and educational pamphlet alone (control) for 6 weeks

Outcomes

Primary outcome of this study is improvement in back pain during pregnancy.

Data collected at baseline, 3 and 6 weeks after interventions

- Demographic data of participants, history of pregnancy, and information about pelvic girdle pain starting from 1 to 2 weeks before referral to the centre.

- For patients with pain in symphysis pubis special tests including palpation of symphysis pubis and 
Abolhasani 2010 (Continued)

modified Trendelenburg was carried out.

- For patients with pain in SI joint, special tests including P4/thigh thrust test, and Patrick's Faber test were carried out.

- Other parts of questionnaire consist of pain drawing, VAS for intensity of pain, OSWESTRY disability index and WHO quality of life questionnaires.

Starting date

2009-10-23 to 2010-10-23: recruitment is complete.

Contact information Maryam Abolhasani; email: m_abolhasani@razi.tums.ac.ir

Notes

Irct registration number : IRCT138812113470N1.

\section{Greene 2009}

\begin{tabular}{ll} 
Trial name or title & Randomised controlled trial for the treatment of pelvic girdle pain in pregnancy \\
\hline Methods & Open-label randomised controlled single-centre trial. \\
\hline Participants & $\begin{array}{l}226 \text { pregnant women (primigravida and multigravida; no age limits) from } 20 \text { to } 35 \text { weeks of gestation } \\
\text { attending Cork University Maternity Hospital (CUMH) low-risk antenatal clinics who are referred to the } \\
\text { physiotherapy department by their health care provider or following self-referral with back pain or pelvic pain } \\
\text { will be assessed for inclusion in the trial. Women referred to the physiotherapy department with symptoms of } \\
\text { pelvic girdle pain (PGP) will be assessed on presentation by a } 1 \text { of } 6 \text { departmental physiotherapists specializing } \\
\text { in women's health }\end{array}$ \\
\hline
\end{tabular}

Interventions $\quad$ Following initial assessment participants will be randomly allocated to 1 of 2 treatment groups (randomisation ratio 1:1). Patients will be asked to keep a pain score diary where they will record their pain score using a visual analogue scoring system. Patients will be asked to record a score every morning and every evening during the treatment course. The first treatment in both treatment arms will be 1 week following initial assessment.

Individual care group: 3 sessions/week, approximately 45 minutes/session.

Group care group: Weekly group exercise classes for 4 weeks (1hour/class), focusing on core stability and strengthening exercises.

In both treatment groups pain scores will be followed up for 1 week post last treatment

Outcomes

Primary outcome: a reduction in the current intensity of PGP related to motion on a 100-point VAS in the morning and in the evening recorded in the patient's diaries ( 0 represented no pain and 100 represented worst conceivable pain)

Starting date

01/04/2009 - estimated end $=31 / 03 / 2010$ - trial completed.

Contact information Prof Richard A Greene, Cork University Maternity Hospital (R.Greene@ucc.ie) 
Trial name or title Osteopathic manipulative medicine in pregnancy: physiologic and clinical effects

Methods Allocation: randomised. Endpoint classification: efficacy study. Intervention model: single group assignment.

Masking: double blind (participant, caregiver). Primary Purpose: treatment

Participants Inclusion Criteria:

The woman must have medical clearance from her obstetrician at each study visit.

Must be less than or at 30 weeks' gestation at the start of the study.

Exclusion Criteria:

Deemed high risk by the obstetrician (including but not limited to: abruptio placenta, placenta previa, severe pre-eclampsia/eclampsia, vaginal bleeding, gestational diabetes).

Age 17 years or younger. Females 17 years of age and younger are considered paediatric high-risk pregnancies and therefore ineligible for inclusion.

If a patient receives any other manual therapies such as massage, physical therapy, or chiropractic therapy, during the trial, she will be dropped from the study.

Participants with a history of syncope either before or during this pregnancy will be excluded from participation in the sub-study

Interventions Other: Osteopathic manipulative treatment.

Other: Placebo ultrasound.

Other: Standard care.

Outcomes

Primary outcomes

Roland-Morris Low Back Pain and Disability Questionnaire at each visit. 5 years No

Quadruple VAS at each visit. 5 years Yes

Ware's Short Form-12 (SF-12) at each visit. 5 years No

PHYSIOLOGICAL STUDY -All measures at visit 1 (30 weeks) and visit 4 (36 weeks) 5 years Yes

Heart rate and blood pressure variability as measured by ECG and power spectral analysis. 5 years Yes

BIOMECHANICAL STUDY - All measures taken at visit 1 (30 weeks) and visit 4 (36 weeks) 5 years No

Step length as measured by the GAITRite walkway. 5 years No

Foot angle of progression as measured by the GAITRite walkway. 5 years No

Gait Symmetry as measured by the GAITRite walkway. 5 years No

Secondary outcome

CLINICAL STUDY 5 years No

Participant confidence in treatment assessment at visits 1,7 , and 9.5 years No

Meconium staining of the amniotic fluid as recorded on the delivery record. 5 years Yes

Other outcomes of pregnancy, labour and delivery including incidence of high-risk status, incidence of preterm labour, length of labour, use of forceps or suction device, and pain medication use as recorded in the prenatal and delivery record. 5 years Yes

PHYSIOLOGICAL STUDY - All measures at visit 1 (30 weeks) and visit 4 (36 weeks) 5 years No

Heart rate as measured by ECG. 5 years Yes

Arterial pressure as measured by finger photoplethysmographic monitor. 5 years Yes

Respiration as measured by a strain gauge belt. 5 years Yes

Saphenous vein diameter and flow as measured by surface ultrasound. 5 years Yes

Calf muscle EMG as measured by surface electromyographic activity of the gastrocnemius 5 years No

Total leg volume as estimated by strain gauge plethysmography. 5 years No

Tissue water content as measured by surface dielectric probe. 5 years No

Venous flow rate as measured by calf plethysmography. 5 years Yes

BIOMECHANICAL STUDY - All measures taken at visit 1 (30 weeks) and visit 4 (36 weeks) 5 years No

Interventions for preventing and treating pelvic and back pain in pregnancy (Review)

Copyright @ 2013 The Cochrane Collaboration. Published by John Wiley \& Sons, Ltd. 
Hensel 2008 (Continued)

Gait cadence as measured by the GAITRite walkway. 5 years No

\begin{tabular}{ll}
\hline Starting date & April 2006 \\
\hline Contact information & $\begin{array}{l}\text { Mayra Rodriguez, BS } \\
\text { tel: 817-735-2910 } \\
\text { marodrig@hsc.unt.edu }\end{array}$ \\
\hline Notes & $\begin{array}{l}\text { Kendi Hensel, D.O., Principal Investigator, University of North Texas Health Science Center - Osteopathic } \\
\text { Research Center. March 8, 2012 - currently recruiting }\end{array}$ \\
\hline
\end{tabular}

\section{Moholdt 2011}

\begin{tabular}{|c|c|}
\hline Trial name or title & Exercise training in pregnancy for obese women (ETIP). \\
\hline Methods & Protocol for a randomised controlled trial. \\
\hline Participants & $\begin{array}{l}150 \text { previously sedentary, pregnant women with a pre-pregnancy BMI at or above } 30 \mathrm{~kg} / \mathrm{m}^{2} \text {; randomised } \\
\text { into intervention and control groups. }\end{array}$ \\
\hline Interventions & $\begin{array}{l}\text { Intervention group: organised exercise training } 3 \text { x/week starting in gestation week } 14 \text { (range 12-16) } \\
\text { Control group: standard antenatal care. }\end{array}$ \\
\hline Outcomes & $\begin{array}{l}\text { Primary outcome: weight gain from baseline to delivery. } \\
\text { Secondary outcomes: changes in exercise capacity, physical activity level, endothelial function, body compo- } \\
\text { sition, incontinence, lumbo-pelvic pain and cardiac function from baseline to gestation week } 37 \text { (range 36- } \\
\text { 38). Offspring outcome measures include anthropometric variables at birth, Apgar score }\end{array}$ \\
\hline Starting date & September 2010. \\
\hline Contact information & Principal Investigator:Trine T Moholdt, PhD. \\
\hline Notes & $\begin{array}{l}\text { Trial registration: ClinicalTrials.gov: NCT01243554. Sponsor: Norwegian University of Science and Tech- } \\
\text { nology }\end{array}$ \\
\hline
\end{tabular}

ECG: electrocardiogram

EMG: electromyography

VAS: visual analogue scale 
DATA ANDANALYSES

Comparison 1. Low-back pain: any exercises + usual prenatal care versus usual prenatal care

\begin{tabular}{lcccc} 
Outcome or subgroup title & $\begin{array}{c}\text { No. of } \\
\text { studies }\end{array}$ & $\begin{array}{c}\text { No. of } \\
\text { participants }\end{array}$ & Statistical method & Effect size \\
\hline 1 Pain intensity & 6 & 543 & Std. Mean Difference (IV, Random, 95\% CI) & $-0.80[-1.07,-0.53]$ \\
2 Disability & 2 & 146 & Std. Mean Difference (IV, Random, 95\% CI) & $-0.56[-0.89,-0.23]$ \\
\hline
\end{tabular}

Comparison 2. Low-back pain: water gymnastics + usual prenatal care versus usual prenatal care

\begin{tabular}{lcccc} 
Outcome or subgroup title & $\begin{array}{c}\text { No. of } \\
\text { studies }\end{array}$ & $\begin{array}{c}\text { No. of } \\
\text { participants }\end{array}$ & Statistical method & Effect size \\
\hline $\begin{array}{l}\text { 1 Number of women taking sick } \\
\text { leave because of back pain after } \\
32 \text { weeks' gestation }\end{array}$ & 1 & 241 & Risk Ratio (M-H, Fixed, 95\% CI) & $0.40[0.17,0.92]$ \\
\hline
\end{tabular}

Comparison 3. Low-back pain: support belts

\begin{tabular}{lcclc} 
Outcome or subgroup title & $\begin{array}{c}\text { No. of } \\
\text { studies }\end{array}$ & $\begin{array}{c}\text { No. of } \\
\text { participants }\end{array}$ & Statistical method & Effect size \\
\hline $\begin{array}{l}\text { 1 Low-back pain, measured with } \\
\text { VAS; 0 to 10; 0 = no pain }\end{array}$ & 1 & & Mean Difference (IV, Fixed, 95\% CI) & Subtotals only \\
$\quad 1.1$ Low-back Pain & 1 & 94 & Mean Difference (IV, Fixed, 95\% CI) & $-0.20[-1.19,0.79]$ \\
1.2 ADL & 1 & 94 & Mean Difference (IV, Fixed, 95\% CI) & $-0.90[-1.81,0.01]$ \\
\hline
\end{tabular}

Comparison 4. Pelvic pain: deep versus superficial acupuncture

\begin{tabular}{lcccc} 
Outcome or subgroup title & $\begin{array}{c}\text { No. of } \\
\text { studies }\end{array}$ & $\begin{array}{c}\text { No. of } \\
\text { participants }\end{array}$ & Statistical method & Effect size \\
\hline 1 Evening pain & 1 & 47 & Risk Ratio (M-H, Fixed, 95\% CI) & $1.06[0.73,1.54]$ \\
\hline
\end{tabular}


Comparison 5. Pelvic + low-back pain: any exercises + usual prenatal care versus usual prenatal care

\begin{tabular}{|c|c|c|c|c|}
\hline Outcome or subgroup title & $\begin{array}{l}\text { No. of } \\
\text { studies }\end{array}$ & $\begin{array}{c}\text { No. of } \\
\text { participants }\end{array}$ & Statistical method & Effect size \\
\hline $\begin{array}{l}1 \text { Women who reported pain on } \\
\text { Visual Analogue Scale }\end{array}$ & 4 & 1344 & Risk Ratio (M-H, Random, 95\% CI) & $0.85[0.73,1.00]$ \\
\hline $\begin{array}{l}2 \text { Women who reported } \\
\text { LBP/PGP-related sick leave }\end{array}$ & 2 & 1062 & Risk Ratio (M-H, Random, 95\% CI) & $0.76[0.62,0.94]$ \\
\hline
\end{tabular}

Comparison 6. Pelvic + low-back pain: acupuncture + usual prenatal care versus usual prenatal care

\begin{tabular}{lcccc} 
Outcome or subgroup title & $\begin{array}{c}\text { No. of } \\
\text { studies }\end{array}$ & $\begin{array}{c}\text { No. of } \\
\text { participants }\end{array}$ & Statistical method & Effect size \\
\hline $\begin{array}{l}\text { 1 Number of women who reported } \\
\text { decreased pain }\end{array}$ & 1 & 72 & Risk Ratio (M-H, Fixed, 95\% CI) & $4.16[1.77,9.78]$ \\
\hline
\end{tabular}

Comparison 7. Pelvic + low-back pain: acupuncture + usual prenatal care versus individualised physio + usual prenatal care

\begin{tabular}{lcccc} 
Outcome or subgroup title & $\begin{array}{c}\text { No. of } \\
\text { studies }\end{array}$ & $\begin{array}{c}\text { No. of } \\
\text { participants }\end{array}$ & Statistical method & Effect size \\
\hline $\begin{array}{c}\text { 1 Numbers of women rating } \\
\text { treatment as good or excellent }\end{array}$ & 1 & 46 & Risk Ratio (M-H, Fixed, 95\% CI) & $1.24[0.96,1.60]$ \\
\hline
\end{tabular}


Analysis I.I. Comparison I Low-back pain: any exercises + usual prenatal care versus usual prenatal care, Outcome I Pain intensity.

Review: Interventions for preventing and treating pelvic and back pain in pregnancy

Comparison: I Low-back pain: any exercises + usual prenatal care versus usual prenatal care

Outcome: I Pain intensity

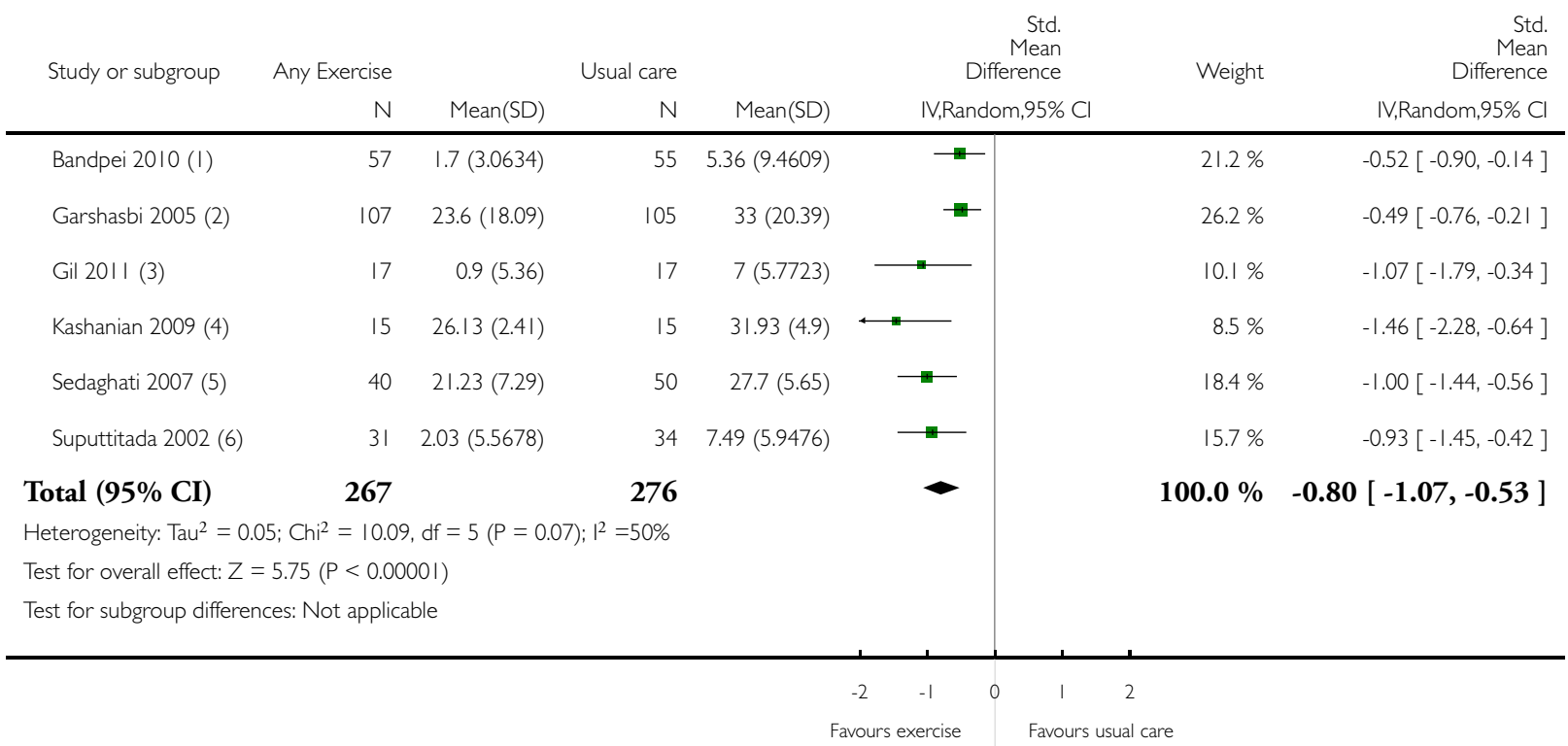

( I) measured W VAS (0 to 10); provided baseline, change score after 3 months \% P => calculated end score w RevMan calculator

(2) pain measured at 12 weeks post-randomisation with the KEBEK; range 0 to $100,0=$ no pain

(3) measured at end of 8th session with VAS 0 to 10; re-calculated SD, assuming reported SD was SE

(4) 8-week intervention; measured 24 weeks post-randomisation with pain section of RMDQ; lower scores = better

(5) measured @ 8 weeks using Quebec LBP questionnaire; lower = better

(6) VAS measured at 8 weeks post-randomisation (end of treatment); measured VAS 0 to I0, so multiplied to give 0 to I00; re-calculated SD, assuming reported SD was SE 
Analysis I.2. Comparison I Low-back pain: any exercises + usual prenatal care versus usual prenatal care, Outcome 2 Disability.

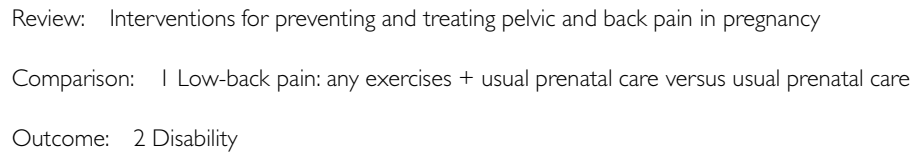

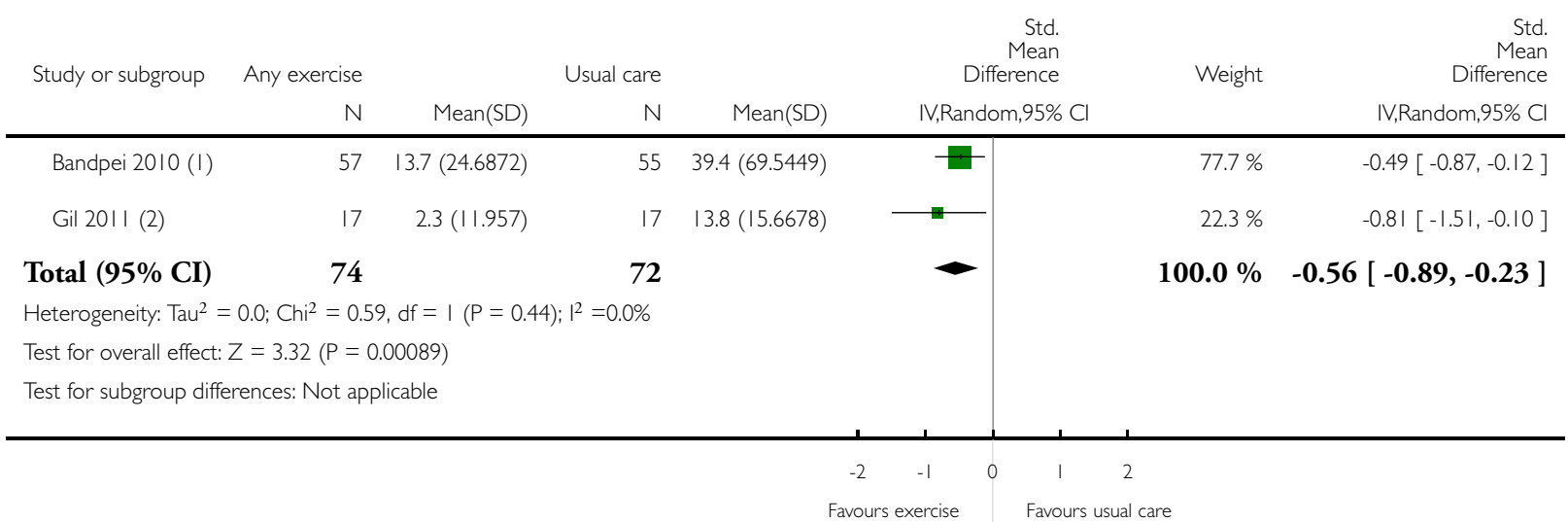

( I) Oswestry 0 to I00; lower = better; RevMan calculator used to calculate SD

(2) Roland Morris 0 to 24; lower = better

Analysis 2.1. Comparison 2 Low-back pain: water gymnastics + usual prenatal care versus usual prenatal care, Outcome I Number of women taking sick leave because of back pain after 32 weeks' gestation.

Review: Interventions for preventing and treating pelvic and back pain in pregnancy

Comparison: 2 Low-back pain: water gymnastics + usual prenatal care versus usual prenatal care

Outcome: I Number of women taking sick leave because of back pain after 32 weeks' gestation

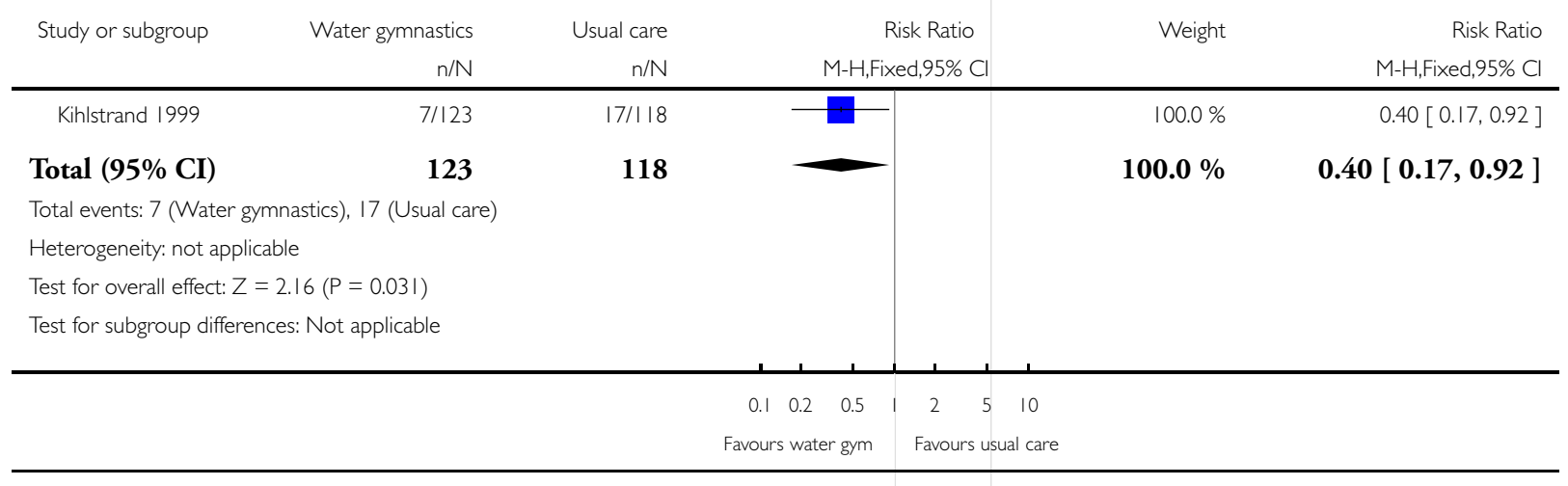

Interventions for preventing and treating pelvic and back pain in pregnancy (Review)

Copyright (c) 2013 The Cochrane Collaboration. Published by John Wiley \& Sons, Ltd. 
Analysis 3.I. Comparison 3 Low-back pain: support belts, Outcome I Low-back pain, measured with VAS; 0 to $10 ; 0=$ no pain.

Review: Interventions for preventing and treating pelvic and back pain in pregnancy

Comparison: 3 Low-back pain: support belts

Outcome: I Low-back pain, measured with VAS; 0 to 10; 0 = no pain

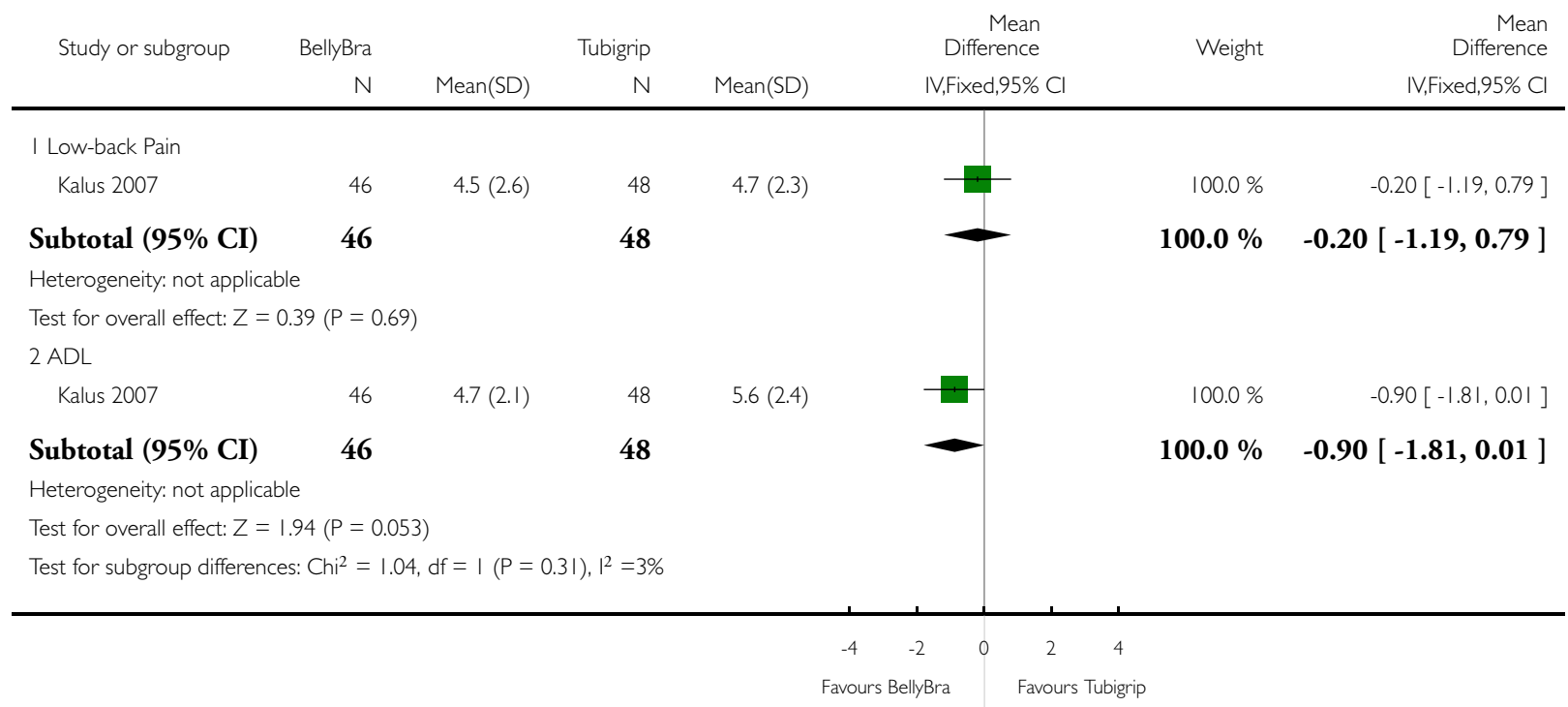




\section{Analysis 4.I. Comparison 4 Pelvic pain: deep versus superficial acupuncture, Outcome I Evening pain.}

Review: Interventions for preventing and treating pelvic and back pain in pregnancy

Comparison: 4 Pelvic pain: deep versus superficial acupuncture

Outcome: I Evening pain

\begin{tabular}{|c|c|c|c|c|c|}
\hline \multirow[t]{2}{*}{ Study or subgroup } & Deep & Superficial & Risk Ratio & Weight & Risk Ratio \\
\hline & $\mathrm{n} / \mathrm{N}$ & $\mathrm{n} / \mathrm{N}$ & M-H,Fixed,95\% Cl & & M-H,Fixed,95\% Cl \\
\hline Lund 2006 & $18 / 25$ & $15 / 22$ & & $100.0 \%$ & $1.06[0.73,1.54]$ \\
\hline Total $(95 \%$ CI $)$ & 25 & 22 & & $100.0 \%$ & $1.06[0.73,1.54]$ \\
\hline
\end{tabular}

Total events: 18 (Deep), 15 (Superficial)

Heterogeneity: not applicable

Test for overall effect: $Z=0.28(P=0.78)$

Test for subgroup differences: Not applicable

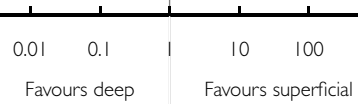

Analysis 5.I. Comparison 5 Pelvic + low-back pain: any exercises + usual prenatal care versus usual prenatal care, Outcome I Women who reported pain on Visual Analogue Scale.

Review: Interventions for preventing and treating pelvic and back pain in pregnancy

Comparison: 5 Pelvic + low-back pain: any exercises + usual prenatal care versus usual prenatal care

Outcome: I Women who reported pain on Visual Analogue Scale

Study or subgroup

Group exercise Usual care

Risk Ratio $\mathrm{M}$ -

H,Random, 95\%

\begin{tabular}{lrr} 
& $\mathrm{n} / \mathrm{N}$ & $\mathrm{n} / \mathrm{N}$ \\
\hline Eggen 2012(1) & $96 / 106$ & $104 / 107$ \\
Martins 2005 (2) & $13 / 33$ & $32 / 36$ \\
M rkved 2007 (3) & $65 / 148$ & $86 / 153$ \\
Stafne 2012 (4) & $292 / 396$ & $272 / 365$
\end{tabular}

Total (95\% CI)

683

661

Weight

Risk Ratio

Cl

$35.2 \%$ $0.93[0.87,1.00]$

Total events: 466 (Group exercise), 494 (Usual care)

Heterogeneity: Tau $^{2}=0.02 ; \mathrm{Chi}^{2}=16.37, \mathrm{df}=3(\mathrm{P}=0.00095) ; \mathrm{I}^{2}=82 \%$

Test for overall effect: $Z=1.97(P=0.049)$

Test for subgroup differences: Not applicable

$\begin{array}{rrr}35.2 \% & 0.93[0.87,1.00] \\ & 9.6 \% & 0.44[0.29,0.69] \\ & 21.0 \% & 0.78[0.62,0.98] \\ & 34.2 \% & 0.99[0.91,1.08]\end{array}$

$100.0 \%$

$0.85[0.73,1.00]$

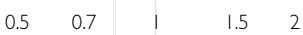

Favours exercises Favours usual care 

(1) 36 week gestation
(2) end of treatment - 8 weeks after randomization at which point women were at least 12 weeks gestation
(3) 36 weeks gestation; $N$ taken from Table II
(4) 32 to 36 weeks gestation; $N$ corrected by author via email

Analysis 5.2. Comparison 5 Pelvic + low-back pain: any exercises + usual prenatal care versus usual prenatal care, Outcome 2 Women who reported LBP/PGP-related sick leave.

Review: Interventions for preventing and treating pelvic and back pain in pregnancy

Comparison: 5 Pelvic + low-back pain: any exercises + usual prenatal care versus usual prenatal care

Outcome: 2 Women who reported LBP/PGP-related sick leave

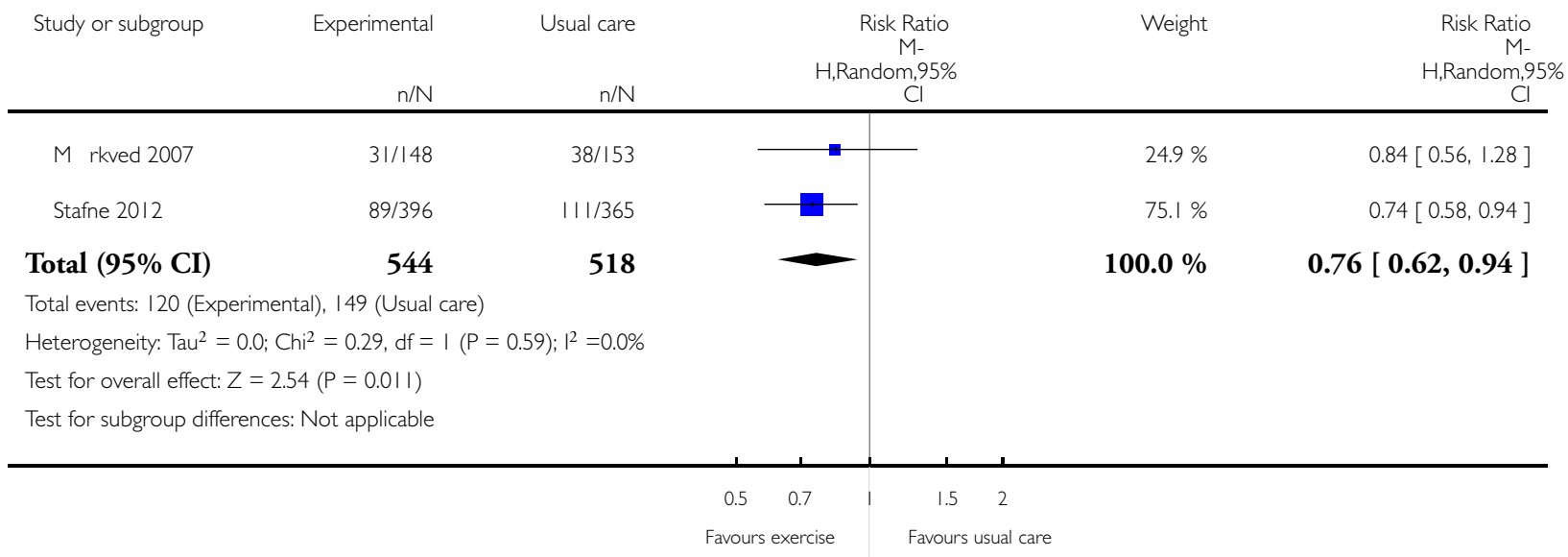


Analysis 6.1. Comparison 6 Pelvic + low-back pain: acupuncture + usual prenatal care versus usual prenatal care, Outcome I Number of women who reported decreased pain.

Review: Interventions for preventing and treating pelvic and back pain in pregnancy

Comparison: 6 Pelvic + low-back pain: acupuncture + usual prenatal care versus usual prenatal care

Outcome: I Number of women who reported decreased pain

\begin{tabular}{ccccc} 
Study or subgroup & Acupuncture & Usual care & Risk Ratio & Wisk Ratio \\
& $\mathrm{n} / \mathrm{N}$ & $\mathrm{n} / \mathrm{N}$ & $\mathrm{M}-\mathrm{H}$, Fixed,95\% Cl & $\mathrm{M}-\mathrm{H}$, Fixed,95\% Cl \\
\hline Kvorning 2004 & $22 / 37$ & $5 / 35$ & & 4.16 [ I.77, 9.78 ]
\end{tabular}

Total (95\% CI)

37

35

$100.0 \%$

$4.16[1.77,9.78]$

Total events: 22 (Acupuncture), 5 (Usual care)

Heterogeneity: not applicable

Test for overall effect: $Z=3.27(P=0.001$ I)

Test for subgroup differences: Not applicable

$\begin{array}{ccccc}0.01 \quad 0.1 & 1 & 10 & 100 \\ \text { Favours usual care } & & \text { Favours acupuncture }\end{array}$

Analysis 7.I. Comparison 7 Pelvic + low-back pain: acupuncture + usual prenatal care versus individualised physio + usual prenatal care, Outcome I Numbers of women rating treatment as good or excellent.

Review: Interventions for preventing and treating pelvic and back pain in pregnancy

Comparison: 7 Pelvic + low-back pain: acupuncture + usual prenatal care versus individualised physio + usual prenatal care

Outcome: I Numbers of women rating treatment as good or excellent

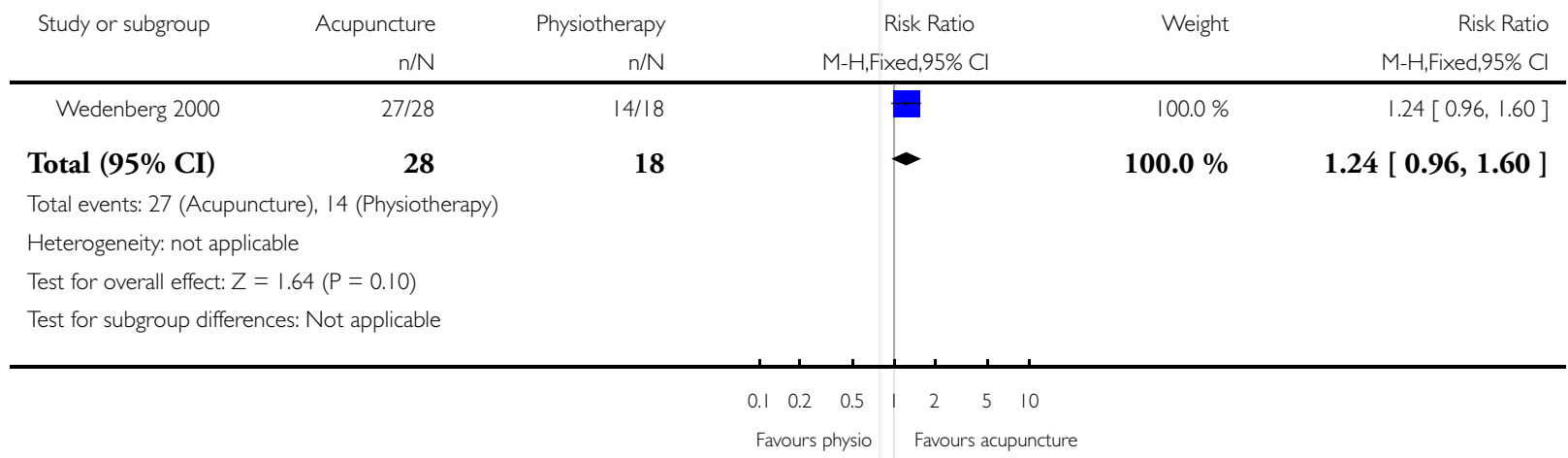




\section{A P P E N D I C E S}

\section{Appendix I. Methods used to assess trials included in previous versions of this review}

The following methods were used to assess Elden 2005; Garshasbi 2005; Kihlstrand 1999; Kvorning 2004; Martins 2005; Suputtitada 2002; Thomas 1989; and Wedenberg 2000.

\section{Selection of studies}

Two review authors (VE Pennick, G Young) independently reviewed the full text of potential studies identified by the Cochrane Pregnancy and Childbirth Group's search strategy and selected studies that met our inclusion criteria. We resolved any disagreements through discussion.

\section{Assessment of methodological quality of included studies}

We then independently evaluated the studies that met our inclusion criteria for methodological quality, without consideration of their results, and again resolved disagreements through discussion. For a description of the criteria used, see Appendix 2. We excluded studies at this point that used methods of allocation that are prone to bias (quasi-randomised trials), such as the use of date of birth, date of admission, hospital numbers or alternation.

\section{Data extraction}

For studies that met our inclusion criteria and methodological assessment, we independently extracted the data onto a form that had been predesigned by the Cochrane Pregnancy and Childbirth Group, then transferred them into Review Manager software (RevMan 2006) for analyses. We resolved disagreements through discussion.

\section{Measures of treatment effect}

Our primary analyses for each category of low-back pain or pelvic pain, or both, examined these comparisons:

(i) intervention added to usual prenatal care versus no treatment (usual prenatal care); and

(ii) intervention added to usual prenatal care versus another treatment added to usual prenatal care.

Where there was clinical homogeneity, suggesting it made sense to synthesise the data, and when there were sufficient data, we had planned to complete statistical analysis of the results using a fixed-effect meta-analysis in RevMan 2006 software. However, in the absence of clinical homogeneity or sufficient data, or both, we briefly described the studies and their results, rather than performing meta-analyses.

For dichotomous data, we had planned to present the results as a summary relative risk with $95 \%$ confidence intervals. For continuous data, we had intended to use the weighted mean difference for outcomes that were measured in the same way between trials and the standardised mean difference to combine trials that measured the same outcome, but used different methods. In the absence of sufficient data to complete our own analyses for outcomes across studies, we used the summary statistics reported by the authors in the study reports.

\section{Dealing with missing data}

We planned to use data for all participants with available data in the group to which they were allocated, regardless of whether or not they received the allocated intervention. In most cases, data in the study reports were only given for participants who had completed the intervention and provided follow-up outcome measures. Participants' data were generally analysed in the groups to which they had been allocated. 


\section{Appendix 2. Assessment of methodological quality of included studies for previous version of review}

Criteria used to assess methodological quality for Elden 2005; Garshasbi 2005; Kihlstrand 1999; Kvorning 2004; Martins 2005; Suputtitada 2002; Thomas 1989; and Wedenberg 2000.

(1) Selection bias (randomisation and allocation concealment):

Method of allocation generation: was it adequate, unclear or inadequate?

(A) adequate randomisation: such as computer-generated random number table;

(B) unclear: study reports a randomisation technique was used, but does not give details of the method;

(C) inadequate: such as allocated using date of birth, date of admission, hospital numbers, alternation.

(2) Allocation concealment:

(A) adequate concealment of allocation: such as telephone randomisation, consecutively-numbered, sealed opaque envelopes;

(B) unclear whether adequate concealment of allocation: such as list or table used, sealed envelopes, or study does not report any concealment approach;

(C) inadequate concealment of allocation: such as open list of random-number tables, use of case record numbers, dates of birth or days of the week.

(3) Attrition bias (loss of participants, eg, withdrawals, dropouts, protocol deviations):

(A) less than $5 \%$ loss of participants;

(B) $5 \%$ to $9.9 \%$ loss of participants;

(C) $10 \%$ to $19.9 \%$ loss of participants;

(D) more than $20 \%$ loss of participants.

(4) Performance bias (blinding of participants, researchers and outcome assessment):

(A) blinding of participants (yes/no/unclear);

(B) blinding of caregiver (yes/no/unclear);

(C) blinding of outcome assessment (yes/no/unclear).

(5) Intention-to-treat analysis: used/unclear/not used:

(A) used: analysis of randomised participants in randomised groups, regardless of noncompliance or cointerventions;

(B) unclear: not clearly reported in study, but analysis appears to be in line with randomisation;

(C) not used: analysis of participants in group to which they self-selected after randomisation

\section{Appendix 3. GRADE criteria (Schünemann 2009)}

Limitations in study design or execution (risk of bias) - overall, the studies that measured the outcome were assessed to have sufficiently high risk of bias that we did not have full confidence in the results

Inconsistency of results - studies that measured the outcome had widely differing estimates of treatment effect

Indirectness of evidence - studies did not measure the outcome directly

Imprecision - studies that measured the outcome included few patients $(<400)$ or few events $(<300)$ and/or wide confidence intervals (included both appreciable harm and appreciable benefit that was greater than $25 \%$ )

Publication bias - overall, the studies that measured the outcome showed a systematic selective publication bias

Interventions for preventing and treating pelvic and back pain in pregnancy (Review)

Copyright $\odot 2013$ The Cochrane Collaboration. Published by John Wiley \& Sons, Ltd. 


\section{F E E D B A C K}

\section{Herxheimer, September 1998}

\section{Summary}

Characteristics of included studies:

Thomas 1989 was a cross-over trial, was it reported as such? The outcome for the first cross-over should be reported separately from the second cross-over. Data for women who did not complete the second period could then be included for the first period. More information about when and for how long women used the pillows would be useful, and at what gestation.

Information about how to get the OZZLO pillow should be presented, and whether it is a patented design. A drawing of the pillow would also be helpful.

Results:

If the reviewers have contact with the trialists it would be useful to know whether they still use the OZZLO pillow, and if not why not.

\section{Reply}

These comments have now been incorporated into the updated review. It is not possible to provide a drawing of the OZZLO pillow within the Cochrane review but we have mentioned in the update that a drawing can be found in the original study, which is referenced. [reply from Gavin Young, October 2001]

\section{Contributors}

Comments received from Andrew Herxheimer, September 1998.

\section{WHAT'S NEW}

Last assessed as up-to-date: 14 December 2012.

\begin{tabular}{|c|c|c|}
\hline Date & Event & Description \\
\hline 14 December 2012 & $\begin{array}{l}\text { New citation required but conclusions have not } \\
\text { changed }\end{array}$ & $\begin{array}{l}\text { With the addition of new trials, there is now more evi- } \\
\text { dence for interventions aimed at preventing and treat- } \\
\text { ing low-back pain, pelvic pain and a combination of } \\
\text { both (lumbo-pelvic pain) }\end{array}$ \\
\hline 18 July 2012 & New search has been performed & $\begin{array}{l}\text { Searches updated. Since the last update in } 2007,47 \\
\text { reports of potentially relevant studies have been iden- } \\
\text { tified and of these: } 18 \text { new trials included (Bandpei } \\
\text { 2010; Depledge 2005; Eggen 2012; Ekdahl 2010; } \\
\text { Elden 2008; Gil 2011; Gross 2012; Kalus 2007; } \\
\text { Kashanian 2009; Kluge 2011; Licciardone 2010; } \\
\text { Lund 2006; Mørkved 2007; Peters 2007; Peterson } \\
\text { 2012; Sedaghati 2007; Stafne 2012; Wang 2009a) } \\
\text {; } 17 \text { studies excluded (Beyaz 2011; Chitryniewicz } \\
\text { 2010; de Jonge-Vors 2011; Field 1999a; Field 2012; } \\
\text { Foxcroft 2011; Granath 2006; Haugland 2006; }\end{array}$ \\
\hline
\end{tabular}

Interventions for preventing and treating pelvic and back pain in pregnancy (Review)

Copyright @ 2013 The Cochrane Collaboration. Published by John Wiley \& Sons, Ltd. 


\section{H I S T O R Y}

Protocol first published: Issue 3, 1998

Review first published: Issue 3, 1998

\begin{tabular}{|c|c|c|}
\hline Date & Event & Description \\
\hline 9 June 2008 & Amended & Converted to new review format. \\
\hline 15 April 2006 & $\begin{array}{l}\text { New citation required but conclusions have not } \\
\text { changed }\end{array}$ & $\begin{array}{l}\text { A new author, Victoria Pennick, joined the review team } \\
\text { and is now the guarantor of the review }\end{array}$ \\
\hline 8 February 2006 & New search has been performed & $\begin{array}{l}\text { This updated review (February 2006) includes an up- } \\
\text { dated search, which identified five new trials that met } \\
\text { the inclusion criteria: two studies examined women } \\
\text { with low-back pain (Garshasbi 2005; Suputtitada 2002) } \\
\text {; one study examined women with pelvic pain (Elden } \\
\text { 2005); and two studies examined a mixed population } \\
\text { with pelvic and back pain (Kvorning 2004;Martins } \\
\text { 2005). In total, we included nine reports (1305 par- } \\
\text { ticipants), describing eight studies. One report was the } \\
\text { abstract of one of the published articles and only gave } \\
\text { preliminary results. } \\
\text { Despite the addition of these studies, the conclusions } \\
\text { remain essentially the same. The specially-designed Oz- } \\
\text { zlo pillow was more effective than a regular one in reliev- } \\
\text { ing back pain, but is no longer commercially available. } \\
\text { Pregnant-specific exercise programs, physiotherapy and } \\
\text { acupuncture added to usual prenatal care all appeared } \\
\text { to reduce back or pelvic pain more than usual prenatal } \\
\text { care. However, all but one study had moderate to high } \\
\text { potential for bias, prohibiting full confidence in these } \\
\text { results. } \\
\text { The updated search also identified three new reports, } \\
\text { which we excluded because they are quasi-random- } \\
\text { ized controlled trials (Ciardi } 2002 \mathrm{C} \text {; da Silva 2004; }\end{array}$ \\
\hline
\end{tabular}


Nilsson-Wikmar 2005) and two ongoing trials (Quinlivan 2005a; Wang 2005a).

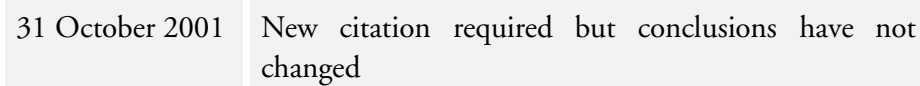

The background section has been enlarged, giving more information about prevalence and prognosis. A distinction is made between pain arising from the lumbo-sacral region (back pain) and pain in the region of the sacroiliac joints and pubic symphysis (pelvic pain). Two new studies are included which assess the role of acupuncture versus physiotherapy, and water gymnastics versus no treatment.

31 October 2001 New search has been performed

Search updated. Two new studies are included which assess the role of acupuncture versus physiotherapy, and water gymnastics versus no treatment.

Authors replied to feedback.

\section{CONTRIBUTIONS OFAUTHORS}

For the 2013 update, Victoria Pennick (VEP) and Dianne Liddle (SDL) selected and assessed the risk of bias of the articles and extracted and analysed the data. They both contributed to the writing of the review. Gavin Young remained available to assist as necessary, but was not involved in the actual production of this review.

For the 2007 update: Victoria Pennick (VEP) and Gavin Young (GY) selected and assessed the methodological quality of the articles and extracted and analysed the data. VEP wrote the first draft of the review; GY reviewed and offered his comments.

For the original review and 2002 update: both review authors, GY and David Jewell, assessed all articles and contributed to the analyses. GY entered the data and wrote the text.

\section{DECLARATIONSOF INTEREST}

None known.

\section{SOURCES OF SUPPORT}




\section{Internal sources}

- Institute for Work and Health, Canada.

\section{External sources}

- Royal College of General Practitioners, UK.

\section{DIFFERENCES BETWEEN PROTOCOLANDREVIEW}

The protocol was originally written in the 1990s. The methodology for conducting Cochrane reviews has changed substantially since then; this update reflects those changes.

\section{INDEX TERMS}

\section{Medical Subject Headings (MeSH)}

Back Pain [* prevention \& control]; Pelvic Pain [prevention \& control]; Physical Therapy Modalities; Pregnancy Complications $\left[{ }^{*}\right.$ prevention \& control]; Randomized Controlled Trials as Topic

\section{MeSH check words}

Female; Humans; Pregnancy 